FACULDADE DE MEDICINA DE RIBEIRÃO PRETO - USP PROGRAMA DE PÓS-GRADUAÇÃO EM IMUNOLOGIA BÁSICA E APLICADA

\title{
O papel do vírus de RNA de Leishmania na modulação da resposta imune inata
}




\section{O papel do vírus de RNA de Leishmania na}

\section{modulação da resposta imune inata}

Tese apresentada ao programa de PósGraduação em Imunologia Básica e Aplicada da Faculdade de Ribeirão Preto da Universidade de São Paulo, como requisito para a obtenção do título de Doutor em Imunologia Básica e Aplicada

Orientador: Prof. Dr. Dario Simões Zamboni 
Autorizo a reprodução e divulgação total ou parcial deste trabalho, por qualquer meio convencional ou eletrônico, para fins de estudo e pesquisa, desde que citada a fonte.

de Carvalho, Renan Villanova Homem

O papel do vírus de RNA de Leishmania na modulação da resposta imune inata, 2019.

149 p. : il. ; $30 \mathrm{~cm}$

Tese de Doutorado, apresentada à Faculdade de Medicina de Ribeirão Preto/USP. Área de concentração: Imunologia Básica e Aplicada

Orientador: Zamboni, Dario Simões

1. Inflamassoma 2. Imunidade inata $3 . \quad$ Leishmania 4. Vírus 5. TLR3 
Trabalho realizado no Laboratório de Patogenicidade Microbiana e Imunidade Inata, Departamento de Bioquímica e Imunologia da Faculdade de Medicina - Universidade de São Paulo, com auxílio financeiro do TDR/WHO, INCTV/CNPq, FAPESP e CAPES 
Nome: Renan Villanova Homem de Carvalho

Título: O papel do vírus de RNA de Leishmania na modulação da resposta imune inata

Tese apresentada ao curso de Pós-graduação em Imunologia Básica e Aplicada da Faculdade de Medicina de Ribeirão Preto da Universidade de

São Paulo, para a obtenção do grau de Doutor em Ciências.

Área de concentração: Imunologia

Aprovado em: 1

\section{Banca Examinadora}

Prof. Dr. Dario Simões Zamboni

Instituição: Faculdade de Medicina de Ribeirão Preto - Universidade de São Paulo Julgamento: Assinatura:

Prof. Dr. José Carlos Farias Alves Filho

Instituição: Faculdade de Medicina de Ribeirão Preto - Universidade de São Paulo Julgamento: Assinatura:

Prof. Dr. Daniel Youssef Bargieri

Instituição: Instituto de Ciências Biológicas - Universidade de São Paulo Julgamento: Assinatura:

Prof. Dr. Marcelo Torres Bozza

Instituição: Universidade Federal do Rio de Janeiro

Julgamento: Assinatura: 
"A vida sem Ciência é uma espécie de morte." (Sócrates)

"Muita gente afirma que o intelecto faz um grande cientista. Estão errados, é o caráter." (Albert Einstein)

"Tempos ruins tem sua importância científica. São ocasiões que um bom aprendiz não pode desperdiçar." (Ralph Waldo Emerson) 


\section{DEDICATÓRIA}

Dedico este trabalho à memória do Prof. Dr. Raúl Marcel González Garcia, falecido em Novembro de 2017, meu primeiro orientador de Iniciação Científica e o primeiro a me guiar dentro do Mundo da Ciência.

Este trabalho também é dedicado a todos os meus mestres, que sempre me incentivaram e me apoiaram, durante toda a minha trajetória acadêmica. 


\section{AGRADECIMENTOS}

Ao(s) Deus(es), que em qualquer de suas formas e/ou estados físicos, possam ter me guiado durante toda a minha trajetória, principalmente nos momentos de dificuldade.

Ao Prof. Dr. Dario Simões Zamboni, pela amizade e por ter sempre confiado e acreditado em mim, me proporcionando uma chance que poucos têm: o privilégio do convívio diário e do aprendizado frente à sua mente brilhante. Muito obrigado por todos os ensinamentos, pelo exemplo de integridade e ética científica, sempre preocupado em fazer Ciência de alto nível. Seus conselhos e nossas conversas irão ecoar pra sempre na minha memória e na minha trajetória.

A todos os Professores do Programa de Imunologia Básica e Aplicada, que estiveram comigo desde o início do meu Doutorado: Profa. Dra. Vânia Deperon Bonato, Profa. Dra. Vanessa Carregaro, Profa. Dra. Beatriz Ferreira, Profa. Dra. Isabel Kinney, Prof. Dr. Marcelo Baruffi, Profa. Dra. Daniela Carlos, etc. Muito obrigado pelas orientações, incansáveis discussões científicas e pelo entusiasmo em fazer o aluno aprender.

Aos meus ex-orientadores, Profa. Dra. Jacy Gameiro (UFJF), Prof. Dr. Raúl Garcia (UFJF - in memorian) e Dr. Paulo Vieira (Instituto Pasteur, Paris, França), que mesmo de longe, sempre me acompanharam e me ajudaram no que fosse preciso, sempre com conversas animadoras e positivas.

A todos os colegas que passaram pelo Laboratório de Patogenicidade Microbiana e Imunidade Inata, durante todos estes anos, pela harmoniosa convivência e integração, e que sem dúvida me auxiliaram durante toda a minha trajetória para me tornar um cientista e uma pessoa melhor. 
Em especial, agradeço ao Drs Djalma de Souza Lima-Júnior e Warrison Andrade, que além de grandes amigos, sempre me auxiliaram na formação do pensamento crítico e no desenvolvimento de Ciência de alto nível. Seus ensinamentos serão levados eternamente em minha memória, assim como a nossa amizade.

Também gostaria de agradecer em especial a alguns outros membros do Laboratório, como os Drs Alexandre Luiz Neves Silva e Catarina Horta, que desde o início do meu Doutorado sempre se mostraram solícitos e dispostos a me ajudar. Sem vocês, jamais teria conseguido avançar passo a passo durante esta etapa. Meu muito obrigado.

À Caroline Vitória, Marisa Dilucca e Júlia DeGrande, por terem me ensinado tanto até quando eu era quem ensinava. Vocês também contribuíram significativamente para a realização deste trabalho e merecem um agradecimento especial.

À Maira Nakamura, por toda a paciência e ajuda nas compras de reagentes para o laboratório e organização do mesmo, sendo de grande importância na realização deste trabalho.

À Ana Cristine S. Ferreira, por toda a amizade, apoio, disponibilidade e dedicação ao trabalho, sempre me incentivando e demonstrando grande satisfação em me escutar e resolver quaisquer problemas, tanto meus quanto do Programa em Imunologia Básica e Aplicada.

Aos funcionários do departamento de Biologia Celular e de Bioquiímica e Imunologia, e de outros laboratórios, em especial: Denise, Wendy, Isa, Aninha, Ana Flávia, Wander, Beth e Roberta, pela disponibilidade em ajudar e ótima convivência. 
A todos que ajudaram e colaboraram no desenvolvimento deste e de outros trabalhos durante minha trajetória: Marcílio Fumagali, Taline Klein, Rafaela Guimarães, Carlos Hiroki, Alexandre Lopes, Patrick Fernandes, Lucas Lorenzon, Tamara Rodrigues, etc. Todos vocês merecem um agradecimento especial.

Aos amigos de outros laboratórios, César Speck, David Cólon, Thiago Malardo, Flávio Protásio, Lucas Arruda, Gabriel Lamak, Vinícius Detoni, Jhimmy Talbot, que sempre foram ombro amigos e me ajudaram a superar as adversidades, com muito diálogo e paciência. Vocês são amizades feitas durante a pós-graduação, que vão durar para a vida toda.

A todos os colegas do Programa de Pós-graduação em Imunologia Básica e Aplicada, pela amizade, intermináveis conversas, risadas, e produtivas discussões científicas, tanto nos eventos internos (Journal Club, Workshops e Cursos de Inverno) quanto nos externos (Congressos da SBI e afins). Todos vocês contribuíram imensamente para minha formação.

Aos ex-presidentes Luís Inácio Lula da Silva e Dilma Rousseff, por terem ousado mexer na pirâmide social brasileira e por terem me fornecido oportunidades acadêmicas e de ensino que permitiram o desenvolvimento de recursos humanos, tendo beneficiado não apenas a mim, mas também muitos outros colegas deste país.

Aos amigos de Juiz de Fora e de Ribeirão Preto, que mesmo não estando dentro do Mundo da Ciência, sempre compreenderam a distância e proferiram palavras de apoio e de motivação, possibilitando que eu seguisse em frente.

Aos amigos do "Habla Mucho Futebol Clube", lendário grupo de futebol da Imunologia, obrigado por tornarem as segundas-feiras tão mais leves, e pela grande amizade durante todo este período. 
Aos técnicos do biotério, Júlio, Adriana, Edir e Rubilan pela amizade, paciência e essencial ajuda com nossos animais de experimentação.

A todos os funcionários dos departamentos de Biologia Celular e de Bioquímica e Imunologia, que de forma direta ou indireta contribuíram para a realização deste trabalho.

A todos aqueles que por ventura não consegui lembrar/mencionar, e que contribuíram para a realização deste trabalho, fica aqui o meu muito obrigado.

\section{Agradecimentos Especiais}

A meu pai, Oscavo, minha mãe, Regina e meu irmão, Luciano, pelo completo incentivo, amor e confiança, comemorando comigo as minhas realizações e chorando comigo minhas frustrações. Vocês são meu maior exemplo, obrigado por terem sempre priorizado minha Educação, mesmo em situações de extrema dificuldade.

À Ana Carolina, minha companheira e namorada, pelo amor, carinho, compreensão, paciência e ajuda nos momentos mais difíceis. Obrigado por todo seu apoio e respeito às minhas escolhas.

Fontes financiadoras: FAPESP (processo n² 2015/25404-2), INCTV/CNPq, CAPES, TDR/WHO, FAEPA e Pró-Reitoria de Pós Graduação, pela concessão da bolsa e pelo apoio financeiro que contribuíram diretamente para o desenvolvimento desse trabalho, bem como para a participação em eventos científicos, que foram de grande importância para minha formação acadêmica, científica e profissional. 


\section{Título: O papel do vírus de RNA de Leishmania na modulação da resposta imune inata}

\section{RESUMO}

Parasitos do gênero Leishmania são os agentes causadores da Leishmaniose, uma importante doença que acomete humanos. Estima-se que mais de 12 milhões de pessoas em todo o mundo estejam infectadas, e que 350 milhões estejam em risco de contrair a doença. A forma mais branda da doença, denominada Leishmaniose cutânea, pode em alguns casos evoluir para uma forma mais grave e devastadora, onde parasitos podem metastizar e atingir os tecidos da naso-faringe, gerando a doença mucocutânea. Para que o fenômeno da metastização aconteça, os parasitos precisam subverter diversas funções do hospedeiro, para que possam se replicar e espalhar eficientemente. Leishmania braziliensis e Leishmania guyanensis são espécies que se encontram variavelmente infectadas pelo vírus de RNA de Leishmania (do inglês LRV), e sua presença correlaciona-se com a forma mais grave da doença. Porém, os mecanismos pelos quais o vírus agrava a Leishmaniose ainda permanecem pouco estudados. O principal tipo celular em que os parasitos replicam é o macrófago, onde modulam diversas vias de sinalização, incluindo aquelas envolvidas na ativação da imunidade inata. Dentre estas, destaca-se o sensor citosólico NLRP3, o qual foi recentemente demonstrado ter papel fundamental no desenvolvimento da infecção por Leishmania. Este sensor de dano celular é capaz de se oligomerizar e ativar uma plataforma citoplasmática denominada inflamassoma, composta por NLRP3, ASC e Caspase-1, que por sua vez pode ser ativada pela via canônica, por meio da geração de espécies reativas de oxigênio e efluxo de $\mathrm{K}^{+}$, principalmente. Por outro lado, a via não-canônica de ativação de NLRP3 acontece pelo reconhecimento de lipopolissacarídeo bacteriano no citoplasma, o qual ativa a enzima caspase-11. Entretanto, ainda não se sabe o papel de caspase-11 no reconhecimento de parasitos, como Leishmania. No presente estudo, nós avaliamos o possível papel do LRV na modulação de receptores da imunidade inata, focando principalmente no NLRP3. Através da análise de aspirados de lesões obtidos de pacientes com Leishmaniose cutânea ou muco-cutânea, observamos que a presença do LRV correlaciona-se com uma maior probabilidade de desenvolvimento da forma mais agressiva da doença, assim como uma menor ativação de moléculas inflamassoma-dependentes, como caspase-1 e IL-1 $\beta$, sugerindo que o LRV possa interferir na ativação de NLRP3 pelo parasito. Para melhor investigar esta hipótese, geramos um clone LRV negativo a partir da cepa M4147 de Leishmania guyanensis, a qual possui alta carga de LRV. Utilizando uma combinação de experimentos realizados em macrófagos murinos e humanos, descobrimos que o LRV, encontrado dentro de vesículas extracelulares (do inglês, EVs) secretadas pelo parasito, é capaz de se ligar ao receptor TLR3 via sua dupla fita de RNA, o qual recruta TRIF e induz a produção de IFN tipo I. Este, por sua vez, é capaz de ativar células de forma parácrina ou autócrina para induzir a autofagia, que por sua vez degrada componentes do inflamassoma localizados no citoplasma, como NLRP3 e ASC, favorecendo a replicação do parasito in vitro e in vivo. Mais além, demonstramos que o LRV é capaz de inibir a ativação da via não-canônica de NLRP3, interferindo com a ativação de caspase-11 efetuada pelo parasito. Desta forma, sugerimos um mecanismo de evasão desencadeado pelo LRV no contexto da infeção por Leishmania, que favorece o crescimento do parasito e o agravamento da doença, indicando vários alvos moleculares para o tratamento e prevenção da devastadora forma mucocutânea da Leishmaniose.

Palavras-chave: Imunidade inata; Virulência; Autofagia; Inflamassoma; Leishmaniose; LRV 


\title{
Title: The role of Leishmania RNA vírus in the modulation of the innate imune
}

response

\begin{abstract}
Parasites from Leishmania genus are the causative agents of Leishmaniasis, an important human disease. It is estimated that over 12 million people are infected worldwide, and 350 million are under risk of acquiring the disease. The cutaneous form is the mildest type of the disease, which may evolve to a devastating outcome, named mucocutaneous leishmaniasis, in where parasites may methastize and reach nasopharingeal tissues. In order to do so, parasites must subvert several imune functions displayed by the host to efficiently establish their replication and dissemination. Leishmania braziliensis and Leishmania guyanensis are some species that may be found variably infected by the Leishmania RNA virus (LRV) in nature, and its presence has been associated with the development of mucocutaneous disease in patients. However, the mechanisms by which LRV enhances disease severity remain largely unknown. Macrophages are the main cell type in which the parasites replicate, where they negatively modulate several innate immune signaling pathways. Among them, we highlight the cytosolic sensor NLRP3, which has recently been shown to be play an important role in parasite control. This sensor is able to sense cellular damage and oligomerize to form a cytoplasmic platform known as the inflammasome, composed by NLRP3, ASC (the adaptor molecule) and Caspase-1. NLRP3 may be activated via the canonical pathway, through reactive oxygen species and potassium efflux, or via the non-canonical pathway, which happens via cytosolic detection of bacterial LPS via caspase11. In the latter case, the role of caspase-11 in the detection of parasitic infections, such as Leishmania, is still unknown. In the current study, we evaluated the possible role of LRV in the modulation of the innate immune response, with special focus given to NLRP3. By analyzing lesion aspirates obtained from patients displaying either cutaneous or mucocutaneous disease, we observed a positive correlation between the presence of LRV and the likelihood of developing the most severe form of the disease, while virus presence correlated with decreased activation of the inflammasome, suggesting that LRV could interfere with NLRP3 activation by the parasite. To better investigate this hypothesis, we generated a LRV negative clone by the M4147 L. guyanensis strain, which harbors high levels of the virus. Through a combination of experiments performed both in mouse and human macrophages, we found that LRV is found within extracelular vesicles secreted by the parasite, which binds to TLR3 via its double-stranded RNA, recruiting TRIF and driving type I IFN production. This cytokine induces autophagy in an autocrine or paracrine manner, which degrades NLRP3 and ASC in the cytoplasm, then favouring parasite replication in vitro and in vivo. Moreover, we show that LRV is capable of blocking caspase-11 and the noncanonical pathway induced by the parasites. Taken together, our results demonstrate an evasion mechanism triggered by LRV in the context of Leishmania infection, favouring parasite replication and the severity of the disease. This work unravels several molecular targets with potential for pharmacological intervention, aiming the treatment and prevention of the devastating disease displayed by people suffering from mucocutaneous Leishmaniasis.
\end{abstract}

Keywords: Innate immunity; Virulence; Autophagy; Inflammasome; Leishmaniasis; LRV. 


\section{ÍNDICE}

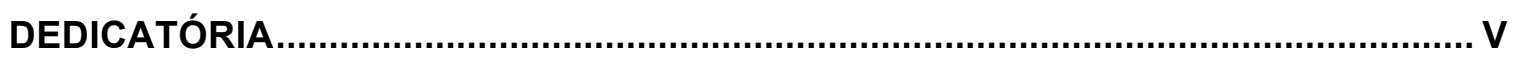

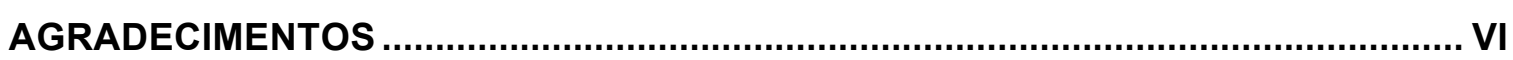

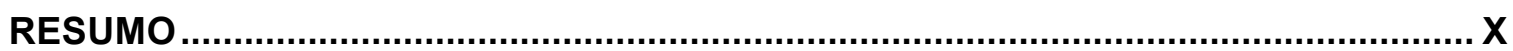

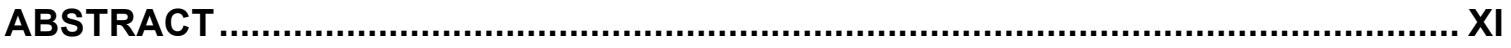

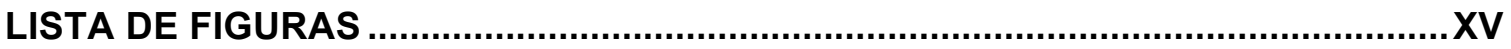

LISTA DE ABREVIATURAS E SIGLAS ..............................................................

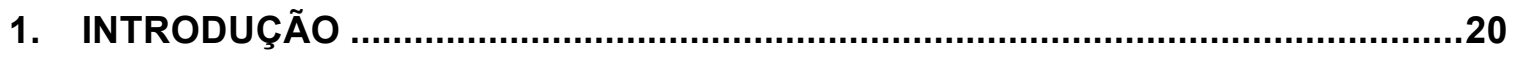

1.1. Epidemiologia e características gerais da Leishmaniose .................................20

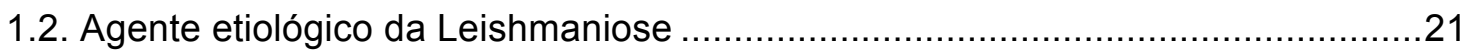

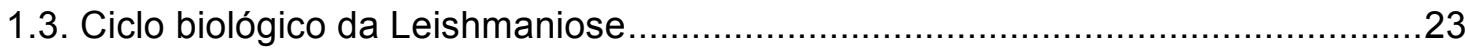

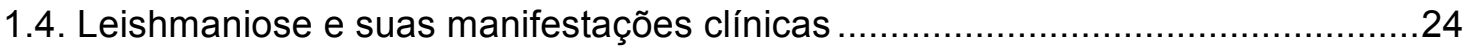

1.5. Eventos imunológicos iniciais na infecção por Leishmania ...............................28

1.6. Aspectos gerais da resposta imune frente à infecção por Leishmania.................29

1.7. Resposta imune inata frente à infecção por Leishmania: receptores do tipo toll..32

1.8. Resposta imune inata frente à infecção por Leishmania: receptores do tipo Nod34

1.9. Resposta imune inata frente à infecção por Leishmania: Autofagia .....................42

1.10. Variáveis que influenciam nas manifestações clínicas da Leishmaniose ...........47

1.11. O vírus de RNA de Leishmania (LRV) e suas implicações na Leishmaniose ....49

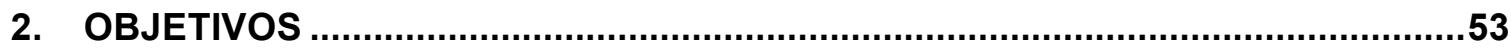

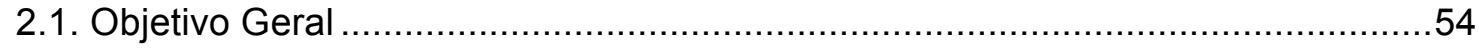

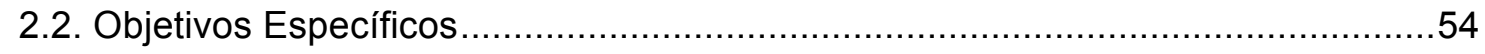

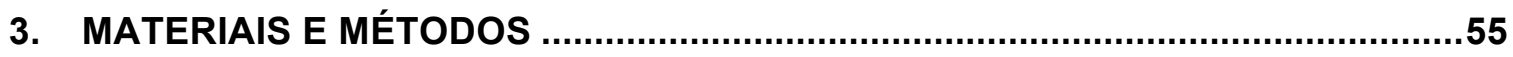

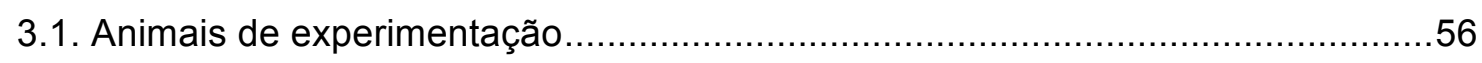

3.2. Geração dos clones 40 (L.g.-) e LRV+ a partir de L. guyanensis M4147 .............56

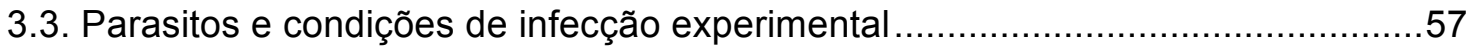

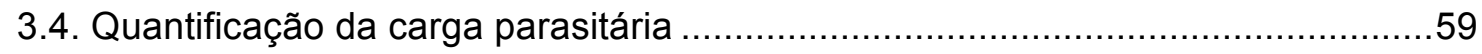

3.5. Purificação de monócitos humanos e diferenciação em macrófagos...................59

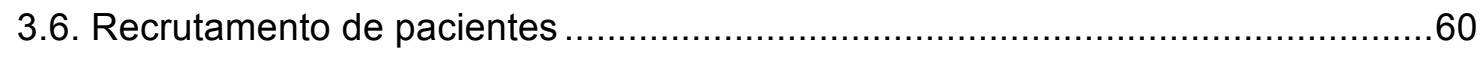


3.7. Coleta e processamento de amostras clínicas 61

3.8. Diferenciação de macrófagos a partir de células da medula óssea 61

3.9. Análise por citometria de células infectadas por L.g..... 62

3.10. Coinfecção com Legionella pneumophila. 63

3.11. Detecção do LRV por PCR 63

3.12. Detecção do LRV por Imunofluorescência 63

3.13. Purificação de vesículas extracelulares (EVs) e ensaios 64

3.14. Ensaios de ELISA 65

3.15. Avaliação de caspase-1 ativa por FACS 65

3.16. Detecção e ativação de caspase-1 e IL-1ß por Western Blotting. 66

3.17. Detecção de proteínas intracelulares por Western Blotting 67

3.18. Avaliação da fagocitose e da atividade leishmanicida de macrófagos 68

3.19. Detecção de espécies reativas de oxigênio (ROS) 68

3.20. Detecção dos níveis intracelulares de potássio. 69

3.21. Extração de DNA e síntese de cDNA 69

3.22. Transdução e análise de BMDMs transduzidos com vetor lentiviral GFP-LC3. .71

3.23. Transdução de macrófagos primários com vetor lentiviral codificando shAtg5..73

3.24. Ensaio de ativação de CASP11 por Pull-down ................................................74

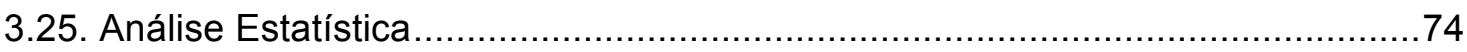

4. RESULTADOS .75

4.1. A magnitude de ativação do inflamassoma está diretamente relacionada com a gravidade da Leishmaniose cutânea em humanos ................................................76

4.2. LRV agrava a infecção e favorece o crescimento de L.g. ..................................79

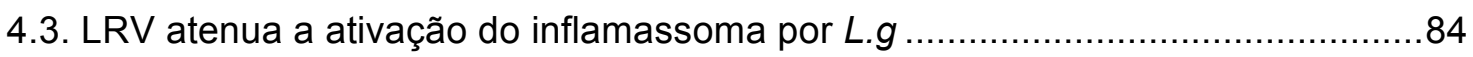

4.4. LRV não interfere com a geração de primeiros ou segundos sinais por L.g ........89

4.5. LRV ativa TLR3/TRIF/IFN- $\beta$ para atenuar a ativação do inflamassoma por L.g ..91

4.6. LRV aumenta a indução de autofagia induzida por L.g. via TLR3/IFN- $\beta$ para

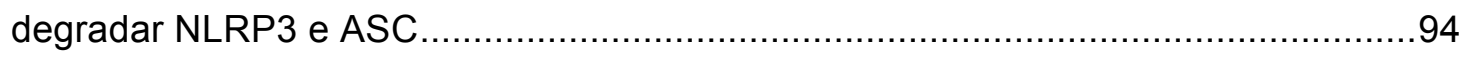


4.7. LRV ativa TLR3 para induzir autofagia e limitar a ativação de NLRP3 por L.g. ...98

4.8. O material genético do LRV encontra-se em EVs do parasito, é transmissível e modula a resposta imune em macrófagos 102

4.9. LRV agrava a infecção por L.g. in vivo via TLR3, ATG5, NLRP3, ASC e CASP1 104

4.10. LRV limita a ativação de NLRP3 por L.g. via TLR3 em macrófagos 107

4.11. Leishmania spp. ativa caspase-11 e a via não-canônica de NLRP3. 110

4.12. LRV inibe a ativação de caspase-11 por L.g. 113

4.13. Isolados clínicos $L R V+$ de Leishmania spp. induzem menor ativação do inflamassoma quando comparados à parasitos LRV115

5. DISCUSSÃO 118

5.1. Discussão 119

6. SUMÁRIO 125

6.1. Sumário 126

7. CONCLUSÃO 127

7.1. Conclusão 128

8. REFERÊNCIAS BIBLIOGRÁFICAS. 129

8.1. Referências Bibliográficas 130

9. ANEXOS 139

9.1. Anexo 1: Prêmios e títulos 140

9.2. Anexo 2: Trabalhos de primeira autoria 142

9.3. Anexo 3: Trabalhos de co-autoria 147

9.4. Anexo 4: Repercussão desse trabalho no cenário nacional e internacional 149 


\section{LISTA DE FIGURAS}

Figura 1. Representação esquemática do ciclo biológico da Leishmaniose ...................... 24

Figura 2. Leishmaniose cutânea e suas diferentes manifestações no Novo Mundo ........... 27

Figura 3. Leishmaniose cutânea e suas diferentes manifestações no Velho Mundo ........... 28

Figura 4. A resposta imune na Leishmaniose cutânea é mediada por células ................... 31

Figura 5. As vias de sinalização desencadeadas pelos receptores TLRs em mamíferos ... 34

Figura 6. Representação esquemática da estrutura dos receptores do tipo NOD .............. 36

Figura 7. Representação esquemática da cascata de ativação dos NLRs ....................... 37

Figura 8. O primeiro (Sinal 1) e o segundo (Sinal 2) sinal são essenciais para a ativação do inflamassoma de NLRP3

Figura 9. Ativação do inflamasoma de NLRP3 por Leishmania spp ................................ 42

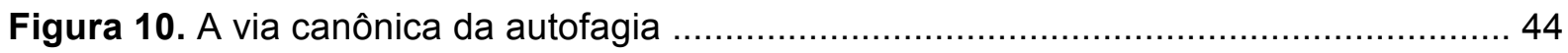

Figura 11. A autofagia limita a ativação do inflamassoma ......................................... 45

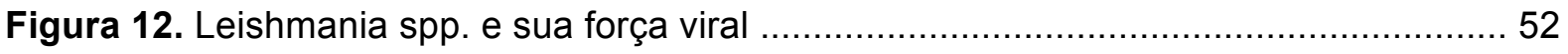

Figura 13. Aspirados de lesões obtidos de pacientes com Leishmaniose em suas diferentes formas clínicas.

Figura 14. LRV e LMC estão associados à diminuição da ativação do inflamassoma......... 79

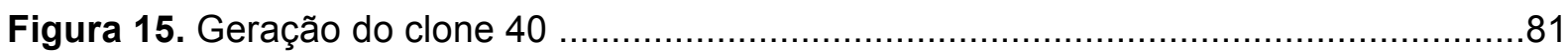

Figura 16. LRV aumenta a virulência de L. guyanensis in vivo ....................................83

Figura 17. LRV aumenta a virulência de L. guyanensis in vitro .......................................

Figura 18. LRV limita a ativação do inflamasssoma por L. g. em BMDMs .........................87

Figura 19. O LRV atenua a ativação do inflamassoma por L.g …...................................88

Figura 20. LRV induz à transcrição de diferentes genes inflamatórios ............................90

Figura 21. LRV não interefere na geração de segundos sinais por L.g ….........................91 
Figura 22. LRV limita a ativação do inflamassoma de NLRP3 por L.g. via TLR3 em BMDMs

Figura 23. Poly:IC e IFN- $\beta$ aumentam a sobrevivência de parasitos L.g

Figura 24. LRV exacerba a autofagia induzida por L.g. via TLR3, desencadeando a degradação de NLRP3 e ASC

Figura 25. LRV não altera a transcrição dos componentes do inflamassoma .98

Figura 26. LRV limita a ativação do inflamassoma por L.g. via autofagia. 101

Figura 27. O RNA viral dentro das vesículas extracelulares (EVs) é transmissível e regula a ativação do inflamassoma por L.g 103

Figura 28. LRV exacerba a infecção por L.g. via NLRP3 e autofagia in vivo. 105

Figura 29. O LRV exacerba a infecção por L. g. via ASC, CASP1 e TLR3 in vivo. 106

Figura 30. O LRV modula a ativação do inflamassoma de NLRP3 em macrófagos humanos via TLR3 109

Figura 31. Leishmania desencadeia a ativação do inflamassoma não-canônico, mediado por caspase-11, em macrófagos 112

Figura 32. LRV limita a ativação de caspase-11 por L.g 114

Figura 33. Isolados clínicos obtidos de pacientes com Leishmaniose em diferentes quadros clínicos da doença 116

Figura 34. Os isolados clínicos LRV+ induzem menor ativação do inflamassoma 117 


\section{LISTA DE ABREVIATURAS E SIGLAS}

ASC: Apoptosis-associated Speck-like protein containg a CARD

APC: Célula apresentadora de antígeno

BMDMs: Macrófagos derivados de células da medula óssea

CARD: Domínio de recrutamento de caspase

CASP1: Caspase-1

CASP11: Caspase-11

DAMPs: Padrões moleculares associados a danos

DC: Célula dendrítica

EVs: vesículas extracelulares

IFN-ץ: Interferon-gama

IL: Interleucina

$\mathrm{KCl}$ : Cloreto de potássio

L.b.: Leishmania braziliensis

LC: Leishmaniose cutânea

L.g.: Leishmania guyanensis

LMC: Leishmaniose mucocutânea

LPG: Lipofosfoglicano

L.p.: Leishmania panamensis

LPS: Lipopolissacarídeo

LRV: vírus de RNA de Leishmania

$\mathrm{NaCl}$ : Cloreto de sódio

NAIP: Proteína inibidora de apoptose neuronal

NF-kB: Fator nuclear kB

NLR: Receptor do tipo NOD 
NLRP: NLR family, pyrin domain containing

NLRP3: NLR family, pyrin domain containing 3

NOD: Domínio de oligomerização nuclear

NOS2: Óxido nítrico sintase 2

NO: Óxido nítrico

Th: T "helper"

Th1: T "helper" tipo 1

Th2: T "helper" tipo 2

TLR: Receptor do tipo Toll

TNF-a: Fator de necrose tumoral alfa

PAMPs: Padrões moleculares associados a patógenos

PBS: Salina tamponada com fosfato

PRRs: Receptores de reconhecimento padrão 
Introdução 


\section{INTRODUÇÃO}

\subsection{Epidemiologia e características gerais da Leishmaniose}

A Leishmaniose constitui um vasto espectro de doenças causadas por protozoários pertencentes ao gênero Leishmania, os quais são parasitos intracelulares obrigatórios de células do sistema fagocítico mononuclear, compreendendo espécies responsáveis por diferentes quadros clínicos patológicos.

O gênero Leishmania engloba aproximadamente 30 espécies, das quais 20 possuem potencial de infecção em humanos, sendo classificadas, portanto, como zoonóticas ou de origem zoonótica. A distribuição da doença é determinada por características climáticas, seus vetores e sistemas de reservatórios (ASHFORD, 2000; ALVAR et al., 2012).

A doença foi primeiramente descrita em 1756, mas foi em 1903 que Leishman identificou o parasito no baço de um paciente, com a forma da doença visceral, o que o fez nomear o gênero com seu nome. No Brasil, o parasito causador da doença cutânea foi identificado como Leishmania braziliensis em um paciente de Além Paraíba, no Rio de Janeiro (VIANNA, 1911). Hoje, sabe-se que a Leishmaniose pode ser causada por grande número de espécies e é transmitida por mosquitos fleblotomíneos do gênero Phlebotomus, no velho Mundo, e Lutysomyia, no novo Mundo (WORLD HEALTH ORGANIZATION, 2010).

De forma geral, a doença é classificada em quatro principais formas clínicas: cutânea localizada (LCL), mucocutânea (LMC), difusa (LCD) e visceral (LV), sendo que no novo Mundo as três primeiras formas são agrupadas em uma única denominação: Leishmaniose tegumentar americana (LTA). Está presente nas Américas, Ásia e África, sendo a principal causa de morte por doenças parasitárias depois da malária (HARTLEY et al., 2014; SCORZA; CARVALHO; WILSON, 2017). 
Estima-se que, no mundo todo, 350 milhões de pessoas corram o risco de contrair Leishmaniose anualmente, enquanto 12 milhões já encontram-se infectadas. A cada ano, aproximadamente dois milhões de novos casos são diagnosticados (1-1,5 milhões de casos de LTA e 500.000 de Leishmaniose visceral) sendo que, destes, uma média de 70.000 resultam em óbito (WHO, 2010). Devido à alta incidência da doença, que se manifesta por lesões incapacitantes, desfigurantes e algumas vezes fatais, a Organização Mundial de Saúde (OMS) inclui a Leishmaniose entre as seis endemias mais importantes em todo o mundo (WHO, 2010; PIGOTT et al., 2014).

Dentre os países da América Latina, o Brasil destaca-se com os maiores índices da doença, sendo a LTA sua forma mais comum. A distribuição geográfica da Leishmaniose no Brasil é ampla e tem sido registrada em todo o território nacional. De 1990 a 2010, foram detectados, em média, cerca de 20 novos casos por 100.000 habitantes no Brasil, sendo que todas as unidades federadas registraram casos autóctones da doença. As regiões Norte e Nordeste vêm contribuindo com o maior número de casos registrados no período de 1990 a 2010 cerca de $40 \%$ e 35\%, respectivamente. No estado de São Paulo, de 1975 a 2008, foram registrados 12.978 casos. Destes, 621, só em 2001. No caso específico da região leste do estado de São Paulo, o número de casos autóctones de LTA tem crescido desde 1975 (ALVAR et al., 2012; PIGOTT et al., 2014; WHO, 2010).

\subsection{Agente etiológico da Leishmaniose}

Os parasitos do gênero Leishmania são pertencentes à ordem Kinetoplastida e à família Trypanosomatidae, sendo caracterizados como protozoários unicelulares. A identificação taxonômica do gênero foi, durante muitos anos, baseada nos aspectos clínicos da doença. Atualmente, o gênero é subdividido em dois 
subgêneros, Viannia e Leishmania, levando-se em conta parâmetros tradicionais (formas clínicas, epidemiologia e distribuição geográfica) e o perfil de colonização do tubo digestivo do vetor. O subgênero Viannia agrupa espécies que inicialmente se desenvolvem no intestino posterior e mais tarde no intestino anterior do inseto transmissor, e o subgênero Leishmania agrupa espécies que se desenvolvem exclusivamente nos intestinos médio e anterior do flebotomíneo (RYAN; LAINSON; SHAW, 1987).

O parasito apresenta dois estágios principais no seu ciclo vital. No trato digestivo dos flebotomíneos fêmeas, se reproduzem as formas flageladas, denominadas promastigotas. São alongadas, possuem flagelo livre e duas principais moléculas de superfície: o lipofosfoglicano (LPG) e a glicoproteína 63 (gp63). Cada promastigota possui $6 \times 10^{6}$ cópias de moléculas de LPG e $5 \times 10^{6}$ cópias de gp63 (BOUVIER; ETGES; BORDIER, 1985) que lhes protegem de processos microbicidas, tais como a lise mediada pelo complemento, ação de radicais de oxigênio e hidrolases presentes no mamífero e no inseto transmissor (ILGOUTZ; MCCONVILLE, 2001). Já nos hospedeiros mamíferos, os parasitos se multiplicam na forma amastigota, dentro do vacúolo parasitóforo nos macrófagos (SCOTT; NOVAIS, 2016). As formas amastigotas são arredondadas e com flagelo diminuído, e são altamente resistentes ao ambiente hostil presente dentro do fagolisossoma das células hospedeiras. Acredita-se que tal capacidade seja devido a moléculas glicoconjugadas, tais como glicoinositolfosfolipídios (GIPLs) e outros glicoconjugados presentes em sua superfície (ILG, 2000). Interessantemente, as formas amastigotas diminuem significativamente a expressão de LPG em sua superfície (PETERS; STIERHOF; ILG, 1997). 


\subsection{Ciclo biológico da Leishmaniose}

O ciclo biológico da doença se inicia quando a fêmea do inseto vetor pica o animal vertebrado infectado e, durante o repasto, ingerem macrófagos infectados com amastigotas de Leishmania. No lúmen intestinal do inseto, ocorre o rompimento do macrófago, liberando as formas amastigotas que sofrem divisão binária e se transformam em promastigotas, que se dividem rapidamente, colonizando o trato digestivo médio e anterior do flebotomíneo. No intestino médio do inseto há a transformação de amastigotas em promastigotas procíclicas, as quais são pequenas, ovóides, com pouca motilidade, multiplicam-se intensamente e em seguida vão se tornando promastigotas longas e com extrema motilidade. Posteriormente, transformam-se em promastigotas metacíclicas, que são menores que a forma procíclica, embora mantenham grande motilidade (SACKS; BRODIN; TURCO, 1990). São as formas metacíclicas que migram para o esôfago, faringe e probóscide do flebotomíneo e são inoculadas durante o repasto sanguíneo, reiniciando assim o ciclo no hospedeiro vertebrado (SACKS; KAMHAWI, 2002) (Figura 1). 


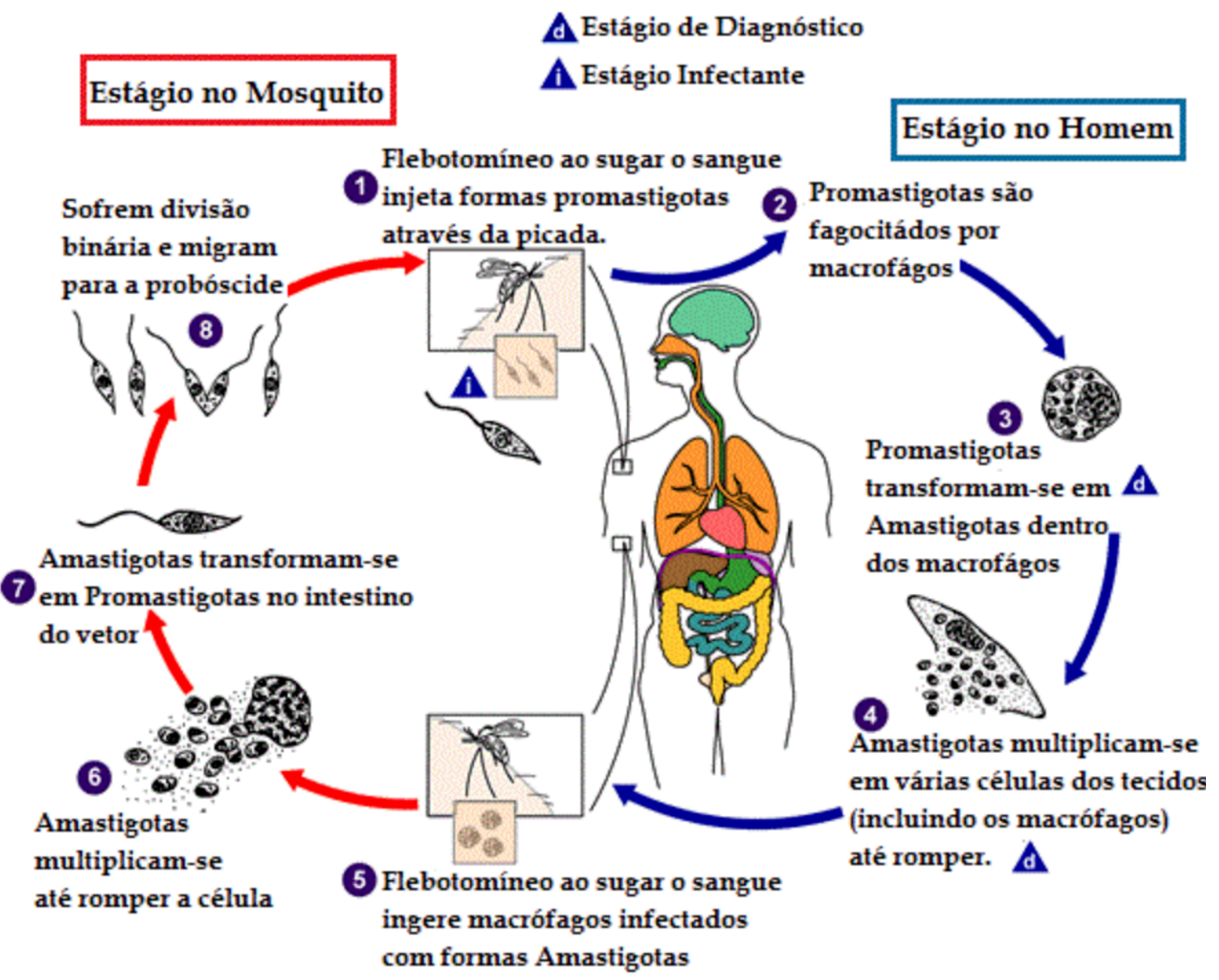

Figura 1: Representação esquemática do ciclo biológico da Leishmaniose. Durante o repasto sanguíneo, o hospedeiro vertebrado (Homem, cão, roedor), o flebotomíneo injeta até 1000 formas de promastigotas metacíclicos na derme (1). Lá, são internalizados por macrófagos (2), onde se diferenciam em amastigotas (3), multiplicam e estabelecem a infecção (4). Quando flebotomíneos picam novamente os hospedeiros vertebrados, ingerem macrófagos infectados contendo as formas amastigotas (5), que se multiplicam (6) e voltam a se diferenciar em formas promastigotas no interior do intestino do inseto (7). Depois, os promastigotas vão se multiplicando e migram para a probóscide do inseto (8), por onde serão inoculados novamente pelo vetor na derme dos hospedeiros, reiniciando o ciclo. Retirado de CDC, Center for Diseases Control and Prevention, EUA.

\subsection{Leishmaniose e suas manifestações clínicas}

A Leishmaniose visceral, que é a forma mais grave da doença, pode ser causada por L. infantum e L. donovani, no velho Mundo, e L. chagasi, no novo Mundo. O início da doença pode se manifestar com febre, mas outros sintomas, como a perda de peso, anemia, hepatoesplenomegalia, caquexia e perda funcional da medula óssea podem surgir de acordo com a progressão da visceralização (ALVAR et al., 2012). Uma outra característica clínica que também pode ocorrer é a 
imunossupressão generalizada, que pode levar o paciente a óbito. Entretanto, a infecção humana por $L$. donovani nem sempre resulta em doença, dado que muitos pacientes podem apresentar um curso de infecção subclínico somente pela presença de anticorpos específicos (SACKS et al., 1987).

As outras formas da doença são agrupadas dentro do grupo das LTA, conforme discutido anteriormente. As espécies responsáveis pela LTA no novo Mundo são: L. braziliensis, L. peruviana, L. guyanensis, L. lainsoni, L. naiffi, L. shawi, L. colombiensis, L. panamensis, L. venezuelensis, L. amazonensis e L. mexicana (GRIMALDI; TESH, 1993). Já no Velho Mundo, L. tropica, L. major e L. aethiopica são as principais espécies descritas (ASHFORD, 2000).

Clinicamente, a Leishmaniose tegumentar apresenta-se de maneira variada, desde formas discretas até ulcerações de pele, que podem ser discretas ou extensas e com evolução espontânea para cura após alguns meses, mesmo com ulcerações múltiplas ou disseminadas. A manifestação clínica mais freqüente da doença é a Leishmaniose cutânea localizada, que se caracteriza por lesões ulceradas, únicas, de bordas elevadas e circulares, com pouca secreção e indolores, podendo haver casos de controle da infecção com cura espontânea (CUENTAS et al., 1984; HERWALDT; ARANA; NAVIN, 1992). A Leishmaniose cutânea localizada pode ser causada principalmente pelas espécies $L$. amazonensis, $L$. braziliensis, $L$. guyanensis, L. panamensis, L. peruviana, L. mexicana e L. venezuelensis, no novo Mundo (Figura 2), e L. major, L.tropica e L. aethiopica, no velho Mundo (Figura 3) (BAILEY, M.S., LOCKWOOD, 2007; REITHINGER et al., 2007).

A forma disseminada é caracterizada por úlceras típicas, associadas a inúmeras lesões papulares, decorrentes de disseminação hematogênica, podendo comprometer as mucosas (COSTA et al., 1986; CARVALHO et al., 1994). É causada 
pelas espécies $L$. aethiopica, no velho Mundo, e L. amazonensis, L. mexicana e $L$. venezuelensis, no novo Mundo (BAILEY, M.S., LOCKWOOD, 2007; REITHINGER et al., 2007). A Leishmaniose cutânea difusa, causada por L. (L.) amazonensis, é uma forma grave não responsiva ao tratamento, anérgica e muito rara. É caracterizada predominantemente por nódulos múltiplos, onde se observa extraordinária riqueza parasitária, podendo ocorrer também lesões tuberosas, placas e raramente aparecem ulcerações (CUENTAS et al., 1984) (Figuras 2 e 3).

A forma mais severa do espectro clínico é a Leishmaniose muco-cutânea, também conhecida como "espúndia", sendo, portanto, uma forma mais grave da Leishmaniose cutânea, e que pode ser fatal. É caracterizada por lesão na mucosa nasal, que pode expandir e acometer palato mole e duro, úvula, faringe, gengivas e lábio superior (LESSA et al., 2007; HARTLEY et al., 2012). Paradoxalmente, por mais que haja destruição da mucosa e extensivo quadro inflamatório, as lesões mucosas contêm um número bastante reduzido de parasitos. O intenso infiltrado de células inflamatórias resulta em exuberante aumento do nariz e do lábio superior, conferindo à lesão um aspecto tumoral e desfigurante, muitas vezes afetando também a vida social do paciente (HARTLEY et al., 2014). A perfuração do septo nasal é observada em torno de $42 \%$ dos pacientes, podendo afetar a mucosa traqueobrônquica e esôfago (BITTENCOURT; BARRAL, 1991; LESSA et al., 2007). No velho Mundo, é causada pelas espécies $L$. tropica, $L$. major, L. aethiopica e $L$. infantum (MORSY et al., 1995; ALIAGA et al., 2003; KHARFI et al., 2003), enquanto no novo Mundo (inclusive no Brasil) a espécie causadora mais freqüente é a $L$. braziliensis, mas também L. panamensis, L. guyanensis, L. mexicana e L. amazonensis (SARAVIA et al., 1985; GRIMALDI; DAVID; MCMAHON-PRATT, 1987; 
SANTRICH et al., 1990; BARRAL et al., 1991; DESJEUX, 1996; REITHINGER et al., 2003) (Figuras 2 e 3).

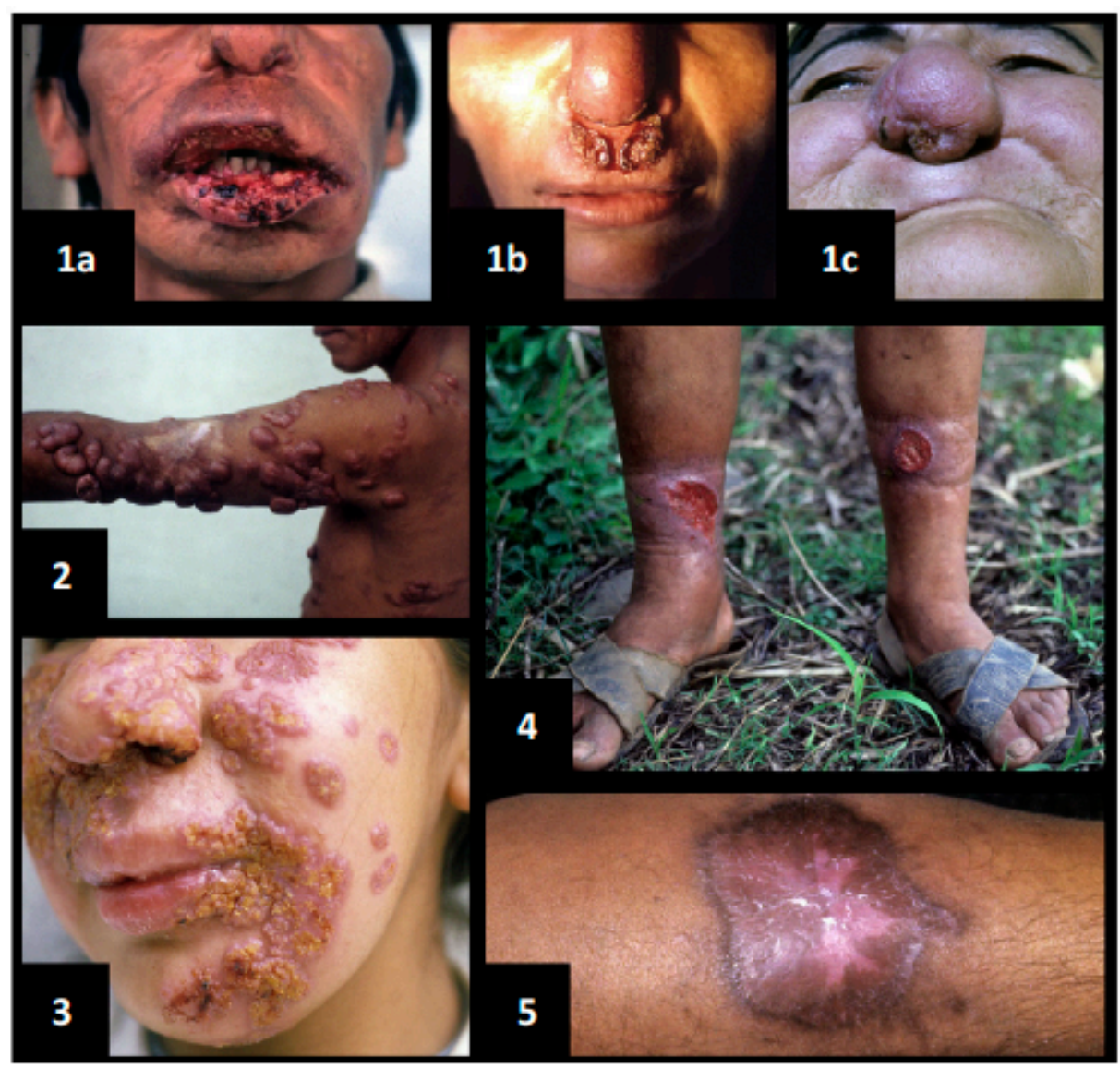

Figura 2: Leishmaniose cutânea e suas diferentes manifestações clínicas no Novo Mundo. A doença pode se manifestar em diferentes formas e níveis de agressividade na América Latina. 1: exemplos de Leishmaniose mucocutânea; (a) forma bucal, (b) forma septal e (c) o clássico "nariz de anta", após desenvolvimento da forma septal (Bolívia). 2: Leishmaniose cutânea difusa (LCD), com múltiplas lesões nodulares (Brasil). 3: Leishmaniose cutânea facial, com desenvolvimento de múltiplas lesões (Bolívia). 4: Lesões ulcerativas clássicas, com bordas aumentadas e exudato (Bolívia). 5: Cicatriz ulcerativa clássica, centralmente hipo-pigmentada, com aspecto mais leve (Brasil). Retirado de Hartley et al, Trends in Parasitology, 2014. 


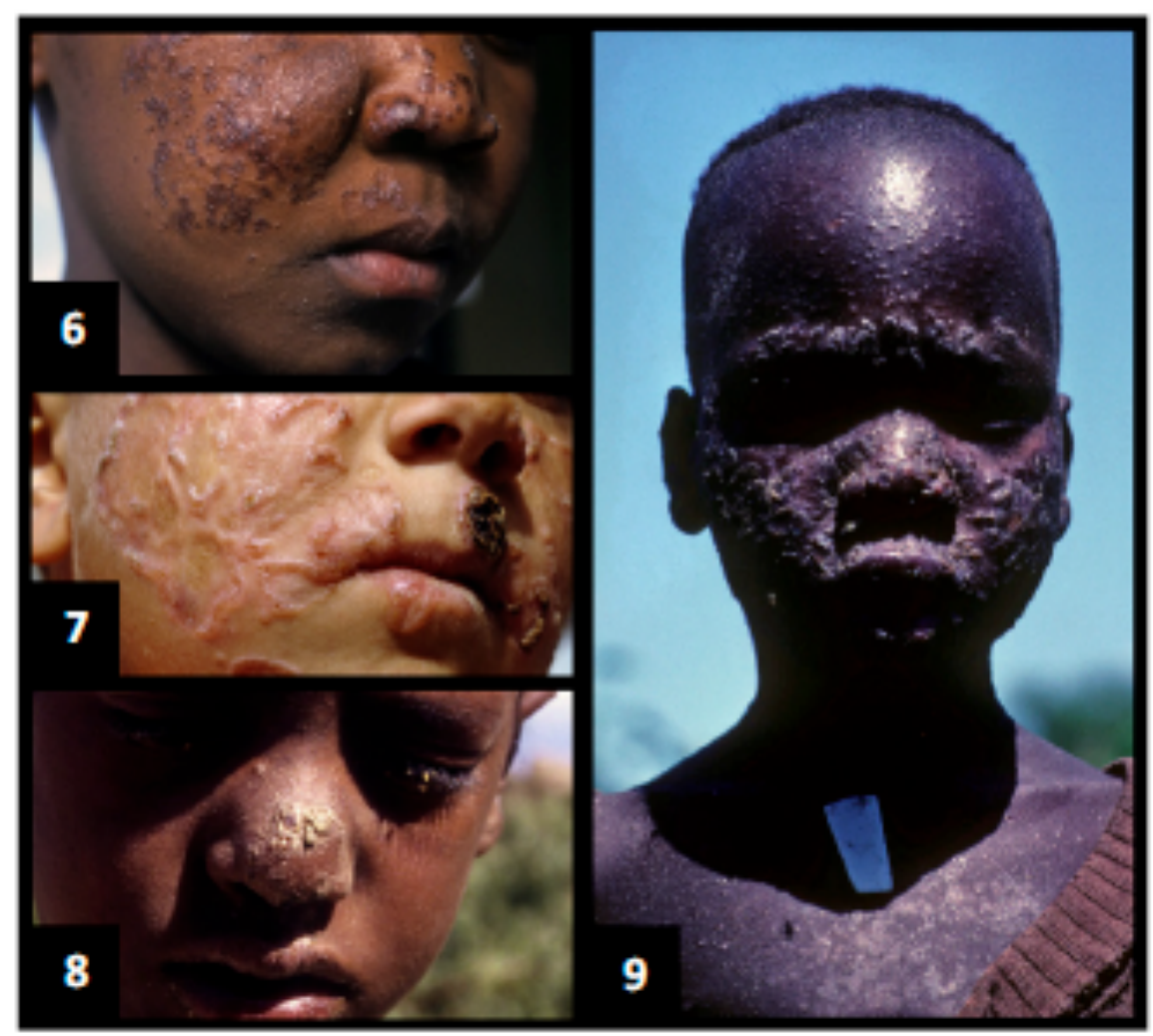

Figura 3: Leishmaniose cutânea e suas diferentes manifestações clínicas no Velho Mundo. A leishmaniose pode se manifestar em diferentes formas e níveis de agressividade também no continente Africano. 6: Leishmaniose cutânea difusa (LCD) com pápulas hiperpigmentadas não-ulcerativas. 7: Leishmaniose recidiva lupóide desfigurativa após reativação da doença na periferia, após a cura de lesões anteriores. 8: Leishmaniose cutânea nasal, sem acometimento da mucosa. 9: Leishmaniose dermal pós Kala-azar, apresentada com despigmentação do tronco e múltiplas pápulas na face. Retirado de Hartley et al, Trends in Parasitology, 2014.

\subsection{Eventos imunológicos iniciais na infecção por Leishmania}

A picada da fêmea do flebótomo resulta na inoculação de promastigotas metacíclicas junto com a saliva do inseto, na derme do hospedeiro mamífero (SCOTT; NOVAIS, 2016). A quantidade de promastigotas inoculadas varia de acordo com a intensidade da infecção do flebótomo, o que parece impactar no desenvolvimento da resposta imune contra o parasito. Estima-se que os flebótomos possam inocular até 1000 promastigotas metacíclicos na derme do hospedeiro mamífero (WARBURG; SCHLEIN, 1986), podendo penetrar em diferentes tipos de células mielóides, como granulócitos, macrófagos (LIMA et al., 1998) e células 
dendríticas (CDs) (MOLL, 2000). Embora os parasitos possam sobreviver dentro de neutrófilos nas primeiras horas após a infecção (LAUFS et al., 2002; VAN ZANDBERGEN et al., 2004), estes granulócitos sofrem apoptose espontânea (AGA et al., 2002), ocasionando a eferocitose de células infectadas por macrófagos (SAVILL et al., 1989), o que impede que suas funções microbicidas sejam ativadas (MEAGHER et al., 1992; VAN ZANDBERGEN et al., 2004). Desta forma, acredita-se que a Leishmania seja internalizada pelo macrófago de forma silenciosa, favorecendo sua replicação (LASKAY; VAN ZANDBERGEN; SOLBACH, 2003). Vale ressaltar que, embora o parasito consiga diferenciar-se em amastigotas e proliferar dentro de células dendríticas (PRINA, E., ABDI, S.Z., LEBASTARD, M., PERRET, E., WINTER, N., ANTOINE, 2004), os macrófagos são as células hospedeiras preferenciais, onde os parasitos proliferam intensamente nos vacúolos parasitóforos (KONECNY et al., 1999). Embora os tipos celulares envolvidos na resposta imune do hospedeiro sejam conhecidos já há algum tempo, os mecanismos e vias de sinalização nos eventos iniciais da doença, que levam à replicação e disseminação parasitária ou ao controle da infecção, não são totalmente entendidos. Além disso, acredita-se que tais eventos sejam cruciais para o desenvolvimento das diferentes formas clínicas da doença (HARTLEY et al., 2014; SCOTT; NOVAIS, 2016).

\subsection{Aspectos gerais da resposta imune frente à infecção por Leishmania}

A resposta imune protetora contra Leishmania é principalmente mediada por células e, embora a presença de anticorpos específicos seja comum na LTA, pouco se sabe sobre a participação dos anticorpos neste processo (SARAVIA et al., 1989). De forma geral, a resposta imune inicia-se quando macrófagos ou células dendríticas infectadas pelo parasito induzem a produção de IL-12, que age sobre 
células NK e NK-T estimulando a produção de IFN-ץ e auxilia na diferenciação de linfócitos $\mathrm{T}$ virgens no subtipo Th1, também produtores de IFN-Y (SCHARTONKERSTEN; SCOTT, 1995; MARTÍN-FONTECHA et al., 2004). Citocinas como o IFNY, TNF- $\alpha$ e IL-1 $\beta$ induzem a secreção de IL-12 por células apresentadoras de antígenos (células dendríticas, macrófagos, monócitos e linfócitos B) e por neutrófilos polimorfonucleares (PMN). A produção inicial de IL-12 pode também ser desencadeada pela fagocitose e reconhecimento do parasito pelos receptores da imunidade inata (SUTTERWALA; MOSSER, 1999), sendo amplificada por IFN-Y. A citocina IL-12, por sua vez, também pode amplificar a produção de IFN-ץ pelas células Th1, estabelecendo, assim, uma importante alça de feedback positivo (HEINZEL et al., 1995). Além disso, IFN-ץ e o TNF-a promovem um efeito sinérgico no macrófago infectado, dado que suas ações combinadas resultam na estimulação da produção de radicais de oxigênio e nitrogênio, como o óxido nítrico (NO), sendo este o principal mediador microbicida responsável pela eliminação dos parasitos a nível intracelular (KEMP, 1997). O papel fundamental do NO, assim como o de espécies reativas de oxigênio (ROS) na atividade leishmanicida exercida pelos macrófagos, foi evidenciado em estudos que encontraram um aumento da carga parasitária quando a óxido nítrico sintase induzível (NOS2) ou a produção de ROS era deletada em animais nocautes, ou bloqueada através de inibidores específicos destas vias (EVANS et al., 1993; MURRAY; NATHAN, 1999; GANTT et al., 2001; MUKBEL et al., 2007). Recentemente, dados publicados pelo nosso laboratório demonstraram que, além do IFN-y e do TNF- $\alpha$, a IL-1 $\beta$, uma das mais antigas citocinas descritas produzida principalmente nos estágios iniciais de infecção pela imunidade inata, também pode induzir a síntese de NO. Essa síntese pode ocorrer tanto em condições onde o IFN-ץ não está presente, como por exemplo em 
macrófagos infectados in vitro, quanto no contexto de infecção in vivo (LIMAJUNIOR et al., 2013a, 2017; DE CARVALHO et al., 2019a, 2019b). Apesar de tanto a resposta inata quanto a adaptativa serem cruciais na patogênese da infecção por Leishmania (SCOTT; NOVAIS, 2016) (Figura 4), a presente tese é focada na investigação dos mecanismos inatos relacionados ao controle do parasito, e, portanto, a imunidade inata será discutida em mais detalhes a seguir.

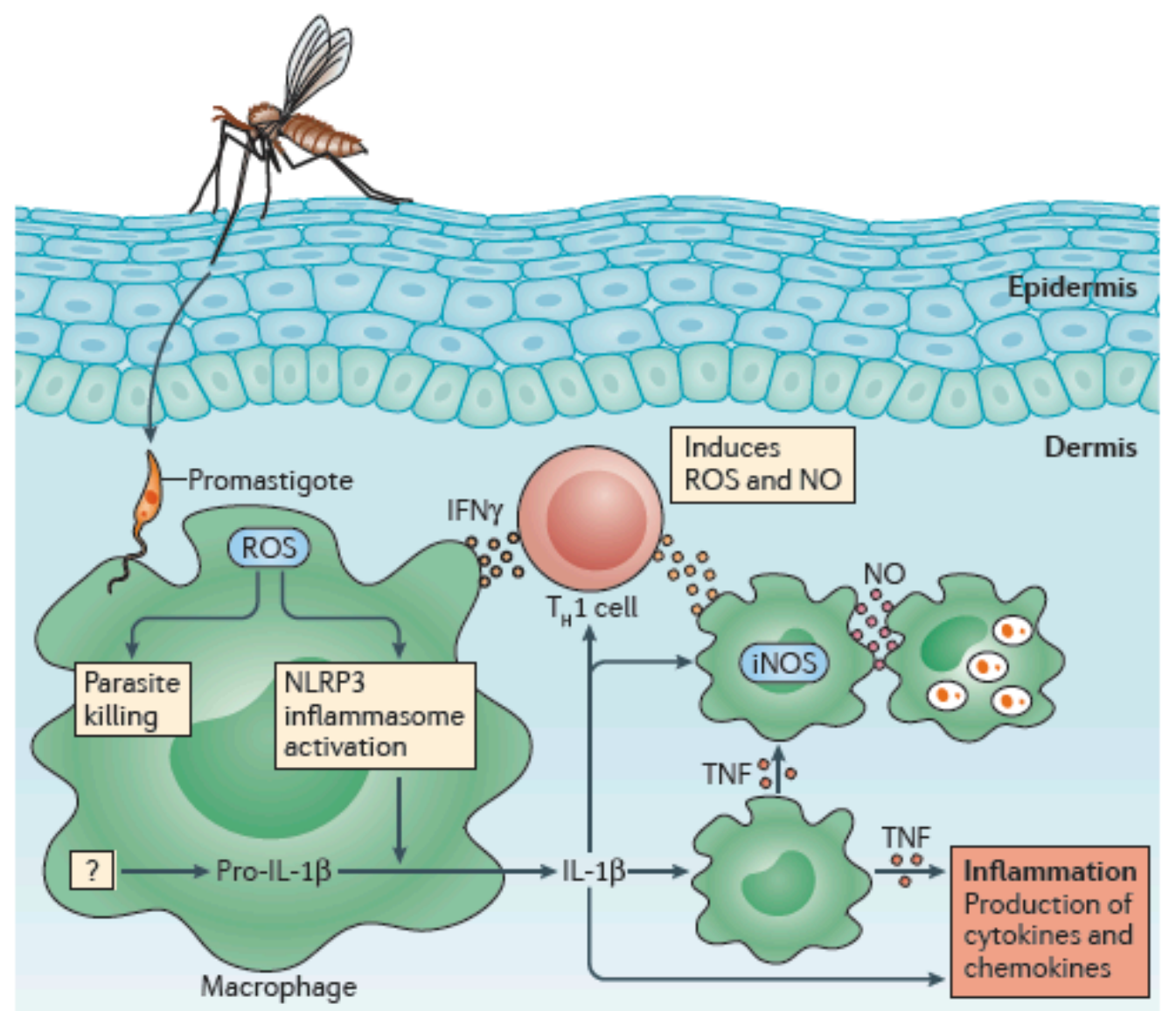

Figura 4: A resposta imune na Leishmaniose cutânea é inflamatória e mediada por células. Esquema simplificado demonstrando eventos imunológicos mais iniciais e mais tardios após a inoculação de Leishmania na derme do hospedeiro, pelo inseto. A fagocitose dos parasitos por macrófagos leva à ativação de receptores da imunidade inata, produção de ROS e citocinas inflamatórias, como TNF- $\alpha$ e IL-1 $\beta$, que podem induzir à produção de NO, eliminando a infecção. Porém, a persistência parasitária leva mais tardiamente à polarização de respostas imunes adaptativas mais robustas, como por exemplo, a de perfil Th1, onde células T produzem IFN- $\mathrm{Y}$, que também pode auxiliar na produção de $\mathrm{NO}$ e eliminação dos parasitos em células infectadas. Entretanto, em alguns casos pode haver um feedback positivo e excesso de produção dos mediadores inflamatórias, contribuindo para a persistência dos parasitos e para o dano tecidual, levando à imunopatologia. Retirado de Scott e Novais, Nature Reviews Immunology, 2016. 


\subsection{Resposta imune inata frente à infecção por Leishmania: receptores do tipo toll}

As células da imunidade inata possuem receptores codificados em linhagens germinativas responsáveis pelo reconhecimento de padrões moleculares associados à patógenos (PAMPs), incluindo ácidos nucléicos, componentes de paredes celulares de fungos e bactérias, proteínas flagelares, dentre outros (MEDZHITOV; JANEWAY, 2000; KARIN; LAWRENCE; NIZET, 2006; O’NEILL; GOLENBOCK; BOWIE, 2013). A primeira família desses receptores estudada em detalhes foi a dos receptores do tipo Toll (TLRs - Toll Like Receptors) (AKIRA; TAKEDA, 2004). Os TLRs constituem uma família de 11 proteínas transmembranas (TLR1 até TLR11, em humanos) que reconhecem diferencialmente PAMPs. Todos os TLRs, quando ativados, recrutam a proteína adaptadora MyD88 (myeloid differentiation primary response gene 88), com exceção do receptor TLR3, que recruta TRIF (TIRcontaining adaptor-inducing IFN (interferon)- $\beta$ ) (O'NEILL; GOLENBOCK; BOWIE, 2013). Uma vez recrutadas, estas moléculas interagem com várias outras e desencadeiam uma cascata de sinalização que ativa proteínas MAPKs (mitogenactivated protein kinases) e leva à translocação de fatores de transcrição para o núcleo, como NF-kB e IRFs (Interferon regulatory factors), culminando na produção de diversas citocinas inflamatórias, tais como a IL-12, TNF- $\alpha$, IL-6, e IFN do tipo I (IFN- $\alpha$ e IFN- $\beta$ ), que são prontamente secretadas. Já a IL-1 $\beta$ é produzida na sua forma inativa, chamada de pro-IL-1 $\beta$, sendo mantida no citoplasma até que um segundo sinal, oriundo da ativação de outros receptores da imunidade inata, os Nodlike (NLRs), a converta na sua forma ativa, secretando-a para então exercer sua atividade altamente inflamatória (BROZ; DIXIT, 2016) (Figura 5). Vários trabalhos têm demonstrado a importância de receptores Toll-like específicos na montagem de 
uma resposta imune eficiente contra parasitos do gênero Leishmania, tais como TLR2, TLR4, TLR7 e TLR9, os quais contribuem para um eficiente controle da infecção por L. major e L. braziliensis (BECKER et al., 2003; DE VEER et al., 2003; KROPF et al., 2004a, 2004b; LIESE; SCHLEICHER; BOGDAN, 2007; SCHAMBERREIS et al., 2013; WEINKOPFF et al., 2013). De forma geral, citocinas produzidas via estes TLRs atuam no controle da infecção por auxiliar na geração de NO, ROS, e moléculas microbicidas, ou por atuarem na polarização de respostas adaptativas protetoras, como a de perfil Th1. Entretanto, vale ressaltar que algumas citocinas, quando produzidas de forma excessiva, podem gerar imunopatologia, necrose tecidual e crescimento parasitário. Como exemplo, podemos citar os IFN do tipo I (IFN- $\beta$ e IFN- $\alpha$ ), que frente à infecção por Leishmania auxilia na sobrevivência do parasito e no agravamento da doença, fator que atribui a esta citocina um papel deletério para o hospedeiro (KHOURI et al., 2009; HARTLEY et al., 2014; IVES et al., 2014; ROSSI et al., 2017; SILVA-BARRIOS; STAGER, 2017). Apesar dos mecanismos antivirais promovidos por IFN- $\alpha / \beta$ serem bastante claros na literatura, pouco se sabe sobre as vias de sinalização desencadeadas por estas citocinas no desenvolvimento da Leishmaniose. 


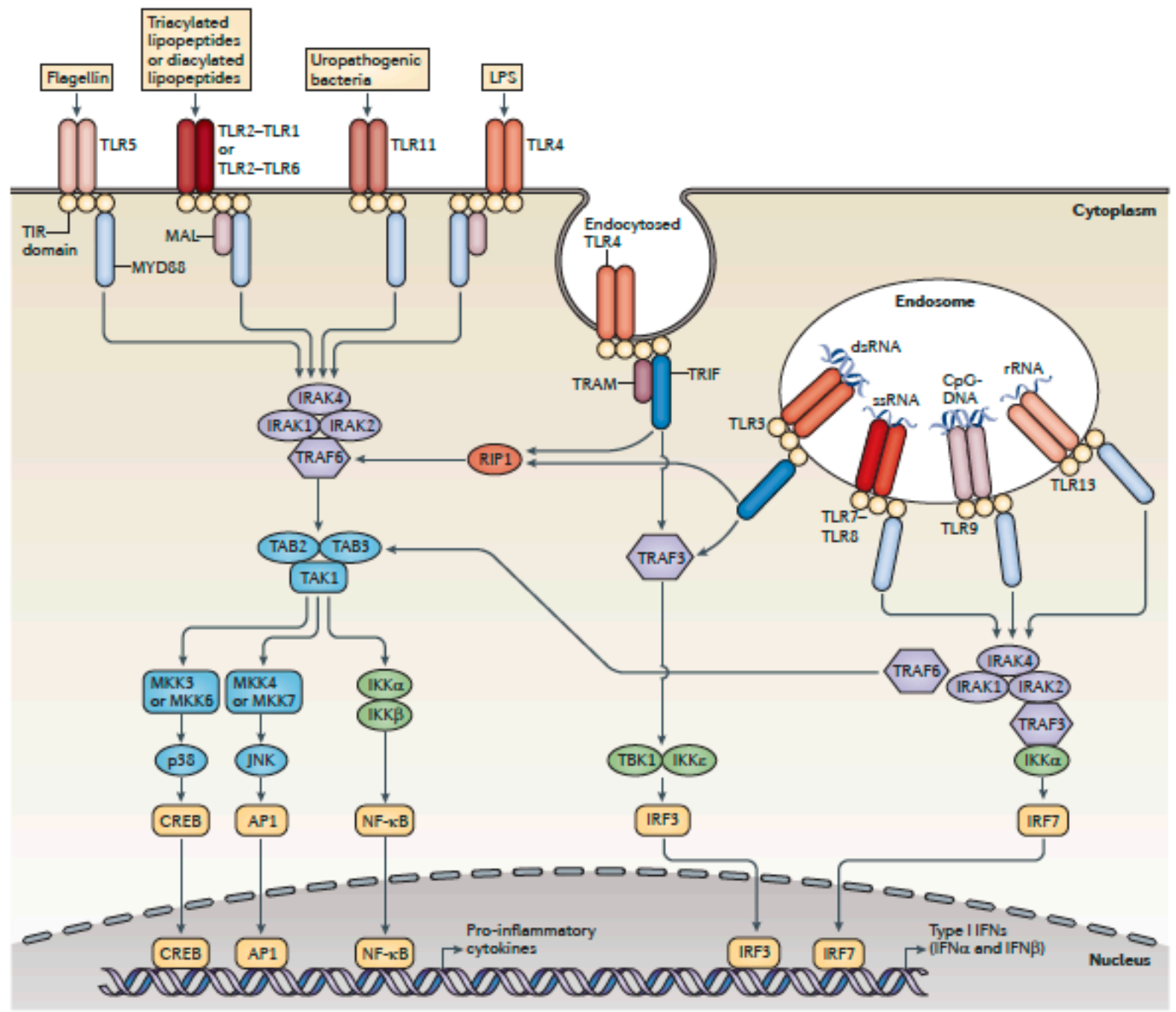

Figura 5: As vias de sinalização desencadeadas pelos receptores TLRs em mamíferos. $O$ engajamento dos diferentes tipos de TLRs por seus respectivos PAMPs leva ao recrutamento da proteína adaptadora MyD88, que ativa vias de sinalização (IRAKs, TRAFs) que culminam na ativação de fatores de transcrição, como NF-kB, AP-1, CREB, IRF3 e IRF7, levando à produção de citocinas inflamatórias. O único TLR que não recruta MyD88 é o TLR3, recrutando TRIF, o qual pode ser utilizado também pelo TLR4. A ativação de TLR3 induz preferencialmente IRFs, que auxiliam na produção de IFN do tipo I, possuindo então importante ação antiviral. Adaptado de O'Neill, Golenbock e Bowie, Nature Reviews Immunology, 2013.

\subsection{Resposta imune inata frente à infecção por Leishmania: receptores do tipo}

Nod

Nos últimos anos, uma nova família de receptores da imunidade inata foi descrita, os receptores do tipo Nod (NLRs). Diferente dos receptores Toll-like (receptores transmembranares), os NLRs consistem de proteínas solúveis que se 
encontram no citoplasma e sinalizam em resposta a patógenos intracelulares. Esses receptores são capazes de reconhecer sinais endógenos de dano celular, como o acúmulo de cristais de ácido úrico (SHI; EVANS; ROCK, 2003), baixas concentrações de potássio intracelular (MARTINON; BURNS; TSCHOPP, 2002), espécies reativas de oxigênio (ROS), ATP extracelular, DNA no citoplasma, dentre outros (BROZ; DIXIT, 2016).

Em humanos, a família dos NLRs é composta de 23 proteínas, e existem aproximadamente 34 genes NLR em camundongos (TING et al., 2008). Homólogos dos NLRs estão presentes em plantas (genes $R-R$ para resistência) e animais, incluindo organismos filogeneticamente mais primitivos, tais como o zebrafish e ouriços do mar, apesar de não serem encontrados em insetos e vermes (INOHARA; NUÑEZ, 2003; HIBINO et al., 2006). Embora primariamente expressos em células imunes, incluindo linfócitos e células apresentadoras de antígenos, tais como macrófagos e células dendríticas, os NLRs podem também ser expressos em células não imunes, incluindo células epiteliais e mesoteliais (CHEN et al., 2009). Os NLRs apresentam uma estrutura característica, composta por três domínios: um domínio carboxi-terminal LRR que é responsável pelo reconhecimento do ligante; um domínio NOD (“Nucleotide-binding Oligomerization Domain”), responsável pela oligomerização do receptor após sua ativação; e um domínio amino-terminal distinto, o qual desencadeia a função efetora do receptor (ATHMAN; PHILPOTT, 2004) (Figura 6). Na ausência de infecção, o NLR encontra-se em uma forma inativa; as regiões efetoras permanecem protegidas pela região $L R R$, o que bloqueia sua ativação. A ligação de moléculas ao LRR promove uma modificação estrutural no receptor resultando na exposição de sítios de ligação ao ATP, permitindo assim a ligação de ATP ao domínio NOD, o qual se oligomeriza promovendo uma 
sinalização celular característica de cada NLR (ZINK et al., 2002) (Figura 7). NLRs incluem proteínas tais como NOD1 (do inglês, nucleotide-binding and oligomerization domain 1), também conhecido como CARD4; NOD2 (também conhecido como CARD15) (INOHARA et al., 2005); NLRPs (proteínas contendo domínios NACHT, LRR e pyrin); NLRC4 ou IPAF (fator ativador da protease ICE, enzima conversora de IL-1), também conhecido como CARD12 (ou CLAN) e NAIPs (proteínas inibidoras de apoptose neuronal) (TING; KASTNER; HOFFMAN, 2006).

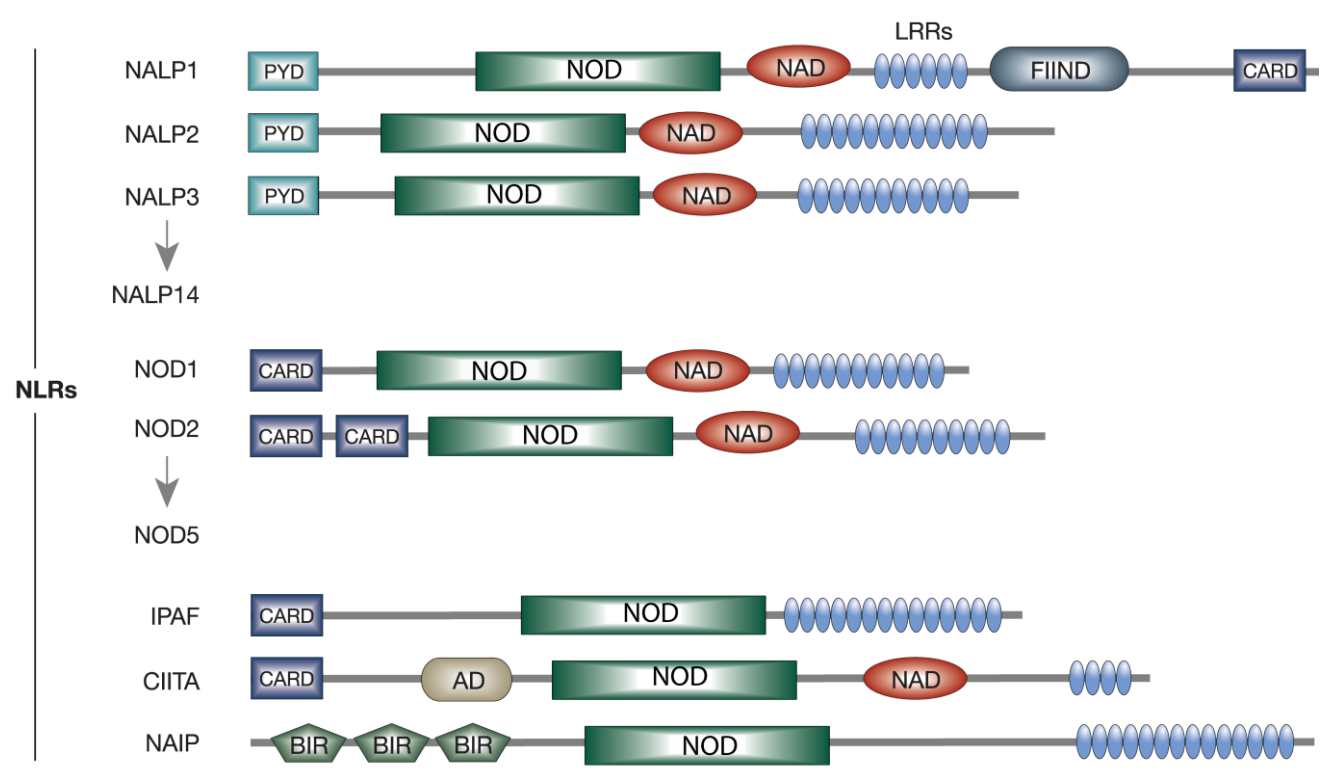

Figura 6: Representação esquemática da estrutura dos receptores do tipo NOD. Os NLRs são caracterizados por três domínios distintos: o domínio C-terminal constituído de regiões ricas em Leucina responsável pelo reconhecimento do ligante (LRRs); o domínio NOD, que medeia a oligomerização do receptor; e um domínio efetor, que pode ser um domínio pyrin (PYD), um CARD (domínio de recrutamento de caspase) ou um domínio BIR (repetições IAP de baculovírus). A maioria dos NLRs também contém um domínio associado ao NOD (NAD). Os NLRs compreendem duas grandes famílias: 14 membros NLRP/NALP contendo o domínio PYD e 5 membros NODs contendo CARD. As duas proteínas contendo o domínio CARD - CIITA e NLRC4/IPAF, e a proteína NAIP contendo BIR, constituem os membros NLRs remanescentes. Vale ressaltar que os NLRPs, eram chamados antigamente de NALPs. Por isso, os termos NALPs e NLRPs são sinônimos. Exemplo: NALP3 da figura é o NLRP3. Retirado de Meylan et al, Nature Reviews Immunology, 2006. 


\section{Cascata de Ativaçäo dos NLRs}

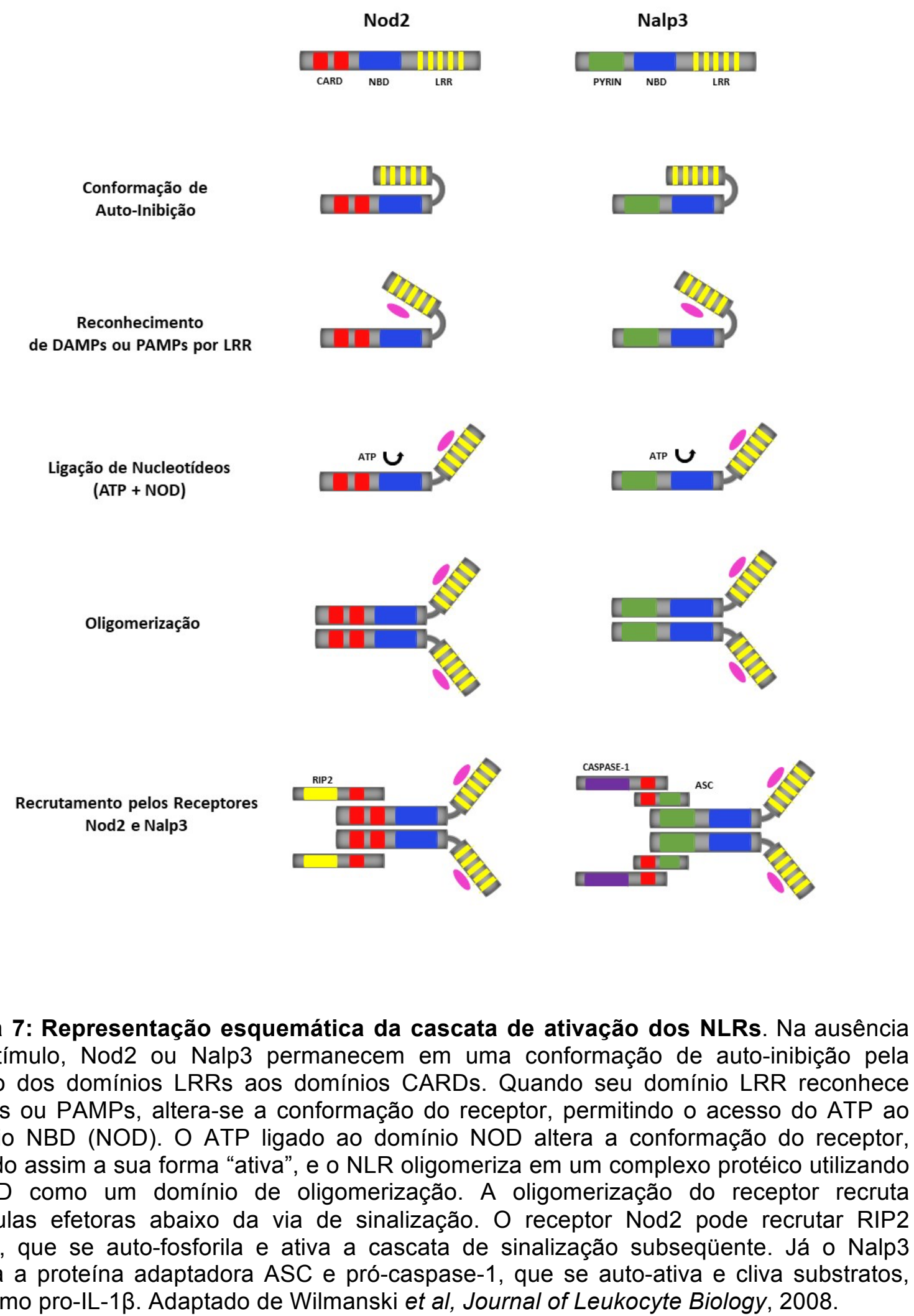

Figura 7: Representação esquemática da cascata de ativação dos NLRs. Na ausência do estímulo, Nod2 ou Nalp3 permanecem em uma conformação de auto-inibição pela ligação dos domínios LRRs aos domínios CARDs. Quando seu domínio LRR reconhece DAMPs ou PAMPs, altera-se a conformação do receptor, permitindo o acesso do ATP ao domínio NBD (NOD). O ATP ligado ao domínio NOD altera a conformação do receptor, gerando assim a sua forma "ativa", e o NLR oligomeriza em um complexo protéico utilizando o NOD como um domínio de oligomerização. A oligomerização do receptor recruta moléculas efetoras abaixo da via de sinalização. O receptor Nod2 pode recrutar RIP2 kinase, que se auto-fosforila e ativa a cascata de sinalização subseqüente. Já o Nalp3 recruta a proteína adaptadora ASC e pró-caspase-1, que se auto-ativa e cliva substratos, tais como pro-IL-1ß. Adaptado de Wilmanski et al, Journal of Leukocyte Biology, 2008. 
Os receptores NLRs, quando ativados, levam à formação do inflamassoma, uma plataforma molecular citosólica composta por um NLR, uma proteína adaptadora, como ASC (apoptosis-associated speck-like containing a CARD domain) e a cisteína-protease caspase-1 (MARTINON; MAYOR; TSCHOPP, 2009). Atualmente, existem seis inflamassomas distintos caracterizados: o inflamassoma de NLRP1, NLRC4/IPAF, NLRP6, NLRP12, AIM2 (um membro da família das proteínas HIN200) e o inflamassoma de NLRP3. Em geral, todos os inflamassomas convergem para ativar caspase-1, a qual é capaz de clivar seus substratos citosólicos, como pro-IL$1 \beta$ e pro-IL-18, em suas formas ativas, que então são secretadas e promovem inflamação (LAMKANFI; DIXIT, 2014a). Recentemente, também foi demonstrado que a caspase-1 e 11 exercem atividade proteolítica na enzima gasdermina $D$, a qual, quando clivada, gera um fragmento $\mathrm{N}$ terminal capaz de se oligomerizar na membrana celular e levar à formação de poros e, eventualmente, a um tipo de morte celular inflamatória denominado "piroptose" (MAN; KANNEGANTI, 2015; SHI et al., 2015; VINCE; SILKE, 2016).

Em geral, a ativação dos inflamassomas necessita da geração de dois sinais: o sinal 1 é promovido pela ativação de receptores do tipo TLRs, ou através da estimulação por citocinas, como IFN-ץ e TNF- $\alpha$, que induzem o aumento da transcrição gênica de componentes da maquinaria dos inflamassomas, como os receptores NLRs, ASC, caspase-1, pro-IL-1ß e pro-IL-18. Uma vez expressos, os diferentes NLRs são capazes de ser ativados por seus respectivos PAMPs ou DAMPs, gerando a montagem da plataforma molecular no citoplasma; este é o chamado sinal 2, que promove então as funções efetoras dos diferentes tipos de inflamassomas, gerando inflamação e morte celular por piroptose (GUO; CALLAWAY; TING, 2015; BROZ; DIXIT, 2016) (Figura 8). 
Dentre os NLRs, o mais bem estudado é o NLRP3 (Nod-like receptor Family Pyrin Domain Containing 3), uma vez que a ativação deste sensor está associada com importantes doenças metabólicas e inflamatórias crônicas, tais como câncer, Alzheimer, diabetes tipo II, obesidade, aterosclerose, doenças intestinais e infecciosas (HANEKLAUS; O’NEILL, 2015; SWANSON; DENG; TING, 2019). O mecanismo pelo qual NLRP3 é ativado ainda permanece desconhecido. Entretanto, é sabido que esta molécula é capaz de agir como um sensor de PAMPs, como toxinas bacterianas e RNA viral, e DAMPs (Damage-associated molecular patterns), como ATP extracelular, cristais de ácido úrico, ROS e efluxo de potássio. Apesar do termo "receptor" estar contido na definição do NLRP3, acredita-se que ele aja na verdade como um "sensor" intracelular de danos (DAMPs), já que, até o presente momento, nenhum trabalho na literatura foi capaz de provar que o NLRP3 é capaz de se ligar a algum agonista específico (SWANSON; DENG; TING, 2019) (Figura 8).

O inflamassoma de NLRP3 pode ser ativado pela via canônica, mediada pelo reconhecimento de DAMPs e PAMPs que levem à produção de ROS e à formação de poros na membrana por proteínas pertencentes à família das gasderminas, as quais são clivadas por caspases inflamatórias, como caspase-1, levando ao efluxo de potássio (SWANSON; DENG; TING, 2019). Mais além, existe também a via nãocanônica de ativação do NLRP3, que ocorre frente ao reconhecimento do lipopolissacarídeo (LPS) bacteriano no citoplasma pela enzima caspase-11. A ativação desta caspase induz a clivagem da gasdermina-D em seu domínio $\mathrm{N}$ terminal, que é capaz de se oligomerizar na membrana plasmática e gerar poros que levam também ao efluxo de potássio (KAYAGAKI et al., 2011; HAGAR et al., 2013; SHI et al., 2015). Apesar da via não-canônica estar bem descrita no contexto de infecções bacterianas, ainda não é conhecido o papel de caspase-11 durante 
infecção por outros microrganismos, como Leishmania (ZAMBONI; LIMA-JUNIOR, 2015) (Figura 8).

Por outro lado, estudos do nosso laboratório e de vários outros grupos independentes demonstraram o papel crucial do inflamassoma de NLRP3 no desenvolvimento da Leishmaniose (Figura 4). Em estudo pioneiro do nosso grupo de pesquisa, demonstramos que o inflamassoma de NLRP3 é montado frente à infecção por Leishmania spp. em macrófagos murinos, levando à produção de IL-1 $\beta$ que, por sua vez, age de maneira autócrina ou parácrina induzindo a produção de NO, importante mediador microbicida que auxilia no controle da infecção (LIMAJUNIOR et al., 2013a). O papel do NLRP3 no desenvolvimento da infecção por Leishmania foi evidenciado em diversos estudos subsequentes, colocando-o como uma molécula chave na patogênese da doença (GURUNG et al., 2015; SHIO et al., 2015; CHARMOY et al., 2016; LIMA-JUNIOR et al., 2017; DEY et al., 2018; CHAVES et al., 2019; DE CARVALHO et al., 2019a, 2019b). Apesar de diversos estudos terem apontado ROS e efluxo de potássio como mecanismos chaves na ativação de NLRP3 pelo parasito (LIMA-JUNIOR et al., 2013a, 2017; SHIO et al., 2015), ainda não se sabe se a diminuição dos níveis intracelulares de potássio ocorre pela via canônica ou pela via não-canônica, mediada por caspase-11 (Figura 9). 


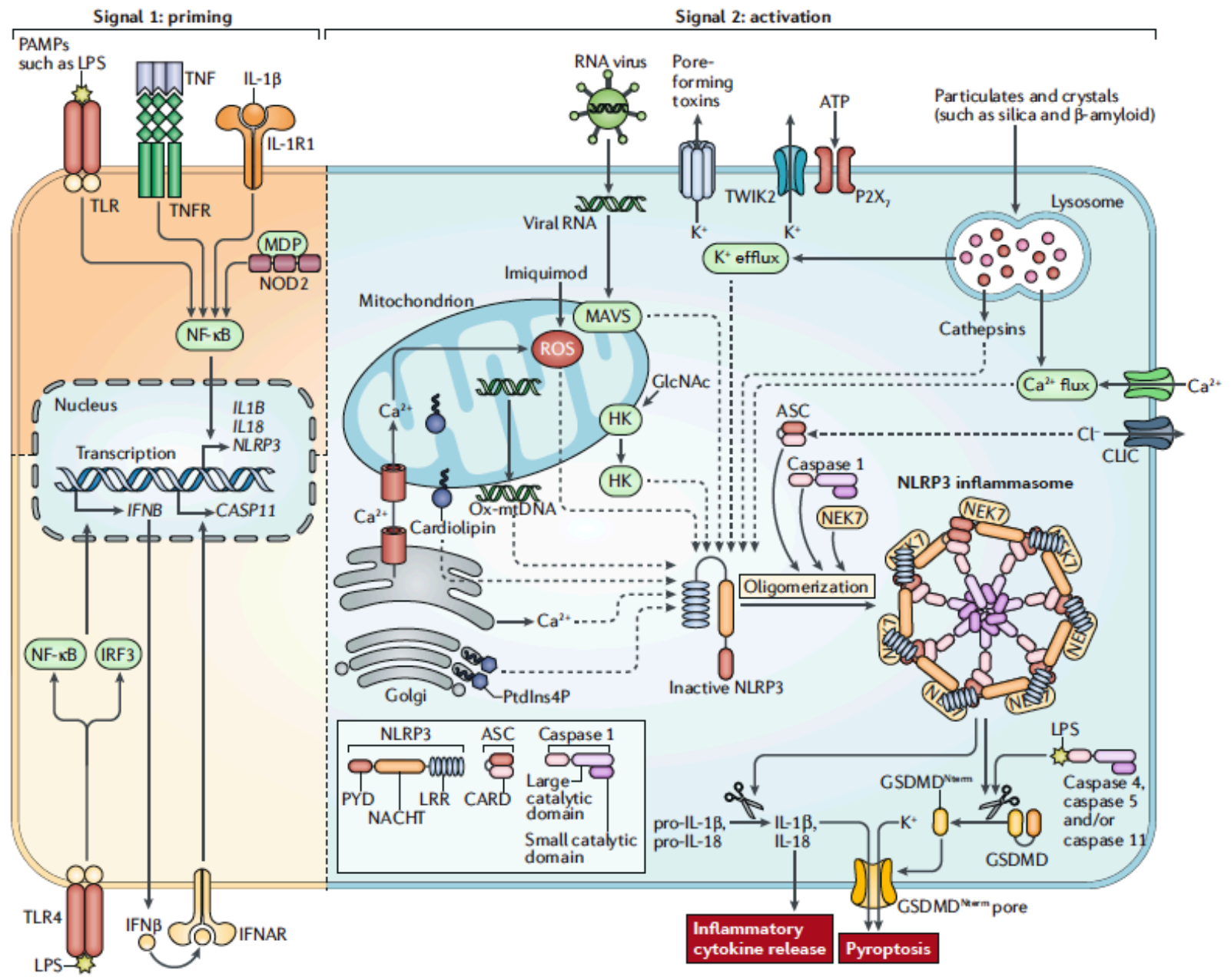

Figura 8: 0 primeiro (Sinal 1) e segundo (Sinal 2) sinal são essenciais para a ativação do inflamassoma de NLRP3. Sinal 1 (laranja): o reconhecimento de PAMPs por TLRs, ou de citocinas por seus receptores, induz a síntese do precursor de pro-IL-1 $\beta$ e componentes do inflamassoma, como o NLRP3. Sinal 2 (azul): PAMPs ou DAMPs são "sentidos" diretamente por NLRP3 no citoplasma, que se oligomeriza e recrutam a proteína adaptadora ASC, que por sua vez recruta caspase-1. Esta, por sua vez, cliva seus substratos (pro-IL-1 $\beta$, pro-IL-18 e gasdermina D), promovendo as funções efetoras do inflamassoma de NLRP3: morte celular por piroptose e liberação de IL-1 e IL-18. O reconhecimento do LPS bacteriano por caspase-11 (em camundongos) ou caspase-4/5 (em humanos) também leva à clivagem de gasdermina $\mathrm{D}$, formação de poros e contribui para ativar NLRP3 pela via nãocanônica. Retirado de Swanson et al, Nature Reviews Immunology, 2019. 


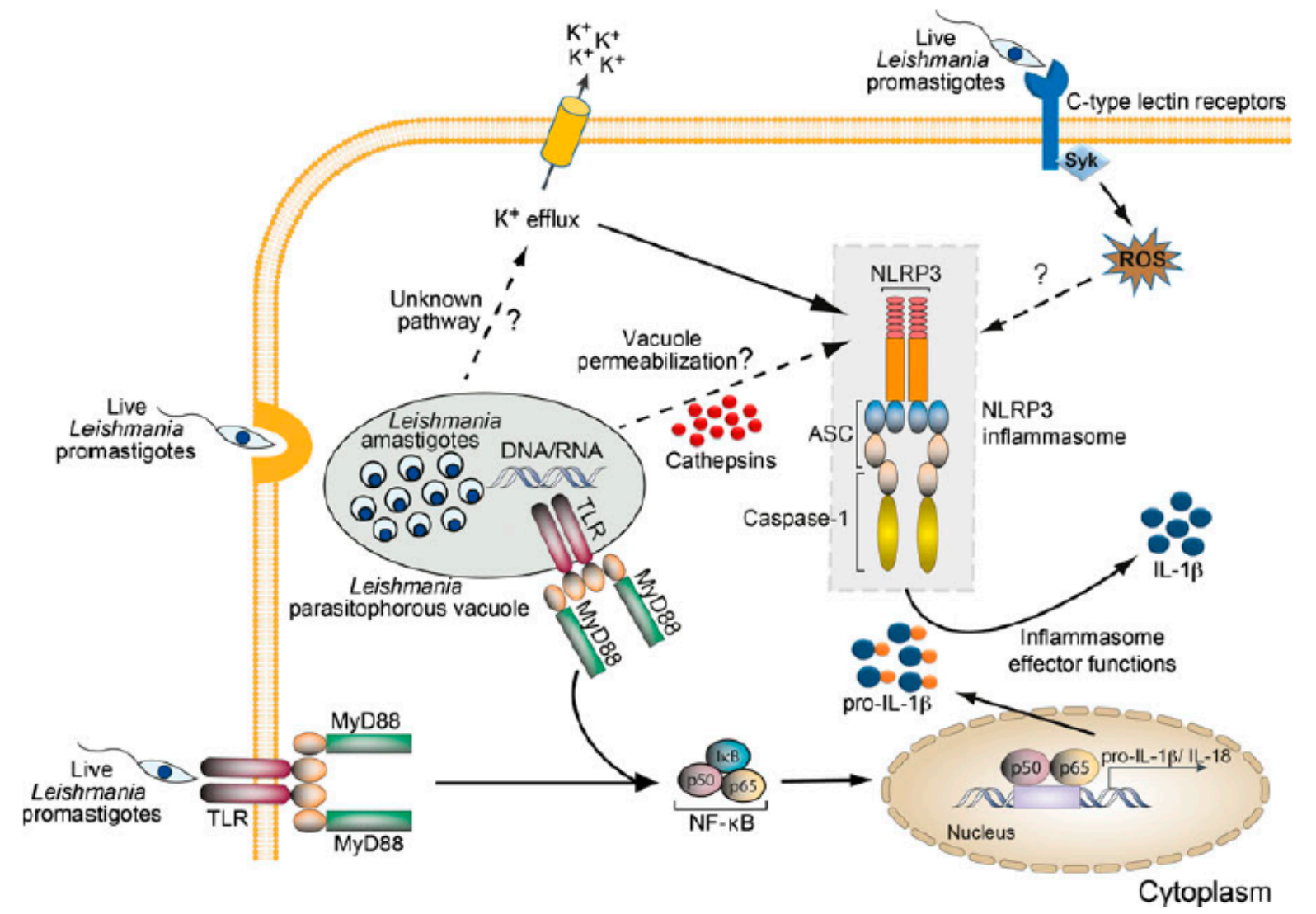

Figura 9: Ativação do inflamassoma de NLRP3 por Leishmania spp. O reconhecimento de PAMPs do parasito por TLRs, ou de citocinas por seus receptores, induz a geração do primeiro sinal, que auxilia na montagem dos precursores necessários para a ativação do inflamassoma de NLRP3. O parasito, uma vez internalizado, gera DAMPs, como ROS, ou efluxo de potássio, levando à oligomerização e ativação do inflamassoma de NLRP3, que cliva a pro-IL-1 $\beta$ em sua forma ativa, permitindo sua liberação. $O$ papel da caspase-11 na geração de poros e efluxo de potássio ainda é desconhecido no contexto de infecções parasitárias. Retirado de Zamboni e Lima-Júnior, Immunological Reviews, 2015.

\subsection{Resposta imune inata frente à infecção por Leishmania: Autofagia}

A autofagia consiste em um processo biológico natural de todos os organismos vivos, tendo sido demonstrada primariamente em fungos unicelulares. É induzida frente a situações de estresse e escassez de nutrientes, levando a célula a degradar componentes citosólicos e organelas senescentes, como retículo liso, rugoso e mitocôndrias, a fim de se obter energia (DERETIC; SAITOH; AKIRA, 2013; SHIBUTANI et al., 2015). A degradação de proteínas citoplasmáticas ocorre via ubiquitinação, realizada por proteínas pertencentes à família das E3-ubiquitina 
ligases, que são enzimas capazes de encaminhar seus alvos, após serem ubiquitinados, para a degradação proteassomal (SHIBUTANI et al., 2015).

Apesar de estudos envolvendo microscopia eletrônica terem reportado estruturas autofágicas desde 1950, o mecanismo molecular da autofagia foi descoberto apenas a partir de 1990, com a elucidação de genes relacionados ao processo em fungos. Mais de 40 genes codificando proteínas relacionadas à autofagia (chamados de "genes $A T G s$ ") já foram reportados, e as moléculas principais pertencentes a este complexo é extremamente conservado de fungos até mamíferos, indicando que a autofagia é um processo evolutivamente conservado (DERETIC; SAITOH; AKIRA, 2013; SHIBUTANI et al., 2015).

De uma maneira geral, a autofagia se inicia através de estímulos, como infecções, citocinas, ativação de PRRs, como os TLRs, e sob situações de estresse celular e deprivação de nutrientes (KLIONSKY et al., 2016). A ativação de fatores de transcrição, como NF-kB e AP-1 e proteínas MAPKs, iniciam a formação do complexo ULK, composto pelas proteínas ULK1, ULK2, ATG13, ATG101 e FIP200, e o complexo ATG9L, composto por ATG9L1 e ATG9L2. Acredita-se que estes dois sejam os complexos mais iniciais da formação da autofagia clássica, que recrutam o complexo $\mathrm{PI}(3)$ kinase classe 3 autofagia-específico, sendo regulados negativamente pelo complexo mTORC1 e positivamente pela kinase AMPK. O complexo $\mathrm{PI}(3)$ kinase autofagia-específico também é conhecido como complexo ATG14L, composto por ATG14L, VPS34, beclina-1 e VPS15, estando localizado no retículo endoplasmático, no qual o processo de formação de uma "membrana de isolamento" se inicia. Assim, o complexo ATG14L gera fosfatidilinositol 3-fosfato, o qual fornece sítios de ligação para as proteínas da família WIPI (WIPI1 até WIPI14). Estas proteínas se ligam e formam um complexo com ATG2A e ATG2B, e a 
dissociação do complexo ATG16L1 (composto por ATG16L1, ATG5 e ATG12), localizado na própria membrana de isolamento, que age como uma ubiquitina ligase E3 sobre a proteína LC3 (LC3-I ou LC3A), lipidando-a na sua forma conjugada (LC3II ou LC3B) para que esta, então, feche a membrana de isolamento e complete a formação do autofagossomo ao redor de sua carga, seja um patógeno, uma organela, ou outros componentes citoplasmáticos (Figura 10). Dado à importância das proteínas pertencentes à família ATG no processo autofágico, a deleção gênica de componentes como ATG5 e ATG7 é extremamente utilizada em modelos animais, para estudo do papel da autofagia. Além disso, dada à extrema importância da conversão do LC3-I em LC3-II para a formação do autofagossomo, a proteína LC3 é comumente utilizada como um "readout" para a avaliação de atividade autofágica (DERETIC; SAITOH; AKIRA, 2013; SHIBUTANI et al., 2015).

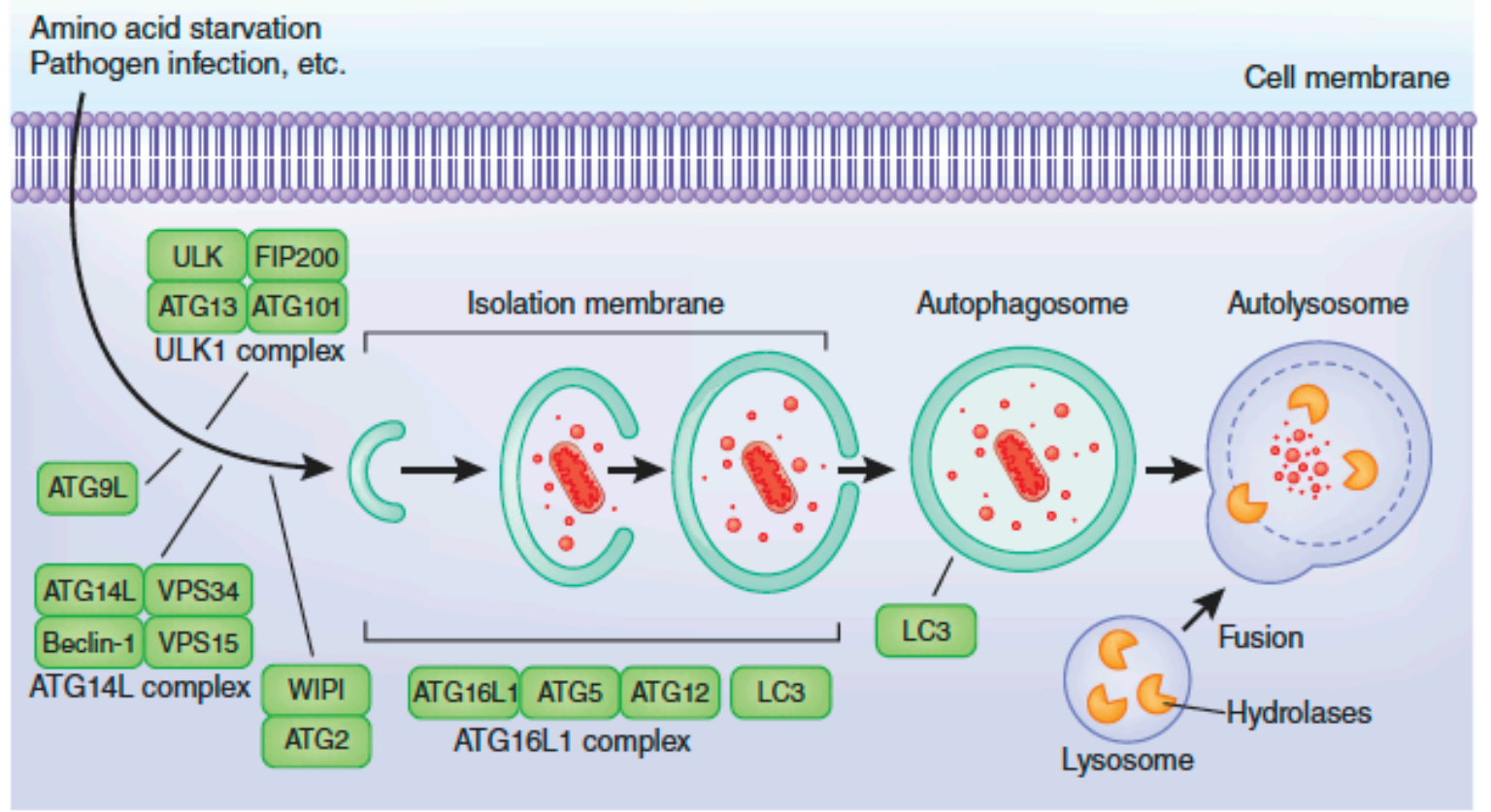

Figura 10: A via canônica da autofagia. Sinais indutores de autofagia, como deprivação de aminoácidos e infecções, iniciam a formação da membrana de isolamento, também chamada de "fagóforo". O fechamento desta membrana resulta na formação do autofagossomo, que possui dupla-membrana característica. A subsequente fusão de lisossomos com os autofagossomos leva à degradação do conteúdo intra-autofagossomal por hidrolases ácidas. As etiquetas em verde indicam proteínas chaves da autofagia envolvidas nas diferentes etapas de formação do autofagossomo, conforme descritas acimas no texto. Retirado de Shibutani et al, Nature Immunology, 2015. 
A remoção autofágica de organelas senescentes ou danificadas, como mitocôndrias, impede a geração de ROS, limitando, portanto, a ativação de NLRP3 indiretamente. Além disso, estudos mais recentes têm demonstrado o papel dos autofagossomos na degradação de proteínas/citocinas inflamatórias e componentes do inflamassoma no citoplasma de forma direta, através da ubiquitinação e degradação proteassomal. Desta forma, hoje na literatura assume-se que, além de um papel crucial na homeostase energética celular, a autofagia desempenha importante papel anti-inflamatório (Figura 11) (NAKAHIRA et al., 2011; SHI et al., 2012; DERETIC; SAITOH; AKIRA, 2013).

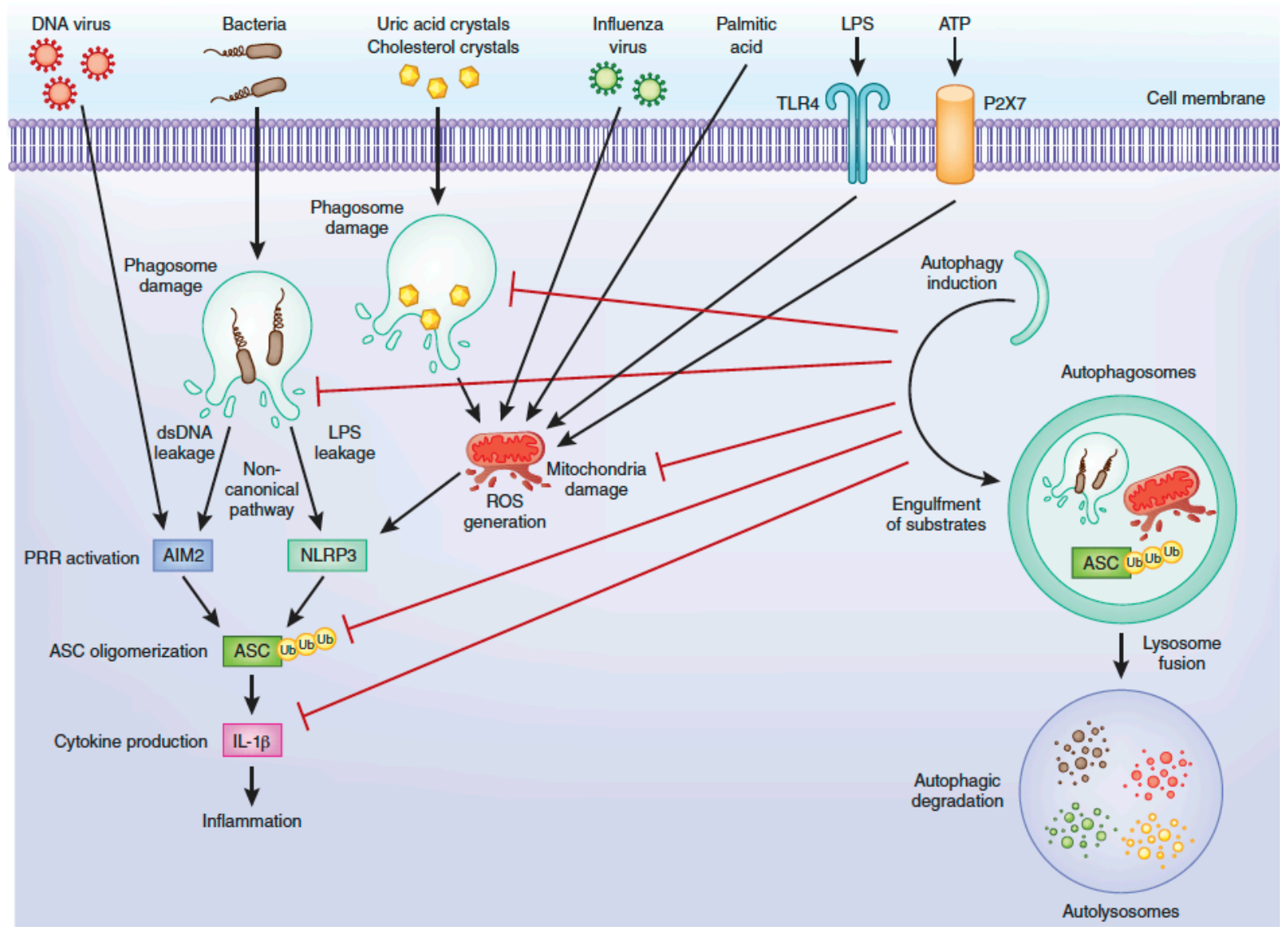

Figura 11: A autofagia limita a ativação do inflamassoma. A autofagia induz a eliminação de mitocôndrias senescentes ou disfuncionais, impedindo a geração de ROS e outros DAMPs que eventualmente ativem o inflamassoma de NLRP3. Além disso, os autofagossomos também eliminam fagossomos e promovem a ubiquitinação de ASC e IL1ß. Adaptado de Shibutani et al, Nature Immunology, 2015. 
A mitofagia é o termo específico que designa a autofagia direcionada às mitocôndrias, sendo exercida por meio de proteínas chaves como a E3-ubiquitina ligase "Parkin" (SLITER et al., 2018). Recentemente, foi demonstrado que patógenos de diferentes naturezas são capazes de induzir autofagia em células infectadas, via citocinas como IFN do tipo I (SCHMEISSER; BEKISZ; ZOON, 2014), TLRs e outros receptores da imunidade inata, o que, em alguns casos, pode levar ao controle do micro-organismo ou auxiliar na multiplicação dos mesmos (DELGADO et al., 2008; SHIBUTANI et al., 2015). Neste caso, o termo específico utilizado é a "xenofagia", designando a autofagia direcionada a agentes infecciosos externos. No caso específico de infecção por Leishmania, vários trabalhos demonstraram que diferentes espécies do parasito podem induzir autofagia (CYRINO et al., 2012; SINGH et al., 2016; PITALE et al., 2019), embora a importância deste processo para a eliminação do micro-organismo seja ainda bastante controversa: enquanto alguns estudos demonstram que a autofagia pode favorecer o crescimento do parasito (PINHEIRO et al., 2009a; DIAS et al., 2018), outros mostraram que o fluxo autofágico contribui na eliminação do parasito (FRANCO et al., 2017; THOMAS et al., 2018). Entretanto, os trabalhos relacionando a infecção por Leishmania com autofagia não utilizaram animais geneticamente modificados para proteínas chaves do fluxo autofágico em sua metodologia, apenas inibidores farmacológicos, que podem atuar tanto no parasito quanto na célula hospedeira; além disso, cada estudo utilizou diferentes linhagens de células hospedeiras e camundongos, e também diferentes espécies de parasitos, tornando difícil a adequada interpretação dos resultados. Em um estudo recente realizado pelo nosso grupo, utilizamos a abordagem de silenciamento gênico da proteína ATG5 para demonstrar o papel fundamental dos TLRs endossomais TLR3, TLR7 e TLR9 na formação do 
autofagossomo e controle da infecção por L. major (FRANCO et al., 2017). Entretanto, os mecanismos de indução de autofagia frente à infecção por Leishmania ainda permanecem pouco explorados.

\subsection{Variáveis que influenciam nas manifestações clínicas da Leishmaniose}

O desenvolvimento de uma forma mais branda ou mais agressiva da doença depende de vários fatores relativos ao hospedeiro e aos próprios parasitos (HARTLEY et al., 2012). Com relação ao hospedeiro, destacam-se as variáveis genéticas individuais que podem predispor um indivíduo a um quadro de maior resistência ou susceptibilidade à infecção. Como exemplo, podemos citar os polimorfismos gênicos associados à resposta imune do hospedeiro, como os associados ao gene da IL-1 e da Linfotoxina- $\alpha$ (LT- $\alpha$ ), que podem ditar uma resposta imune mais eficiente ou mais branda contra o parasito (FERNÁNDEZFIGUEROA et al., 2012; MORAVEJ et al., 2012). Da mesma forma, outros fatores relativos ao hospedeiro sem base genética, como por exemplo, a imunossupressão causada por tratamentos farmacológicos com glicocorticoides em pacientes transplantados, ou pacientes co-infectados com HIV e/ou portadores da síndrome da imunodeficiência adquirida (do inglês AIDS), dentre outros, são fatores importantes que determinam a evolução da Leishmaniose (WOLDAY et al., 1999).

Dentre os fatores relativos ao parasito que determinam o quadro clínico da doença, o principal é a espécie infectiva. A forma visceral da doença é causada por Leishmania (Leishmania) infantum chagasi, que é muito recorrente no Brasil e Índia, e se não tratada pode levar ao óbito (CHAPPUIS et al., 2007). No caso específico do Brasil, as principais espécies causadoras de leishmaniose são Leishmania (Leishmania) amazonensis e Leishmania (Viania) braziliensis, induzindo as formas 
cutânea e mucocutânea da doença (REITHINGER et al., 2007). Aproximadamente 10\% dos casos de leishmaniose cutânea progridem para a forma mucocutânea da doença, que usualmente apresenta lesões secundárias destrutivas na mucosa nasal e bucal, um quadro altamente devastador e debilitante. Vale ressaltar que neste caso, o paciente também têm sua vida social afetada e necessita de tratamento farmacológico de urgência, já que, diferentemente da doença cutânea, a mucocutânea não se cura espontaneamente com o passar do tempo (HARTLEY et al., 2012, 2014).

Um outro fator importante na evolução para a doença mucocutânea é a presença de um vírus de RNA (denominado Leishmania RNA virus - LRV) no interior do parasito (HARTLEY et al., 2014). Em 1974, um primeiro trabalho demonstrou partículas virais no interior de Leishmania hertigi (MOLYNEUX, 1974), mas foi no início da década de 1990 que trabalhos pioneiros demonstraram a estrutura molecular de um vírus presente em alguns parasitos - principalmente espécies do complexo Viannia - L. braziliensis, L. guyanensis e L. panamensis, os quais encontram-se variavelmente infectados com o LRV na natureza (TARR et al., 1988; STUART et al., 1992). Até hoje, apenas um único trabalho reportou a presença do LRV em L. major, uma espécie fora do complexo Viannia (SCHEFFTER et al., 1995), estabelecendo que LRVs pertencentes à família Viannia fossem denominados LRV1, e LRV2 para o de L. major. Desta forma, cada vírus presente em diferentes cepas do complexo Viannia recebe uma numeração diferente. Por exemplo, o vírus da cepa de L. guyanensis CUMC1 recebe o nome de LRV1-1, enquanto o vírus da cepa padrão da OMS de L. guyanensis M4147, recebe o nome de LRV1-4. 


\subsection{0 vírus de RNA de Leishmania (LRV) e suas implicações na Leishmaniose}

Trabalhos a nível molecular realizados na última década determinaram a estrutura do LRV, classificando-o como uma partícula não envelopada, de 40 nanômetros e icosaédrica, contendo dupla fita de RNA (dsRNA) positiva entre 4 e 8 kb em comprimento, e codificando a proteína principal do capsídeo e a proteína de fusão RNA-polimerase (RDRP), a qual é essencial para a replicação da dsRNA do vírus. O LRV pertence à família Totiviridae, a qual possui outros membros já encontrados em outros protozoários, como Giardia lamblia e T. vaginialis (WANG, 1991; STUART et al., 1992; WEEKS et al., 1992).

Os mecanismos pelos quais o LRV1 é mantido e transmitido no subgênero $L$. (Viannia) ainda são pouco conhecidos. Dentro da família Totiviridae, a transmissão normalmente ocorre de forma vertical, frente à divisão celular. Apesar de rara, a infecção extracelular por Totivírus já foi demonstrada para G. Lamblia (RO; SCHEFFTER; PATTERSON, 1997). Vários estudos antigos tentaram infectar cepas de Leishmania vírus-negativas com LRV, mas a incorporação das partículas virais pelo parasito normalmente falham, ou duram apenas de forma transiente (ARMSTRONG et al., 1993). Foi apenas em um estudo publicado este ano que pela primeira vez obteve-se sucesso na infecção de parasitos com LRV. Utilizando vesículas extracelulares (EVs) derivadas de um clone de L. guyanensis LRV+, os autores conseguiram infectar cepas de L. mexicana e L. panamensis de forma eficiente, durando até pelo menos 2 semanas (ATAYDE et al., 2019; OLIVIER; MINGUEZ-MENENDEZ; FERNANDEZ-PRADA, 2019).

Vários trabalhos na literatura evidenciaram a presença do LRV como uma vantagem evolutiva para os parasitos que lhe comportam. Alguns estudos demonstraram que o vírus ajuda na resistência ao estresse oxidativo promovido pelo 
hospedeiro, auxiliando na regulação de enzimas chaves na produção de óxido nítrico (NO), como arginase e óxido nítrico-sintetase induzível (iNOS) (ACESTOR et al., 2006; VENDRAME et al., 2010). Outros trabalhos mostraram a correlação entre a presença do LRV e a resistência dos parasitos a tratamentos convencionais para Leishmaniose, como os antimoniatos pentavalentes, facilitando a metastização dos parasitos, a latência e a cronificação da Leishmaniose (MARSDEN, 1986; MOTTA et al., 2003). Em 2011, um estudo demonstrou que a ligação da dupla fita de RNA do vírus no receptor TLR3, localizado no vacúolo parasitóforo, desencadeia uma resposta imune hiperinflamatória que favorece a metastização do parasito, classificando-o como um importante fator de risco para o desenvolvimento da doença mucocutânea (IVES et al., 2011). Alguns anos depois, outros trabalhos demonstraram que a ativação do TLR3 por LRV auxilia na indução de AKT, microRNA 155 (miR-155), IFN do tipo I e de um perfil de resposta Th17, que seriam cruciais para o agravamento da infecção, enquanto o papel do LRV na modulação do inflamassoma ainda permanece pouco explorado (HARTLEY et al., 2014, 2016, 2018; EREN et al., 2016; ROSSI et al., 2017) (Figura 12).

Embora estes estudos tenham sido de extrema importância para se estabelecer o conceito de que o LRV agrava a Leishmaniose por mudar o curso da resposta imune do hospedeiro, várias limitações impedem a conclusão de resultados mais sólidos e satisfatórios. Primeiramente, o modelo murino experimental em animais C57BL/6, apesar de bastante informativo, não apresenta características de metastização de parasitos durante a infecção. Isto é apenas observado em animais deficientes em IFN-y, uma citocina chave para a resistência ao parasito, sendo, portanto, um modelo artificial que pouco mimetiza a infecção em humanos (HARTLEY et al., 2016). Além disso, os trabalhos realizados em murinos 
compararam isolados clínicos metastáticos e não-metastáticos, com ou sem a presença do LRV, respectivamente (IVES et al., 2011). Estes isolados apresentam diversas diferenças genéticas e epigenéticas entre si e passaram por diferentes padrões de adaptação em seus hospedeiros, o que aumenta significativamente a quantidade de variáveis e complica a interpretação sobre o papel do LRV na patogênese da doença. Da mesma forma, em outros estudos (EREN et al., 2016; HARTLEY et al., 2016) os autores compararam o parasito M4147 da OMS, que possui altas cargas do LRV, com um clone LRV-negativo derivado do mesmo (RO; SCHEFFTER; PATTERSON, 1997). Esse clone foi gerado por incorporação de um plasmídeo de resistência à higromicina, o que também o torna um clone geneticamente modificado, e cujas variáveis possam ir além de apenas a ausência do LRV. Desta forma, acreditamos que ferramentas experimentais mais robustas são necessárias para permitir o avanço sobre as vias de sinalização desencadeadas por LRV em modelos animais.

Conforme mencionado anteriormente, apesar de fatores relacionados ao parasito, como espécie infectiva e presença ou ausência do LRV, e a resposta imune exercida pelo hospedeiro sejam críticos para a conversão da forma cutânea na forma mucocutânea, as características específicas da resposta imune que ditam as manifestações da doença ainda permanecem amplamente desconhecidas (KAYE; SCOTT, 2011).

Embora estudos realizados ao longo dos últimos 8 anos terem identificado o papel central do inflamassoma de NLRP3 na Leishmaniose, assim como o papel do LRV no desencadeamento de uma resposta inflamatória exacerbada no hospedeiro, pouco se sabe sobre o papel desempenhado pelo vírus no desenvolvimento da resposta imune do hospedeiro. A melhor elucidação das vias de sinalização 
moduladas pelo LRV, como possivelmente aquelas pertencentes à imunidade inata e à ativação do inflamassoma, possibilitaria apontar diversos novos alvos para a prevenção e tratamento da desfigurante forma mucocutânea da doença.

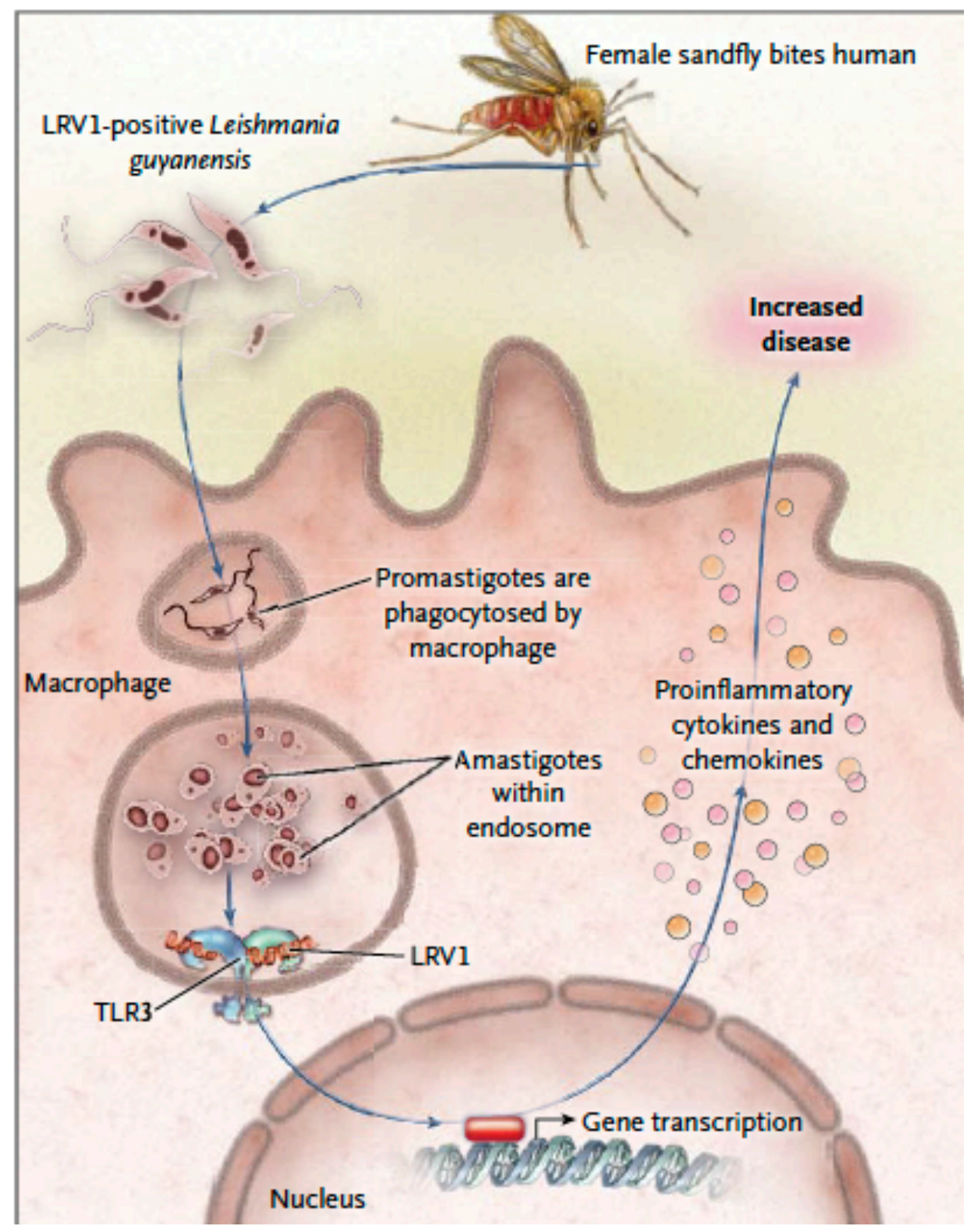

Figura 12: Leishmania e sua força viral. Parasitos pertencentes ao complexo Viannia (L. guyanensis, L. braziliensis e L. panamensis) podem ser encontrados variavelmente portando um vírus de RNA de dupla fita, denominado LRV. Recentemente, demonstrou-se que o material genético do vírus é reconhecido pelo receptor TLR3 dentro do vacúolo parasitóforo, desencadeando uma resposta imune inata hiperinflamatória, que pode contribuir para o crescimento do parasito e agravamento da infecção, podendo também justificar a metastização e surgimento da Leishmaniose mucocutânea. Entretanto, os mecanismos abaixo de TLR3 que contribuem para este quadro clínico permanecem amplamente desconhecidos e pouco estudados em detalhes. Retirado de Scott, New England Journal of Medicine,2011. 


\section{Objetivos}




\section{OBJETIVOS}

\subsection{Objetivo geral}

Avaliar o papel do vírus de RNA de Leishmania (LRV) na modulação do inflamassoma e da resposta imune inata do hospedeiro

\subsection{Objetivos específicos}

2.2.a. Determinar a magnitude de ativação do inflamassoma em pacientes com diferentes quadros clínicos da doença (Cutânea/Mucocutânea), e o papel do LRV neste processo.

2.2.b. Gerar espontaneamente um clone LRV- (L.g.-) a partir da cepa M4147 de L. guyanensis (LRV+, L.g.+), sem modificações genéticas induzidas.

2.2.c. Comparar o desenvolvimento da infecção por L.g.- e L.g.+ em camundongos.

2.2.d. Determinar o papel do LRV na modulação do inflamassoma frente à infecção por L. guyanensis, em macrófagos.

2.2.e. Determinar os mecanismos responsáveis pela modulação do inflamassoma pelo LRV, no contexto da infecção por L. guyanensis, em macrófagos murinos e humanos.

2.2.f. Avaliar a transmissibilidade do LRV por vesículas extracelulares (EVs) e seu papel na modulação da resposta imune inata de macrófagos.

2.2.g. Determinar o papel do inflamassoma de NLRP3 no agravamento da infecção promovido por LRV em camundongos.

2.2.h. Avaliar o papel de caspase-11 e da via não-canônica do inflamassoma de NLRP3 no contexto da infecção por Leishmania spp, in vitro e in vivo.

2.2.i. Determinar o possível papel do LRV na modulação de caspase-11. 


\section{Material e Métodos}




\section{MATERIAL E MÉTODOS}

\subsection{Animais de experimentação}

Foram utilizados camundongos selvagens da linhagem C57BL/6, fêmeas, com 6 a 8 semanas de idade, durante todo o estudo. Animais geneticamente

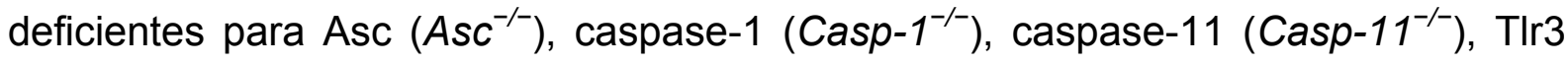
$\left(\right.$ TIr $\left.^{-/-}\right)$e Trif $\left(\right.$Trif $\left.^{--}\right)$foram backcrossed com camundongos C57BL/6 por nove ou oito gerações, respectivamente, para garantir similar background genético. Camundongos $\mathrm{NIrp3}^{-/-}$(MARIATHASAN et al., 2006) foram gentilmente cedidos pelo Dr. Vishva Dixit (Genentech, EUA) e pelo Dr. Shizuo Akira (Universidade de Osaka, Japão), respectivamente. Camundongos Parkin $\left(\operatorname{Prkn}^{-/-}\right)$foram gentilmente cedidos pela Dra. Larissa Cunha (USP/RP), e os animais $L y s M^{\text {Cre/t }} \operatorname{Atg} 5^{F / / F I}$ pelo Dr. Noburu Mizushima (Universidade de Tokyo, Japão). Os respectivos controles de ninhada foram gerados no Biotério da USP em Ribeirão Preto, Brasil. Os camundongos foram mantidos em condições livres de patógenos específicos, ambiente com temperatura controlada $\left(22\right.$ a $\left.25{ }^{\circ} \mathrm{C}\right)$ e receberam água e ração ad libitum. Os experimentos foram conduzidos de acordo com o Comitê de Ética em pesquisa animal (CETEA) da Faculdade de Medicina de Ribeirão Preto, da Universidade de São Paulo, SP (Processo No 014/2016).

\subsection{Geração dos clones 40 (L.g.-) e LRV+ a partir de L. guyanensis M4147}

Uma antiga cultura de L.g. M4147 foi utilizada com o intuito de se saber se todos os parasitos eram portadores do LRV. Células únicas foram isoladas em meio semi-sólido para se obter isolados de colônias, conforme descrito por lovannisci \& Ullman (1983) com algumas modificações. Promastigotas crescendo exponencialmente foram lavadas duas vezes com PBS $1 \mathrm{X}$ e diluídos numa 
concentração de 3000 células por mL, em meio M199 fresco. Após isto, foram espalhadas em placas semisólida contendo 1\% de Ágar (Sigma-Aldrich), para uma densidade final de 300 colônias por placa. As placas foram mantidas em inbucadoras a $5 \% \mathrm{CO}_{2}$ e $26^{\circ} \mathrm{C}$. Colônias de L. guyanensis foram visíveis após 10 dias e cada colônia isolada foi transferida para meio M199 10\% SFB, até a chegada da fase estacionária. De todos os isolados de colônias, apenas o clone 40 mostrouse negativo para o LRV1-4 (L.g.-). 5 clones LRV+ foram escolhidos para utilização em experimentos in vitro.

\subsection{Parasitos e condições de infecção experimental}

Formas promastigotas de parasitos L. guyanensis M4147 (MHOM/BR/75/M4147 - L.g.+) e seus clones derivativos LRV+ ou LRV- (L.g.-), Leishmania (L.) amazonensis (IFLA/BR/67/PH8), Leishmania (L.) amazonensis expressando constitutivamente a proteína GFP (L.a.-GFP; MHOM/BR/73M2269), Leishmania (V.) braziliensis (MHOM/BR/75/M2903), Leishmania (L.) major LV39 (MRHO/SU/59/P) e Leishmania (L.) infantum chagasi (HU-USF8) foram cultivadas a $26^{\circ} \mathrm{C}$ em meio de cultura Schneider (Sigma-Co, St. Louis, MO, EUA), contendo $10 \%$ de soro fetal bovino (SFB) (GIBCO) e $2 \%$ de urina humana masculina em garrafas de cultura (Corning Incorporated, Corning NY-USA). Após seis passagens em cultura, os parasitos foram serialmente passados em camundongos C57BL/6 a fim de manter sua virulência. As formas promastigotas metacíclicas (infectivas) foram isoladas de culturas contendo parasitos em fase estacionária de crescimento através de centrifugação em gradiente de densidade, como descrito anteriormente (SPÄTH; BEVERLEY, 2001). Para infecções in vivo com L.g.+, L.g.- e L. amazonensis, os camundongos foram inoculados com $10 \mu \mathrm{L}$ de salina tamponada com fosfato $0,1 \mathrm{M}$ 
$\mathrm{pH} \mathrm{7,2} \mathrm{(PBS)} \mathrm{contendo} 1 \times 10^{6}$ promastigotas em fase estacionária de crescimento, $1 \times 10^{3}$ ou $1 \times 10^{5}$ promastigotas metacíclicas, por via intradérmica na orelha esquerda. O curso de infecção foi acompanhado através da mensuração do desenvolvimento da lesão. As orelhas infectadas e controle foram mensuradas semanalmente durante oito semanas utilizando um paquímetro. O tamanho da lesão foi obtido pela diferença entre a medida da orelha infectada e orelha controle.

Os parasitos utilizados em cada experimento foram obtidos do nitrogênio líquido ou diretamente de animais infectados. Em todos os experimentos envolvendo L.g.- e L.g.+, os ciclos dos parasitos foram sincronizados por duas passagens consecutivas em meio axênico, enquanto em fase Log (2 dias de crescimento em meio Schneider, $10^{5}$ parasitos por $\mathrm{mL}$ ). Após isto, um terceiro repique é realizado para a infecção, onde os parasitos são deixados até o quinto dia de crescimento, para atingirem a fase estacionária. Cada passagem de repique ou infecção é contabilizada para realização dos experimentos. Depois da sexta passagem, os parasitos são descartados ou inoculados em camundongos para recuperarem a virulência. Para experimentos in vitro, as placas são centrifugadas logo após a infecção (1200 RPM por 5 minutos), para sincronizar a entrada dos parasitos nas células. Em ensaios onde não se utiliza o sobrenadante de cultura (exemplos: Giemsa e FACS), a infecção dura por 1 hora, quando as placas são então lavadas com PBS 1X duas vezes e o meio então é substituído por RPMI 10\% SFB fresco. Em ensaios onde utiliza-se os sobrenadantes livres de células (Exemplos: ELISA, WB para casp1 p20 e outros), as culturas infectadas não são lavadas. 


\subsection{Quantificação da carga parasitária}

Com o intuito de se determinar o parasitismo durante o curso da infecção, a orelha infectada, linfonodo drenante e baço foram coletados de forma asséptica em PBS. O número de parasitos presentes nos órgãos avaliados foi determinado pela técnica de diluição limitante (AFONSO; SCOTT, 1993) com algumas modificações. Resumidamente, os órgãos foram triturados por meio de dissociadores de tecido (Medcons, Becton Dickinson, São José, Ca, EUA) em um volume de $2 \mathrm{~mL}$ de meio de cultura Schneider (Sigma, St. Louis, MO, EUA) suplementado com $10 \%$ de SFB (GIBCO), 100 unidades/mL de penicilina G potássica (USB) e $2 \%$ de urina humana masculina. Os medcons foram então lavados com $10 \mathrm{~mL}$ de meio de cultura. A suspensão celular foi então centrifugada a 1540 × $g$ por 10 minutos para a separação das células contendo os parasitos. Em seguida, o sedimento foi suspenso em $1 \mathrm{~mL}$ de meio e distribuído em placas estéreis de 96 poços, sendo dispostos 200 $\mu \mathrm{L}$ da suspensão por cavidade, em duplicata. Dessa suspensão foi retirada uma alíquota de $20 \mu \mathrm{L}$ e adicionada em outro poço contendo $180 \mu \mathrm{L}$ de meio. Essa diluição de 1:10 foi feita onze vezes, sempre trocando as ponteiras de um poço para outro. A placa foi então incubada a $25^{\circ} \mathrm{C}$ e a verificação do crescimento de parasitos feita após 10 dias de cultura. O resultado foi expresso como média do - $\log _{10}$ do título de parasitos +1

\subsection{Purificação de monócitos humanos e diferenciação em macrófagos}

O sangue total foi coletado de doadores saudáveis (Protocolo do Comitê de Ética 18492/2014) em tubos contendo EDTA (BD Vacutainer CPT ${ }^{\mathrm{TM}}$ ), de acordo com as instruções do fabricante. O material foi centrifugado a 400 x g por 10 minutos em temperatura ambiente. Depois, o plasma foi descartado e o precipitado celular foi 
ressuspedido em PBS $1 \mathrm{X} \mathrm{pH} 7,4$ (GIBCO, BRL). As células foram aplicadas na coluna de gradient de Ficoll-Paque ${ }^{T M}$ PLUS (GE Healthcare Biosciences AB, Uppsala, Sweden). Depois, foram centrifugadas a $600 \times g$ por 30 minutos à temperatura ambiente para obtenção da fração mononuclear purificada, que foi cuidadosamente coletada e transferida para um novo tubo. Após esta etapa, as células foram lavadas e o pellet ressuspendido em PBS 1X, para posterior incubação com beads magnéticas acopladas à CD14 (MiltenyiBiotec, Auburn, CA, EUA), utilizando uma coluna magnética para separação. A população resultante deste processo (monócitos CD14+ purificados) foi confirmada por FACS (ACCURI C6, BD Biosciences), e as células então foram cultivadas em RPMI 1640 (GIBCO, BRL) contendo $10 \%$ de SFB e $50 \mathrm{ng} / \mathrm{mL}$ de GM-CSF humano (R\&D Systems). Após 7 dias, os monócitos encontravam-se diferenciados e prontos para serem utilizados nos experimentos.

\subsection{Recrutamento de pacientes}

As amostras foram coletadas de 49 pacientes convidados a comparecer ao CEMETROM, Hospital de Medicina Tropical que é referência em Rondônia. Eles foram diagnosticados com Leishmaniose cutânea ou mucocutânea entre Junho e Novembro de 2017. Todos os padrões éticos foram seguidos e apresentam-se sobre este código de apreciação Ética (CAAE): 54386716.1.0000.0011, fornecido pelo CEP/CEPEM. Pacientes que concordaram em participar voluntariamente na pesquisa foram apropriadamente informados e assinaram um termo de consentimento. Os diagnósticos clínicos foram realizados de acordo com as recomendações do Ministério da Saúde Brasileiro, rotineiramente aplicados no 
Hospital, que inclui critérios clínicos e epidemiológicos. As manifestações clínicas foram classificadas como Leishmaniose cutânea (LC) ou mucocutânea (LMC). Dos 49 pacientes selecionados, 40 apresentavam LC e 9 apresentavam LMC. Todos os pacientes realizaram exames de sangue para HIV, e portanto, todos os 49 são negativos para o vírus causador da AIDS.

\subsection{Coleta e processamento de amostras clínicas}

A coleta de amostras foi realizada utilizando uma escova cervical estéril, em direto contato com o lado interno das lesões. Em pacientes LC, as amostras foram coletadas das lesões cutâneas, enquanto pacientes LMC, foram coletadas da mucosa nasal. O material obtido foi imediatamente guardado em solução de RNAlater (Ambion, Austin, TX, USA) a $-20^{\circ} \mathrm{C}$, para preservação dos conteúdos moleculares, e utilizado para a extração de RNA (PCR para LRV) e quantificação de proteínas pelo método de Bradford (Sigma-Aldrich). Os níveis de diferentes citocinas foi avaliado por kits humanos de ELISA BD (IL-1 $\beta$ and TNF- $\alpha$ ) ou R\&D (Casp1 p20), e os valores individuais de cada citocina foi normalizado pela concentração de proteínas de cada amostra (medidos por Bradford), sendo representado por picogramas de citocinas por miligramas de proteína total.

\subsection{Diferenciação de macrófagos a partir de células da medula óssea}

Macrófagos diferenciados de células precursoras da medula óssea (BMDMs) foram utilizados como modelo para experimentos in vitro. As células precursoras de macrófagos foram obtidas da medula óssea de fêmures e tíbias de camundongos e cultivadas em meio RPMI condicionado, sendo suplementado com $20 \%$ de soro fetal bovino (GIBCO), 2 mM de glutamina, 25 mM de HEPES pH 7,2, 100 unidades/mL de 
penicilina G potássica (USB) e com 30\% de sobrenadante de cultura de células L929 (meio R20/30) conforme descrito previamente (WARREN; VOGEL, 1985), com algumas modificações. Resumidamente, camundongos foram eutanasiados e seus fêmures e tíbias cuidadosamente removidos, seccionados em ambiente estéril e lavados com PBS utilizando uma seringa com agulha $13 \times 4,5 \mathrm{~mm}$. As células recém colhidas foram lavadas e centrifugadas a $300 \times g$ por 5 minutos. Em seguida, as células foram diluídas em meio R20/30 e distribuídas em placas de cultura em volume de $10 \mathrm{~mL}$ por placa utilizada (um fêmur $=4$ placas). Um total de $10 \mathrm{~mL}$ de meio R20/30 foi adicionado após quatro dias de cultura. Entre o sétimo e o oitavo dia de cultura as células foram fenotipadas por citometria de fluxo - FACSCantoll (BD). Os experimentos foram conduzidos com culturas de células possuindo no mínimo 95\% de positividade para CD11b e F4/80.

\subsection{Análise de citometria de células infectadas por L.g.}

$10^{7}$ parasitos metacíclicos de L.g.- ou L.g.+ foram incubados com $1 \mathrm{~mL}$ de meio RPMI 10\% SFB e $10 \mu \mathrm{M}$ de CFSE (CellTraceTM CFSE Cell Proliferation Kit, Invitrogen). As suspensões foram incubadas por 1 hora a 37 graus Celsius, sendo homogenizadas de 15 em 15 minutos. Depois, os parasitos foram lavados com 10 $\mathrm{mL}$ de PBS1X fresco (Gibco) e ressuspendidos em $5 \mathrm{~mL}$ de PBS1X, sendo deixados por mais 30 minutos adicionais para desesterificação da sonda. Finalmente, os parasitos foram centrifugados (4000 RPM/10 minutos) e ressuspendidos em volumes apropriados para a infecção. BMDMs foram lavados após 1 hora de infecção e deixados em cultura até 96 horas. Os dados foram adquiridos pelo aparelho FACS ACCURI C6 (BD Biosciences) e analizados pelo software FlowJo (Tree Star). 


\subsection{Coinfecção com Legionella pneumophila.}

Nos experimentos de coinfecção, BMDMs foram infectados com L.g.- ou L.g.+ por 20 horas, e depois infectados com JR32 Legionella pneumophila mutante para a flagelina (flaA- Legionella) em MOI 10, por 4 horas adicionais, totalizando 24 horas de infecção. Os sobrenadantes foram coletados e os níveis de IL-1ß foram quantificados por ELISA, como descrito abaixo.

\subsection{Detecção do LRV por PCR}

Um total de $5 \times 10^{7}$ promastigotas foi lavado com PBS $1 \mathrm{X}$ e centrifugado a 4000 RPM por 10 minutos. Depois, foram ressuspendidos em $750 \mu \mathrm{L}$ de Trizol (Life Technologies). RNA total foi isolado de acordo com as instruções do fabricante. O DNA complementar (cDNA) foi preparado com $1 \mu \mathrm{g}$ de RNA total e hexâmeros utilizando o High-Capacity cDNA Reverse Transcription Kit (Applied Biosystems), de acordo com as instruções do fabricante. O PCR foi realizado com 30 ciclos, usando primers específicos para LRV1 (LRV1-4 F: 5'-TAATCGAGTGGGAGTCCCCC-3' e LRV1-4 R: 5'-GATCCTCCACACCGACCGTA-3') que amplificaram um segmento de 151 nucleotídeos dentro da região LRV1 5'UTR. Primers específicos para Leishmania (G6PD F: 5'-CAGATGGAAGCGTGTGATCG-3'- G6PD R: 5'TGCGAGCATAGCCGACA-3') foram utilizados como controles. Os produtos de RTPCR foram analisados em gel de agarose a 1.5\%, em tampão TAE 1X.

\subsection{Detecção do LRV por Imunofluorescência}

Um total de $8 \times 10^{6}$ promastigotes em fase estacionária foi lavado com PBS $1 \mathrm{X}$ e fixado com formaldeído $2 \%$ em PBS, por 20 minutos a temperatura ambiente. As células foram lavadas 3 vezes com PBS e depois incubadas com 0,2M de Glicina 
por mais 20 minutos. Após isto, mais duas lavagens foram realizadas e o pellet final foi ressuspendido em $300 \mu \mathrm{L}$ de PBS, e colocado em lâminas de microscopia por 30 minutos a temperatura ambiente. As lâminas foram lavadas e as células foram permeabilizadas/bloqueadas com $0.2 \%$ Triton 100X em PBS (Sigma-Aldrich), 1\% BSA (Fraction V, Sigma) e 5\% de soro de cabra, por 30 minutos a temperatura ambiente. Após isto, as células foram incubadas por 1 hora com o anticorpo monoclonal anti-dsRNA J2, feito em camundongos (1:800, English \& Scientific Consulting), em 1\% BSA / PBS 1X. Células foram lavadas 5 vezes em PBS e incubadas por 1 hora em câmara escura com um anticorpo secundário de cabra, contra camundongo, conjugado à AlexaFluor 594 (Millipore, Temecula, CA, USA), diluído 1:100. Após esta etapa, os parasitos foram lavados e incubados 10 minutos com $0.5 \mathrm{mg} / \mathrm{ml}$ de 49,6-Diamidino-2-phenylindole (DAPI, Invitrogen), lavados novamente e colocados em meio de montagem (Dako), até análise no microscópio, feita no equipamento confocal Leica TCS SPE (Leica Microsystems, Wetzlar, Germany).

\subsection{Purificação de vesículas extracelulares (EVs) e ensaios}

Parasitos foram lavados em PBS 1X, ressuspendidos em meio RPMI 1640 sem SFB e fenol vermelho, e incubados a $37^{\circ} \mathrm{C}$ por 4 horas, conforme já descrito (ATAYDE et al., 2015). Depois, parasitos foram centrifugados a 3000 RPM por 10

minutos a $25{ }^{\circ} \mathrm{C}$, e o sobrenadante obtido foi centrifugado por 10000 RPM por 15 minutos para eliminação de debris celulares. Os pellets foram então removidos, e o sobrenadante contendo as EVs foi obtido, conforme descrito previamente (ATAYDE et al., 2019). EVs foram analisadas e caracterizadas pelo sistema de nanopartículas do sistema NanoSight NS300 (Malvern instruments, Malvern, UK), equipado com 
laser de $405 \mathrm{~nm}$. As vesículas foram coletadas e analisadas pelo software NTA (versão 3.2.16). Para estimulação de BMDMs, $10^{7} \mathrm{EVs}$ purificadas de ambos os clones foram adicionadas no momento da infecção, em placas de 24 poços $\left(5 \times 10^{5}\right.$ macrófagos/poço). Para experimentos de transferência do LRV, $3 \times 10^{7}$ parasitos em fase estacionária foram incubados com EVs derivadas de L.g.+ por 2 horas em meio Schneider, conforme previamente descrito (ATAYDE et al., 2019). Após isto, os parasitos foram isolados para extração de RNA e PCR, ou para a realização de infecções em BMDMs.

\subsection{Ensaios de ELISA}

Os níveis de IL-1 $1 \beta$ e TNF- $\alpha$ em sobrenadantes de cultura livres de células foram quantificados usando kits de ELISA para IL-1 e TNF- $\alpha$ (BD Biosciences). A produção de IL-1 1 In vitro foi analisada em BMDMs pré-estimulados com $500 \mathrm{ng} / \mathrm{ml}$ de LPS ultrapuro (InvivoGen), $10 \mathrm{ng} / \mathrm{ml}$ de TNF-a (eBioscience) ou $300 \mathrm{ng} / \mathrm{mL}$ de PAM(3)CSK(4) (InvivoGen) por 4 horas, e em seguida infectados com promastigotas metacíclicos ou em fase estacionária de Leishmania spp. em diferentes MOI.

\subsection{Avaliação de caspase-1 ativa por FACS}

Para avaliar a ativação da caspase-1, 1 × $10^{6}$ macrófagos foram infectados por 24 horas com L.g.-, L.g.+, L. amazonensis, L. braziliensis, L. major (10 parasitos/ célula ou nas proporções indicadas). Os macrófagos foram removidos da placa com PBS gelado e transferidos para um tudo de polipropileno. A marcação da caspase-1 ativa foi feita por uma hora com o reagente carboxyfluorescein FLICA (FAM-YVADFMK, Immunochemistry Technologies, LLC), como recomendado pelo fabricante. 
Após esse período, as células foram lavadas por cinco vezes com PBS/Soro fetal bovino $1 \%$ e a aquisição das mesmas realizadas no citômetro de fluxo FACSCantoll (BD) sendo as análises realizadas por meio do software "FlowJo" (Tree Star, Ashland, OR, EUA).

\subsection{Detecção da ativação de caspase-1 e IL-1ß por Western Blotting}

Um total de $10 \times 10^{6}$ BMDMs foram adicionados em placas de 6 poços, ativados com LPS ultrapuro (500 ng/mL, InvivoGen) por 4 horas e então infectados com diferentes espécies de Leishmania (10 parasitos/célula) por 48 horas. Os sobrenadantes foram coletados e precipitados com $50 \%$ de ácido tricloroacético e acetona. As células remanescente nos poços foram lisadas com tampão RIPA (10 $\mathrm{mM}$ Tris- $\mathrm{HCl}, \mathrm{pH} 7.4,1 \mathrm{mM}$ EDTA, $150 \mathrm{mM} \mathrm{NaCl}, 1 \%$ Nonidet $\mathrm{P}-40,1 \%$ deoxycholate, and $0.1 \%$ SDS) contendo um coquetel de inibidores de protease (Roche). Os lisados e sobrenadantes foram ressuspendidos em tampão de amostra contendo SDS (50 mM Tris ; pH 6,8), 2\% SDS (USB Corporation, USA), 0,1\% azul de bromofenol (Synth, USA), 10\% glicerol (USB Corporation, USA), 2,5\% $\beta$ mercaptoetanol). As proteínas foram, então, transferidas para uma membrana de nitrocelulose (GE Healthcare, USA) utilizando o sistema de transferência Semidry Transfer Cell (Bio-Rad Laboratories, USA) a 15 volts por 40 minutos. Neste sistema foi utilizado tampão de transferência (50 mM Tris, 40 mM glicina e 10\% metanol). As membranas foram bloqueadas por 12 horas a $4^{\circ} \mathrm{C}$ em tampão Tris (TBS - Tris buffered saline) (25 mM Tris - Hexis Científica, BR, pH 7.4, 0,3 mM KCl - J.T. Backer e $140 \mathrm{mM} \mathrm{NaCl}$ - J.T. Bacher) contendo 0,1\% Tween-20 (TBS-T) e 5\% de leite em pó desnatado. Após o bloqueio, as membranas foram incubadas com os anticorpos monoclonais anti-caspase-1 p20 (clone 4B4 - Genentech) (1:250) e anti-IL-1 p p-17 
(1:200) (Sigma Aldrich) por 1 hora a temperatura ambiente. As membranas foram então lavadas em TBS-T e incubadas por 1 hora a $25^{\circ} \mathrm{C}$ com anticorpo secundário apropriado conjugado com peroxidase (diluição 1:3000; KPL, USA). Para a detecção das proteínas ligadas aos anticorpos específicos foi utilizado o reagente ECL luminol (GE Healthcare) e filme Hyperfilm (GE Healthcare).

\subsection{Detecção de proteínas intracelulares por Western Blotting}

Um total de $5 \times 10^{5}$ BMDMs foram plaqueados e infectados com L.g.- ou L.g.+ por 9 ou 24 horas. Os sobrenadantes foram descartados e as células foram lisadas em tampão RIPA, contendo $100 \mathrm{mM} \mathrm{NaCl}, 20 \mathrm{mM}$ Tris (pH7.6), 10mM EDTA (pH 8), 0.5\% SDS, e 1\% Triton X-100 com inibidor de protease (Roche), e incubadas por 20 minutos em gelo. O tampão de amostra foi adicionado aos lisados e as amostras foram fervidas por 5 minutos a 100 graus Celsius. As proteínas foram corridas em gel $15 \%$ SDS-PAGE e transferidas para membranas de nitrocelulose. Os seguintes anticorpos primários foram utilizados: anti-NLRP3 (1:1000; Adipogen; número de catálogo AG-20B-0014), anti-ASC (1:1000; Santa Cruz; número de catálogo sc33958) anti-Atg5 (1:1000; Abcam; número de catálogo 108327), anti-LC3 (1:1000; Sigma; número de catálogo L7543), e anti $\beta$-actin (1:1000; Santa Cruz; número de catálogo sc-47778). Anticorpos secundários específicos foram utilizados após isto. Em macrófagos humanos, LC3-II foi normalizado pela $\beta$-actina, utilizando o software ImageJ. 


\subsection{Avaliação da fagocitose e atividade leishmanicida de macrófagos}

Culturas de BMDMs foram ajustadas na concentração de 1 × $10^{5}$ células $/ \mathrm{mL}$ em meio RPMI acrescido de 10\% de SFB (GIBCO) (meio R10). As células foram distribuídas em placas de cultura de 24 poços (Becton Dickinson Labware, N.J, USA), contendo lâminas redondas ao fundo dos poços para aderência dos macr'ófagos, sendo $0,5 \mathrm{~mL}$ por poço e mantidas em repouso durante 90 a 120 minutos para a aderência. Foram realizadas duas lavagens com PBS estéril a fim de remover as células não aderidas à placa. Para a avaliação da atividade leishmanicida, as culturas de macrófagos foram infectadas com promastigotas de fase estacionária ou promastigotas metacílicas. Após duas horas de infecção foram realizadas três lavagens com PBS estéril para a retirada dos parasitos extracelulares e posteriormente adicionado meio fresco. Em alguns experimentos, a retirada dos parasitos extracelulares e adição de meio fresco foi realizada após uma ou três horas de infecção. A cultura foi então mantida a $33^{\circ} \mathrm{C}$, em estufa de $\mathrm{CO}_{2}(5 \%)$. Após 24, 48, 72 e 96 horas de infecção foi determinada a atividade leishmanicida dos BMDMs pela contagem de preparações celulares coradas por Giemsa, utilizando um microscópio de luz com objetiva de 40X. Nesta análise, as taxas de infecção foram determinadas pela contagem de células infectadas e não infectadas (100 BMDMs) e o número de amastigotas intracelulares médio por célula infectada.

\subsection{Detecção de espécies reativas de oxigênio (ROS)}

Para a detecção de ROS intracelular, BMDMs foram infectados ou não com promastigotas de L.g. ou tratados com Rotenona $(50 \mu \mathrm{M})$ ou PMA (100 ng/mL) por 2 horas. 30 minutos antes do fim da incubação, uma concentração de $10 \mu \mathrm{M}$ de dichlorodihydrofluorescein diacetate (H2DCFDA) e MitoSOX (2.5 $\mu \mathrm{M})$ foi adicionada 
à cultura celular e incubada por 30 minutos para permitir a ligação da sonda. Posteriormente, as células foram lavadas três vezes com PBS e a conversão da não fluorescente H2DCFDA na espécie altamente fluorescente dichlorofluorescein (DCF) foi mensurada por citometria de fluxo (BD FACSCanto II).

\subsection{Detecção dos níveis intracelulares de potássio}

Para avaliar o efluxo de potássio, BMDMs foram infectados com L.g. e incubados com a sonda Asante Potassium Green-2 (APG-2, TEFLabs, Austin, TX, USA), que se liga especificamente ao $\mathrm{K}+$. As células foram analisadas em um equipamento confocal High Content.

\subsection{Extração de RNA e síntese de cDNA}

A extração de RNA total foi realizada a partir de amostras obtidas de experimentos in vitro, nos quais BMDMs foram estimulados com Poly:IC (5 microgramas $/ \mathrm{mL}$ ) ou LPS (500 nanogramas $/ \mathrm{mL}$ ), ou infectados por Leishmania spp. por 6 ou 24 horas. As amostras foram coletadas utilizando-se o reagente Trizol (Invitrogen ${ }^{\mathrm{T} M}$, Carlsbad, CA, EUA) para posterior extração de RNA utilizando um kit específico para tal (Promega, Madison, WI, EUA). Brevemente, para cada amostra, em um tubo de fundo cônico de $1,8 \mathrm{~mL}$, foi adicionado o reagente Trizol $(1 \mathrm{~mL} / \mathrm{mg}$ de tecido ou $1 \mathrm{~mL}$ para cada $2 \times 10^{6}$ células), sendo agitado por 30 segundos e deixado a temperatura ambiente por 15 minutos. Para cada um $\mathrm{mL}$ da suspensão foram adicionados $200 \mu \mathrm{L}$ de clorofórmio (Sigma) e os tubos centrifugados a 12000 x g por 15 minutos a $4^{\circ} \mathrm{C}$. A fase aquosa foi transferida para um tubo novo, onde foi acrescentado etanol $70 \%$ em proporções iguais à amostra (v/v). A solução amostra/etanol foi agitada delicadamente e transferida para uma coluna de afinidade 
para RNA (Illustra RNAspin Mini - GE Healthcare, USA). Foram adicionados tampões específicos, intercalados por rápidas centrifugações por 15 segundos a 8000 x g cada. Finalmente, após várias lavagens com estes diferentes tampões, as amostras de RNA foram eluídas da coluna com $50 \mu \mathrm{L}$ de água deionizada e livre de RNAse, sendo armazenadas a $-70^{\circ} \mathrm{C}$, até a confecção do DNA complementar (cDNA). O DNA genômico contido nas amostras foi digerido através do tratamento das mesmas com RQ1 RNAse-Free Dnase (Promega), de acordo com as especificações do fabricante. Uma alíquota de $5 \mu \mathrm{L}$ foi utilizada para a obtenção da concentração de RNA/ $\mu \mathrm{L}$ nas amostras, determinada por espectometria a $260 \mathrm{~nm}$. O DNA complementar (cDNA) foi sintetizado através de uma reação de transcrição reversa. Primeiramente, foi adicionado oligo-dT (500 mg/mL) (Invitrogen), dNTPs (10 mM) (Invitrogen) e a enzima ImPromll Reverse Transcriptase (1 $\mu \mathrm{L} /$ reação) (Promega, USA) em $10 \mu \mathrm{L}$ de solução contendo $1 \mu \mathrm{g}$ de RNA e a reação mantida a $42^{\circ} \mathrm{C}$ durante 60 minutos. Posteriormente, a reação foi inativada por 15 minutos a $70^{\circ}$ C. A expressão quantitativa de genes de diferentes proteínas foi analisada através de reações de PCR em tempo real, utilizando-se o sistema SYBR Green e o aparelho ABI Prism 7000 Sequence Detection System (Applied Biosystems, Warrington, Reino Unido). Os primers utilizados foram: NIrp3 (NIrp3F:5'GTGGTGACCCTCTGTGAGGT-3'-NIrp3R:5'TCTTCCTGGAGCGCTTCTAA-

3');Asc(AscF:5'-CCAGTGTCCCTGCTCAGAGT-

3)AscR:5'TCATCTTGTCTTGGCTGGTG-

3');Casp1(Casp1F:5'AGATGCCCACTGCTGATAGG-3'-

Casp1R:5'TTGGCACGATTCTCAGCATA-

3');//1b(//1bF:5'CCAAGCAACGACAAAATACC-3'I/1bR:5'GTTGAAGACAAACCGTTTTTCC- 
3');Tnfa(TnfaF:5'TGTGCTCAGAGCTTTCAACAA-

3',TnfaR:5'CTTGATGGTGGTGCATGAGA-

3');/fnb(IfnbF:5'TCCGAGCAGAGATCTTCAGGA-3'-

IfnbR:5'TGCAACCACCACTCATTCTGAG-

3');//12(I/12F:5'TGGTTTGCCATCGTTTTGCTG-3'-

I/12R:5'ACAGGTGAGGTTCACTGTTTCT-

3').HPRT forward(5'TCAGTCAACGGGGGACATAAA-

3'), reverse(5'AAGCCATGCCAATGTTGTCT-

3'), Tnfaforward(5'TGTGCTCAGAGCTTTCAACAA-

3'), reverse(5'CTTGATGGTGGTGCATGAGA-

3')eNos2 forward(5'CGAAACGCTYCACTTCCAA-

3'), reverse(5'GGGGCTGTACTGCTTAACCAG -3').

\subsection{Transdução e análise de BMDMs transduzidos com vetor lentiviral GFP. LC3}

O vetor lentiviral que codifica a proteína LC3 fusionada com GFP, assim como os vetores auxiliares pCMVR8.91 e pMDG foram gentilmente cedidos por Leonardo Travassos e Dana Philpott (Universidade de Toronto, Canadá). Células HEK293T foram transfectadas com os plasmídeos usando Polyethylemine (Sigma) em placas 100X200 $(B D)$ para a produção das partículas virais. Quarenta e oito horas após a transfecção, o sobrenadante das culturas contendo partículas virais foi coletado, centrifugado a $1000 \mathrm{rpm}$ por $5 \mathrm{~min}$ e filtrado em $45 \mu \mathrm{m}$. Células da medula óssea de camundongos selvagens foram isoladas e cultivadas por três dias em meio R20/30. Após esse período, as células foram coletadas pela lavagem com monocamadas de PBS gelado, centrifugadas e ressuspendidas em $8 \mathrm{~mL}$ de meio R20/30 e mantidas 
em placas de petri de dimensões $90 \times 15 \mathrm{~mm}(B D)$. Nessas placas também foi adicionado $8 \mathrm{~mL}$ de sobrenadante contendo partículas virais expressando GFP-LC3 e mantidas a $37^{\circ} \mathrm{C}$ com $5 \%$ de $\mathrm{CO}_{2}$. No dia seguinte, foi descartado todo o meio das placas e mais uma vez adicionado $8 \mathrm{~mL}$ de meio R20/30 e $8 \mathrm{~mL}$ de sobrenadante contendo partículas virais expressando GFP-LC3. As células foram então cultivadas por mais 3 dias e retiradas por lavagem com PBS gelado para utilização em experimentos. Após o fim das infeções, a avaliação da indução de autofagia foi realizada pela contagem do número médio dos pontos LC3+ detectados em 100 células fotografadas aleatoriamente, descriminando as não infectadas das infectadas pela marcação com DAPI (aumento de 1000x), no microscópio Leica DMI 4000B. 


\subsection{Transdução de macrófagos primários com vetores lentivirais codificando} shRNA para silenciamento de atg5.

Células HEK293 foram transfectadas usando Polyethylemine (Sigma) em placas $100 \times 20 \mathrm{~mm}(B D)$ com os seguintes vetores lentivirais: vetores auxiliares pMDG.2 e pAX.2 como também os vetores codificando uma sequência não codificadora, caracterizada como scramble, ou codificando shRNA para o silenciamento gênico do atg5. Macrófagos de camundongos selvagens foram isolados e cultivados por três dias em meio R20/30. Após esse período, as células foram coletadas pela lavagem com monocamadas de PBS gelado, centrifugadas e ressuspendidas em $8 \mathrm{~mL}$ de meio $\mathrm{R} 20 / 30$ e mantidas em placas de petri de dimensões 90 × $20 \mathrm{~mm}$ (Corning). Nessas placas também foi adicionado $8 \mathrm{~mL}$ de sobrenadante contendo partículas virais codificando as respectivas sequências e mantidas a $37^{\circ} \mathrm{C}$ com $5 \%$ de $\mathrm{CO}_{2}$. No dia seguinte foi descartado todo o meio das placas e acrescentado $8 \mathrm{~mL}$ de $20 / 30$ contendo $3 \mu \mathrm{g} / \mathrm{mL}$ de puromicina para seleção das células transduzidas. As células foram então cultivadas por mais 2 dias e retiradas por lavagem com PBS gelado para utilização em experimentos. Para avaliar a eficiência do silenciamento gênico do atg5 por shRNAs, foi analisada a expressão da proteína ATG5 em macrófagos, por Western Blotting. Para isso, macrófagos selvagens foram transduzidos com vetores lentivirais codificando uma sequência controle (scramble) ou sequências que codificam shRNA para o silenciamento de atg5, e adicionados em placas de 24 poços, $1 \times 10^{6}$ células/poço e cultivados por 72 horas. Os extratos celulares foram submetidos a Western Blotting. 


\subsection{Ensaios de ativação de caspase-11 por pull-down.}

Para determinação da ativação de CASP11 ativa por pull-down, BMDMs foram estimulados com PAM(3)CSK(4) (300 ng/mL) por 4 horas, depois por 15 minutos com 20 mM de biotina-VAD-FMK (Enzo). Após estas etapas, os macrófagos foram infectados por 24 horas e posteriormente, os sobrenadantes foram removidos e as células foram lisadas com o tampão RIPA (10mM Tris- $\mathrm{HCl}$ (pH 7.4), 1mM EDTA, $150 \mathrm{mM} \mathrm{NaCl}, 1 \%$ Nonidet P-40, 1\% (w/v) deoxicolato de sódio e $0.1 \%(\mathrm{w} / \mathrm{v})$ SDS) suplementado com inibidor de protease (Roche). Os lisados foram equalizados após quantificação das amostras por Bradford, incubados overnight com beads de streptavidina-agarose (Invitrogen), e depois lavados com tampão RIPA. As proteínas ligadas às beads foram eluídas com tampão Laemmli, fervidas por 5 minutos e corridas em gel SDS-polyacrylamide, para análise por Western Blotting.

\subsection{Análise Estatística}

Os resultados estão representados como média mais desvio padrão (SD). Para comparação entre múltiplos grupos, foi utilizada a análise de variância (two-way ANOVA ou one-way ANOVA), seguida pelo pós-teste de Bonferroni. Diferenças nos valores entre dois grupos foram determinadas utilizando o teste $t$ de Student. Todas as análises foram feitas com o auxílio do software GraphPad-Prism (GraphPad Software Inc., San Diego CA, EUA). Foram consideradas estatisticamente significativas as diferenças que apresentaram valores de $P$ igual ou menor a 0,05. 
Resultados 


\section{RESULTADOS}

\subsection{A magnitude de ativação do inflamassoma está diretamente relacionada com a gravidade da Leishmaniose cutânea em humanos}

Espécies pertencentes ao gênero Viannia, como Leishmania braziliensis (L.b.) e Leishmania guyanensis (L.g.), causam diferentes tipos de Leishmaniose, mas os mecanismos que levam ao surgimento de uma ou outra forma clínica da doença ainda não são completamente entendidos. Apesar de já existirem trabalhos demonstrando a ativação de receptores NLRs em pacientes acometidos pela Leishmaniose cutânea, ainda não se sabe sobre possíveis diferenças na ativação do inflamassoma entre diferentes espectros da doença. Para isto, nós obtivemos material clínico (aspirados de lesão) de 40 pacientes diagnosticados com leishmaniose cutânea (LC) e 9 com mucocutânea (LMC), no Estado de Rondônia, Brasil (Fig. 13), e quantificamos os níveis de caspase-1 clivada (p20) e IL-1ß, ambas oriundas da ativação do inflamassoma. Interessantemente, os aspirados de pacientes LC apresentam mais IL- $\beta$ e caspase-1 p20 (CASP1) do que os de LMC, apesar de não haver diferença estatística na CASP1 (Fig. 14a,b). A partir destes resultados, nos perguntamos se o vírus de RNA de Leishmania (LRV) poderia estar associado com a ativação do inflamassoma. A fim de se investigar esta hipótese, nós realizamos análise por PCR nos parasitos isolados dos 49 pacientes utilizados, e identificamos que $67 \%$ dos pacientes LMC apresentam o vírus, enquanto $32 \%$ dos pacientes LC são LRV+ (Fig. 14c e Fig. 13). Nós também plotamos os resultados do mesmo grupo de pacientes, de acordo com a presença ou ausência do vírus ( $\mathrm{n}=30$ LRV+ e 19 LRV-). Os resultados demonstram que a presença do LRV correlacionase com menores níveis de IL- $\beta$ e caspase-1 p20, independentemente do quadro clínico da doença (Fig. 14d,e). Os níveis de TNF-a, uma citocina inflamassoma- 
independente, também foram medidos, e não encontramos diferença entre os dois grupos, apesar de haver uma tendência de aumento em pacientes LRV+ (Fig. 14f). De forma importante, apenas $10 \%$ dos pacientes LRV- desenvolveram mucocutânea, enquanto $31 \%$ dos pacientes LRV+ desenvolveram a forma mais agressiva da doença. (Fig.14g). De forma conjunta, os resultados obtidos com estas amostras clínicas indicam que a ativação do inflamassoma está diretamente relacionada com a presença do LRV e a gravidade da Leishmaniose. 


\begin{tabular}{|c|c|c|c|c|}
\hline $\begin{array}{c}\text { Número do } \\
\text { paciente }\end{array}$ & Espécie infectiva & Região & $\begin{array}{l}\text { Forma } \\
\text { clínica }\end{array}$ & LRV Status \\
\hline 1 & L. braziliensis & Rondônia, Brazil & $\overline{L C}$ & POSITIVO \\
\hline 2 & Leishmania spp. & Rondônia, Brazil & LC & NEGATIVO \\
\hline 3 & Leishmania spp. & Rondônia, Brazil & LMC & NEGATIVO \\
\hline 4 & Leishmania spp. & Rondônia, Brazil & LC & NEGATIVO \\
\hline 5 & L. braziliensis & Rondônia, Brazil & LC & POSITIVO \\
\hline 6 & L. braziliensis & Rondônia, Brazil & LC & NEGATIVO \\
\hline 7 & L. braziliensis & Rondônia, Brazil & $\mathrm{LC}$ & POSITIVO \\
\hline 8 & L. braziliensis & Rondônia, Brazil & $\mathrm{LC}$ & POSITIVO \\
\hline 9 & Leishmania spp. & Rondônia, Brazil & $\overline{L C}$ & NEGATIVO \\
\hline 10 & Leishmania spp. & Rondônia, Brazil & LC & NEGATIVO \\
\hline 11 & Leishmania spp. & Rondônia, Brazil & $\mathrm{LC}$ & NEGATIVO \\
\hline 12 & L. braziliensis & Rondônia, Brazil & LMC & POSITIVO \\
\hline 13 & L. braziliensis & Rondônia, Brazil & LC & POSITIVO \\
\hline 14 & L. braziliensis & Rondônia, Brazil & LC & NEGATIVO \\
\hline 15 & Leishmania spp. & Rondônia, Brazil & $\mathrm{LC}$ & NEGATIVO \\
\hline 16 & Leishmania spp. & Rondônia, Brazil & $\mathrm{LC}$ & NEGATIVO \\
\hline 17 & Leishmania spp. & Rondônia, Brazil & $\overline{\mathrm{LC}}$ & POSITIVO \\
\hline 18 & L. guyanensis & Rondônia, Brazil & LC & NEGATIVO \\
\hline 19 & L. braziliensis & Rondônia, Brazil & LMC & POSITIVO \\
\hline 20 & L. braziliensis & Rondônia, Brazil & LC & POSITIVO \\
\hline 21 & L. guyanensis & Rondônia, Brazil & LC & POSITIVO \\
\hline 22 & L. braziliensis & Rondônia, Brazil & LC & NEGATIVO \\
\hline 23 & L. braziliensis & Rondônia, Brazil & $\mathrm{LC}$ & NEGATIVO \\
\hline 24 & Leishmania spp. & Rondônia, Brazil & $\mathrm{LC}$ & NEGATIVO \\
\hline 25 & L. braziliensis & Rondônia, Brazil & $\overline{L C}$ & NEGATIVO \\
\hline 26 & L. braziliensis & Rondônia, Brazil & LMC & NEGATIVO \\
\hline 27 & Leishmania spp. & Rondônia, Brazil & $\mathrm{LC}$ & NEGATIVO \\
\hline 28 & L. braziliensis & Rondônia, Brazil & LMC & POSITIVO \\
\hline 29 & Leishmania spp. & Rondônia, Brazil & LMC & POSITIVO \\
\hline 30 & Leishmania spp. & Rondônia, Brazil & LC & NEGATIVO \\
\hline 31 & Leishmania spp. & Rondônia, Brazil & $\overline{L C}$ & NEGATIVO \\
\hline 32 & L. braziliensis & Rondônia, Brazil & LC & POSITIVO \\
\hline 33 & L. guyanensis & Rondônia, Brazil & LMC & NEGATIVO \\
\hline 34 & Leishmania spp. & Rondônia, Brazil & $\mathrm{LC}$ & NEGATIVO \\
\hline 35 & L. braziliensis & Rondônia, Brazil & LMC & POSITIVO \\
\hline 36 & L. braziliensis & Rondônia, Brazil & LMC & POSITIVO \\
\hline 37 & L. braziliensis & Rondônia, Brazil & $\overline{L C}$ & NEGATIVO \\
\hline 38 & Leishmania spp. & Rondônia, Brazil & LC & NEGATIVO \\
\hline 39 & L. braziliensis & Rondônia, Brazil & $\overline{L C}$ & POSITIVO \\
\hline 40 & L. braziliensis & Rondônia, Brazil & LC & POSITIVO \\
\hline 41 & Leishmania spp. & Rondônia, Brazil & $\overline{L C}$ & NEGATIVO \\
\hline 42 & L. guyanensis & Rondônia, Brazil & LC & NEGATIVO \\
\hline
\end{tabular}

Figura 13. Aspirados de lesões obtidos de pacientes com Leishmaniose em suas diferentes formas clínicas. O diagrama mostra a distribuição das amostras testadas na figura 14, de acordo com a espécie do parasito infectante, local de isolamento, forma da doença ( $L C=$ Leishmaniose cutânea, $L M C=$ Leishmaniose mucocutânea) e o status do LRV. 


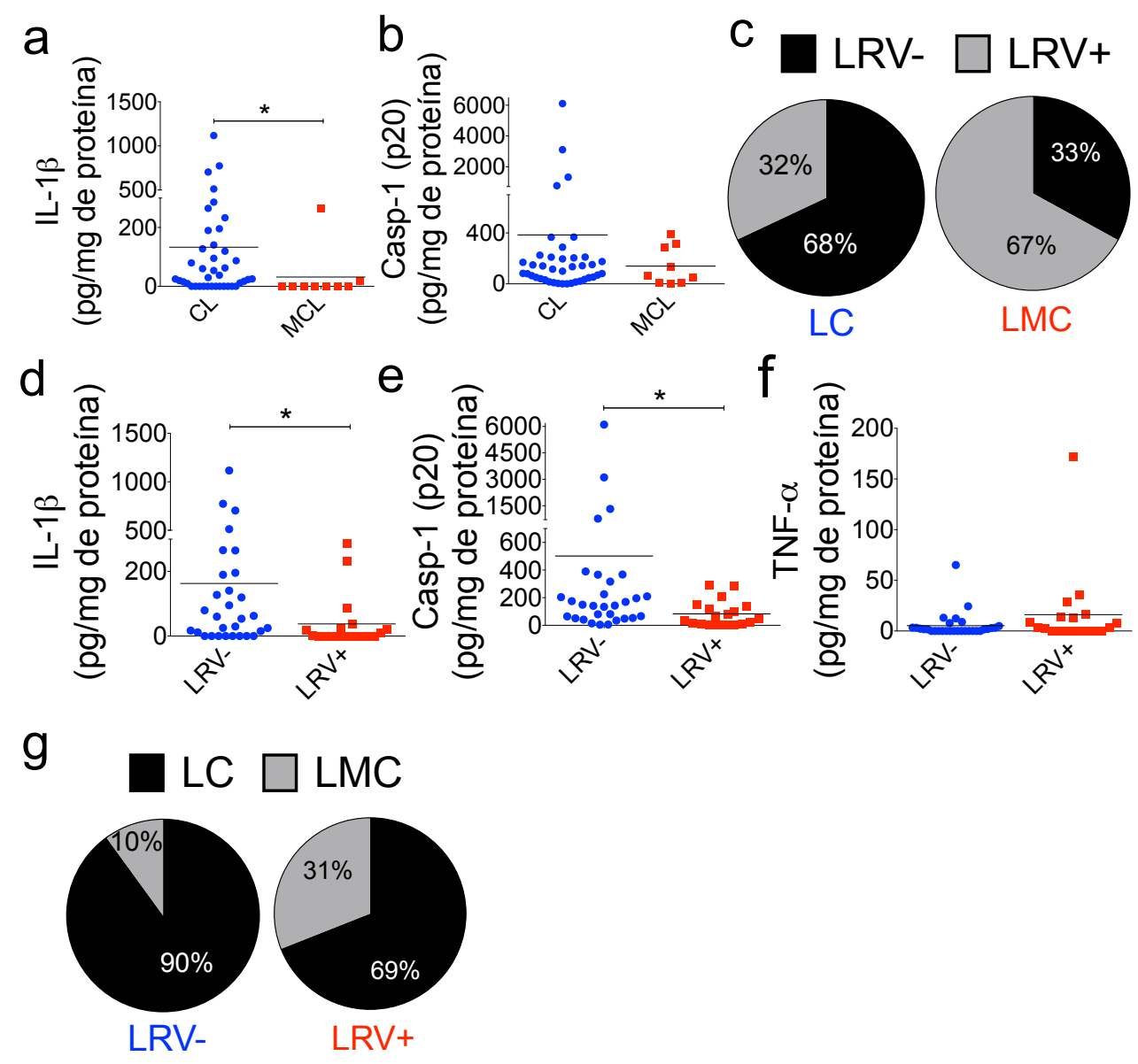

Figura 14. LRV e LMC estão associados à diminuição da ativação do inflamassoma. (a-c) Os pacientes foram agrupados de acordo com a forma clínica da doença (LC = Leishmaniose Cutânea; LMC = Leishmaniose Mucocutânea), independentemente da espécie infectante de Leishmania. Os níveis de IL-1ß (a) e Casp1 clivada (b) foram quantificados por ELISA em aspirados de lesões de pacientes LC $(n=40)$ e LMC $(n=9)$; a freqüência de parasitos LRV + e LRV- entre cada grupo é mostrado (c). (d-g) O mesmo grupo de pacientes foi distribuído de acordo com o status do LRV, independentemente da

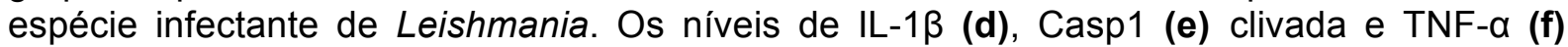
foram plotados em aspirados de ambos os pacientes LRV + $(n=19)$ e LRV- $(n=30)$, e a frequência de CL e MCL entre cada grupo também é mostrada (g). Cada valor foi corrigido para a respectiva quantidade de proteína (determinada por Bradford) de cada paciente. A análise estatística foi realizada pelo teste de Mann-Whitney. $P<0,05\left(^{*}\right)$ foi considerado estatisticamente significativo.

\subsection{LRV agrava a infecção e favorece o crescimento de L.g.}

Os dados obtidos em pacientes nos encorajaram a investigar mais a fundo os mecanismos que explicam nossos achados clínicos. A ativação do inflamassoma de NLRP3 já foi extensamente estudada utilizando macrófagos derivados de medula óssea (BMDMs) e em modelo murinho de Leishmaniose (ZAMBONI; SACKS, 2019). 
Desta forma, combinamos experimentos em BMDMs e em animais C57BL/6 para melhor investigar a participação do LRV na modulação da resposta imune do hospedeiro à infecção. A cepa de referência de L.g. da OMS (WHO, em ingles), M4147, é conhecida por seus altos níveis do LRV. A partir desta ferramenta, nós geramos de forma espontânea uma linhagem clonal de L.g. M4147, que não contém o LRV. Através do semeamento dos parasitos selvagens $($ L.g.+) em placa de ágar e posterior isolamento de colônias (Fig. 15a), nós obtivemos um único clone (Clone 40) que se mostrou LRV- pela técnica de PCR, sendo denominado L.g.- (Fig. 15b). Nós também confirmamos a geração de L.g.- por imunofluorescência, através da marcação intracelular dos parasitos com o anticorpo J2, que marca fita dupla de RNA e, portanto, o LRV (Fig 15c e 15d). Mais além, demonstramos que a ausência do LRV não afetou a capacidade proliferativa de L.g. em meio axênico (Fig. 15e). 

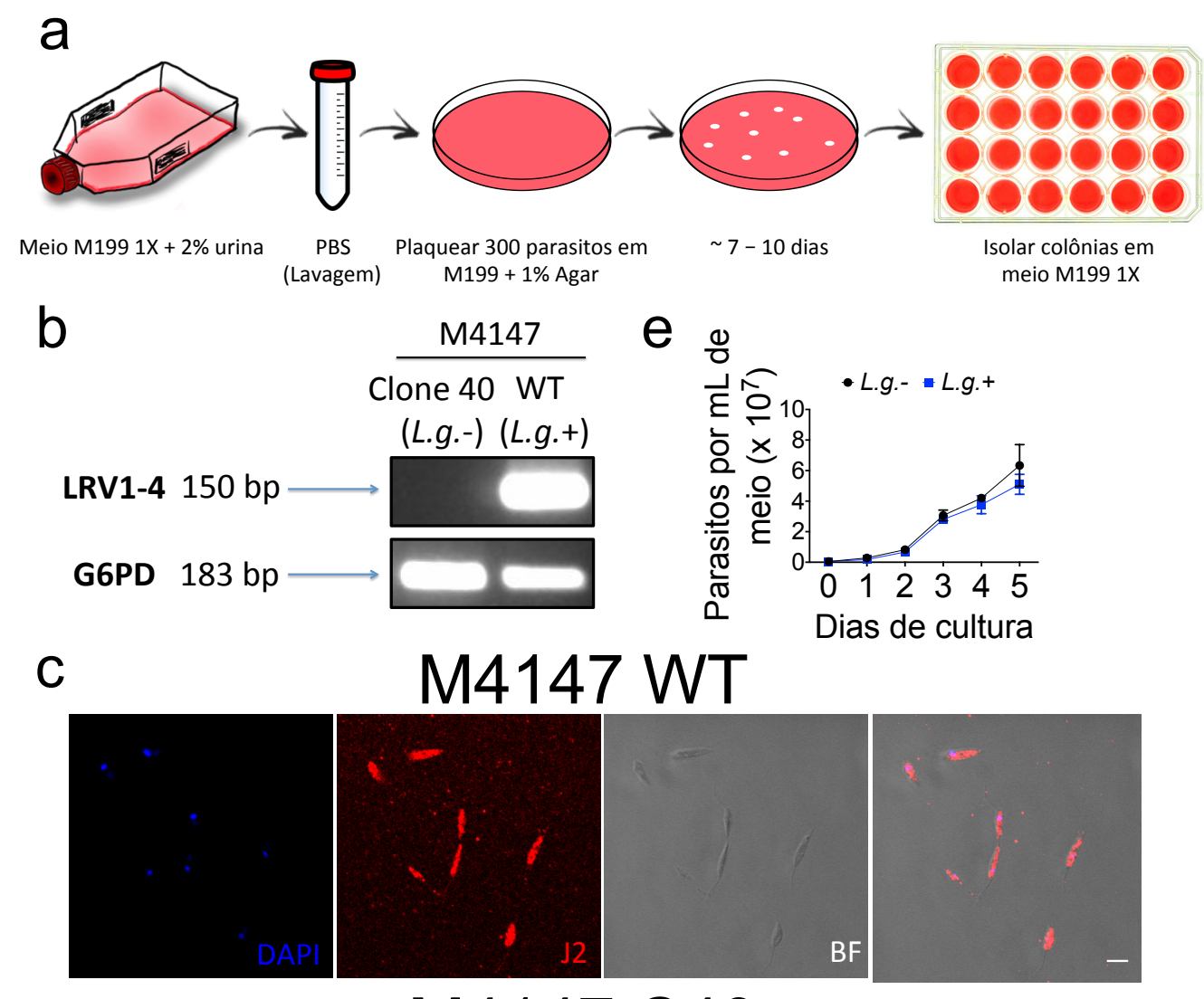

M4147 WT
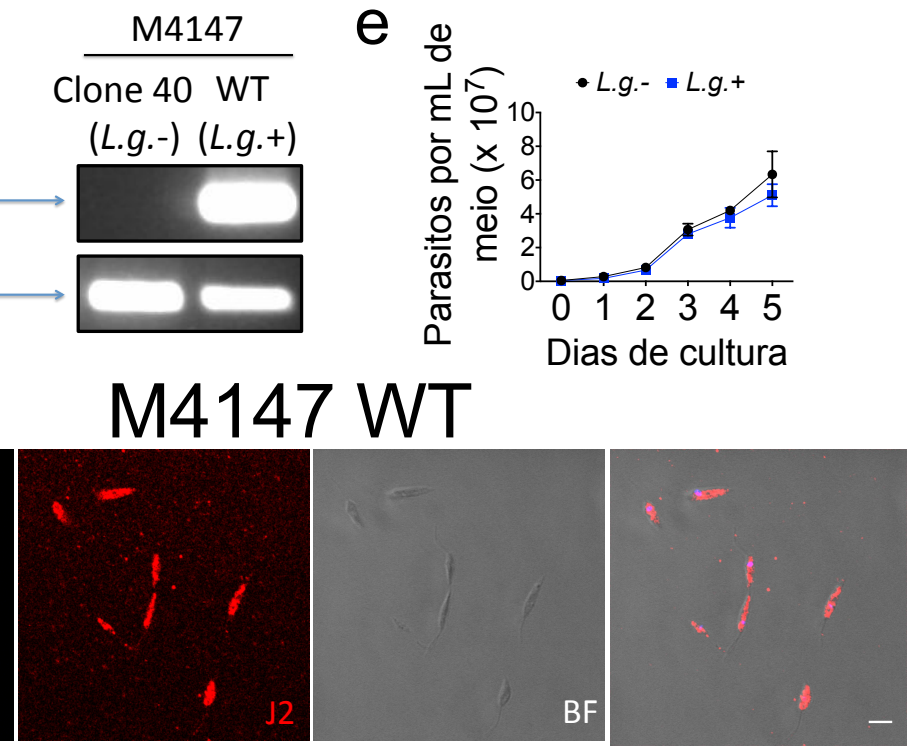

d

M4147 C40
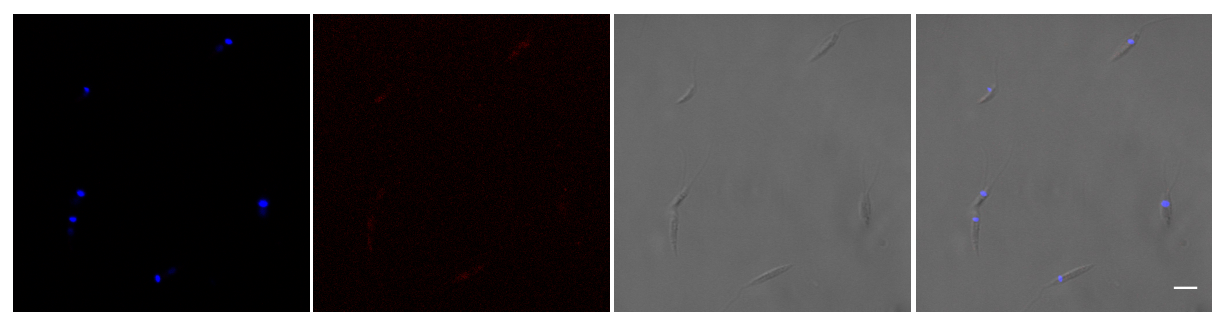

Figura 15. Geração do clone 40 (L.g.-). (a) Esquema da geração do clone 40 (L.g.-). (b) PCR para o produto de LRV (150 pb) e de Leishmania, G6PD (183 pb), em ambos os clones (L.g.- e L.g +). (c, d) Microscopia confocal em $8 \times 10^{6}$ promastigotas fixados e permeabilizados da linhagem WT e seu clone negativo para o LRV (L.g.-). Parasitos foram corados nos núcleos (DAPI) e dsRNA (anticorpo J2). Barra de escala: $5 \mu \mathrm{M}$. BF: campo claro. (e) $O$ crescimento de ambos os clones foi seguido em meio Schneider, e a concentração de parasitos foi determinada diariamente por contagem manual na câmara de Neubauer. Os resultados são mostrados como média \pm DP.

A geração de um clone sem vírus (L.g.-) a partir de uma cepa parental LRV+ (M4147, L.g.+), nos proporcionou a ferramenta ideal para a investigação do papel do LRV no curso da infecção por Leishmania. Logo, infectamos animais C57BL/6 com promastigotas L.g.- e L.g.+ em fase estacionária (FE) na orelha, e acompanhamos o 
desenvolvimento de lesão por quatro semanas. Os resultados demonstram que camundongos infectados com L.g.+ possuem maior espessura de orelha, quando comparados aos animais infectados com L.g.- (Fig. 16a). De forma similar, a carga parasitária ao fim da quarta semana, tanto na orelha (Fig. 16b) quanto no linfonodo (Fig. 16c), mostrou-se aumentada em animais infectados com L.g.+. Resultados similares foram obtidos ao realizarmos a infecção com parasitos metacíclicos (Fig. 16d-f). A fim de se verificar o papel do LRV na replicação de L.g. in vitro, BMDMs foram infectados com parasitos metacíclicos e acompanhados até 96 horas após a infecção. Os resultados demonstram que, apesar do LRV não impactar a fagocitose/internalização de L.g. pelos macrófagos 1 hora após a infecção, a presença do vírus confere ao parasito melhor sobrevivência (Fig. 17a) e replicação (Fig. 17b) dentro das células. Depois, verificamos se estes resultados in vitro ocorrem devido a uma menor indução de morte celular frente à L.g.+. Para testar esta hipótese, nós pré-incubamos ambos os clones de L.g. com a sonda fluorescente CFSE e, após a infecção, analisamos por FACS os macrófagos infectados e não-infectados, marcados pela sonda de viabilidade celular Live/Dead. Os resultados demonstram que, embora observemos baixo nível de morte celular frente à infecção, LRV não impacta este processo (Fig 17c-g). De forma conjunta, nossos resultados demonstram que o vírus promove resistência à L.g. frente aos mecanismos microbicidas exercidos pela célula hospedeira, agravando a infecção tanto em macrófagos quanto in vivo. 
Promastigotas em fase estacionária

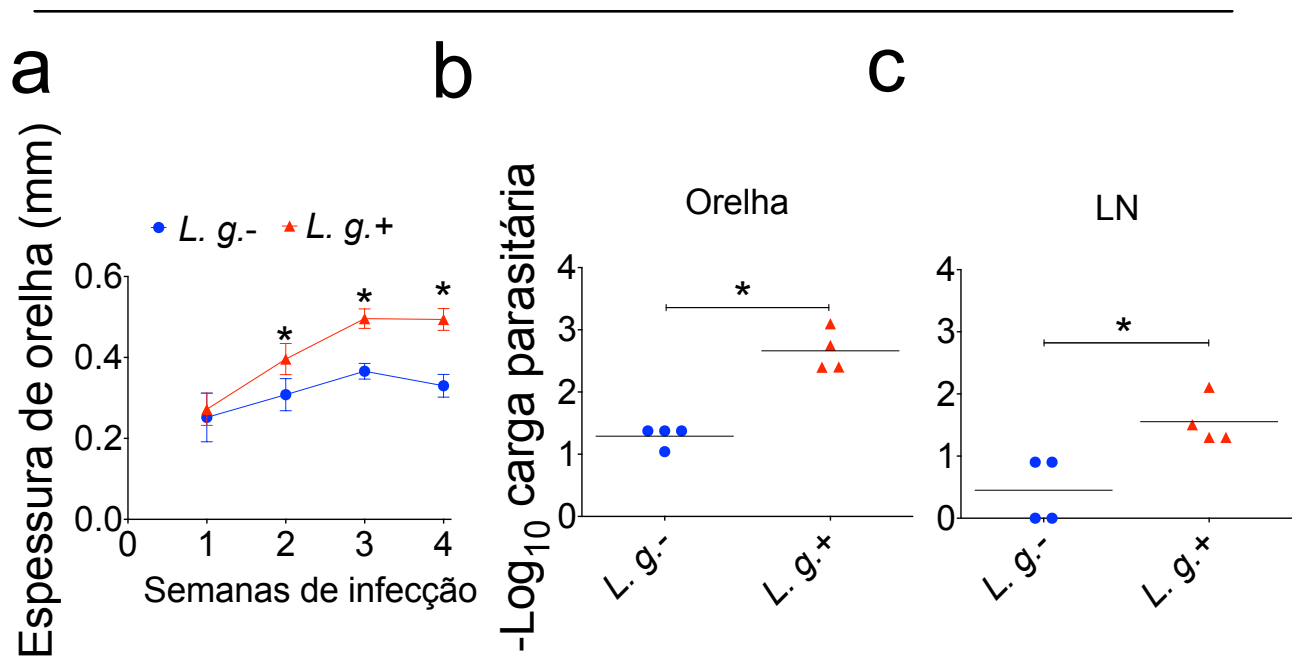

\section{Promastigotas Metacíclicos}
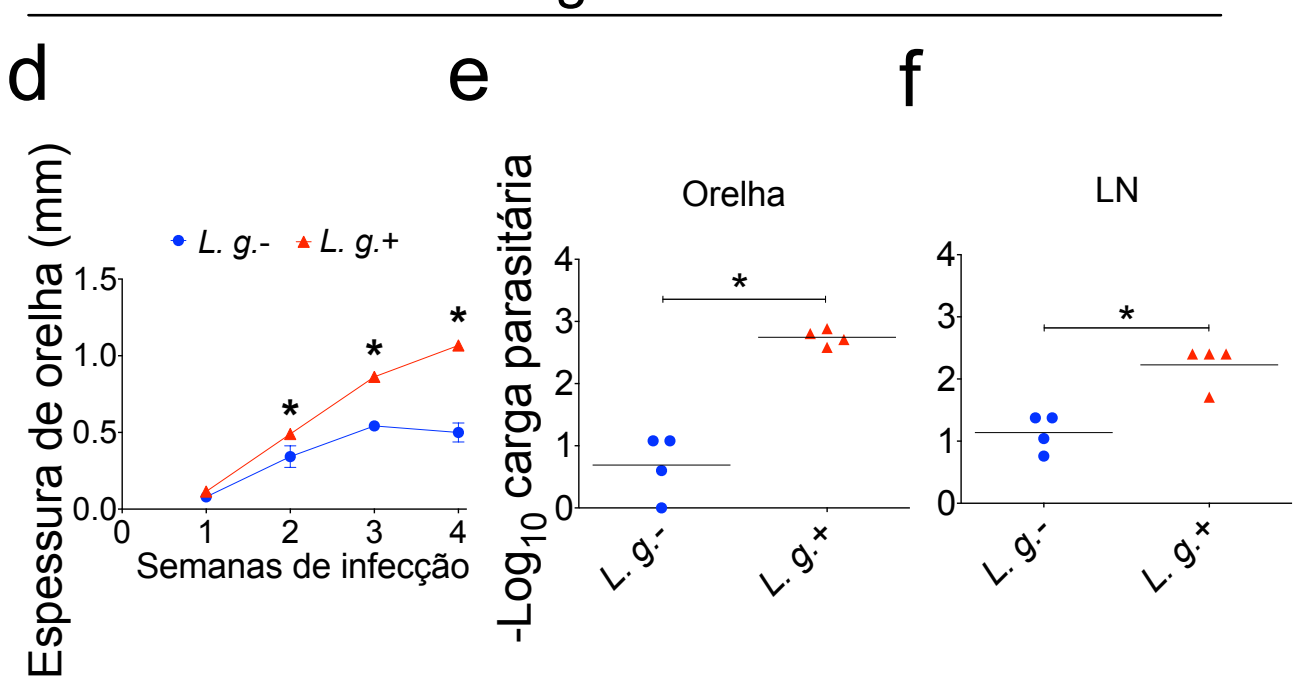

Figura 16. LRV aumenta a virulência de L.g. in vivo. (a-f) Camundongos C57BL/6 ( $n=4$ por grupo) foram injetados intradermicamente na orelha esquerda com promastigotas em fase estacionária (a-c) ou metacíclicos (d-f) de L.g.- ou L.g.+, e as espessuras de orelha foram seguidas semanalmente $(a, d)$. Aos 4 w.p.i, os títulos de parasitos foram determinados nas orelhas infectadas (b, e) e nos linfonodos drenantes (c, f). Um experimento representativo de três experimentos independentes realizados é mostrado, com replicatas biológicas. Os resultados são mostrados como média \pm DP. A análise estatística foi realizada por ANOVA de duas vias com o teste de comparação múltipla de Bonferroni. $P$ $<0,05$ foi considerado estatisticamente significativo $\left(^{*}\right)$. 
a

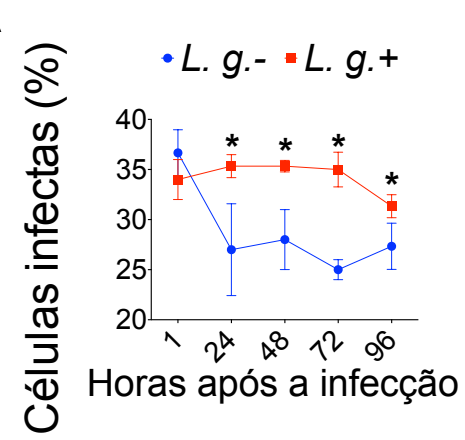

b

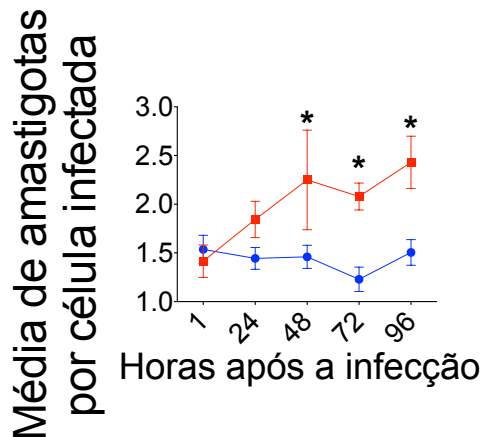

C

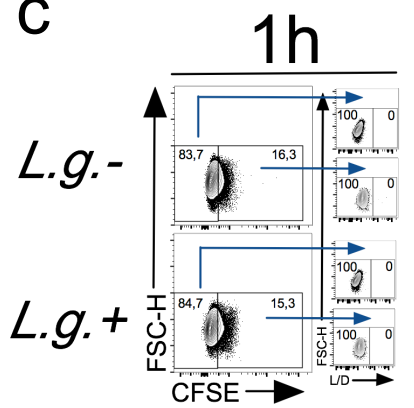

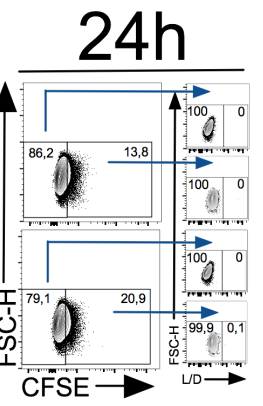
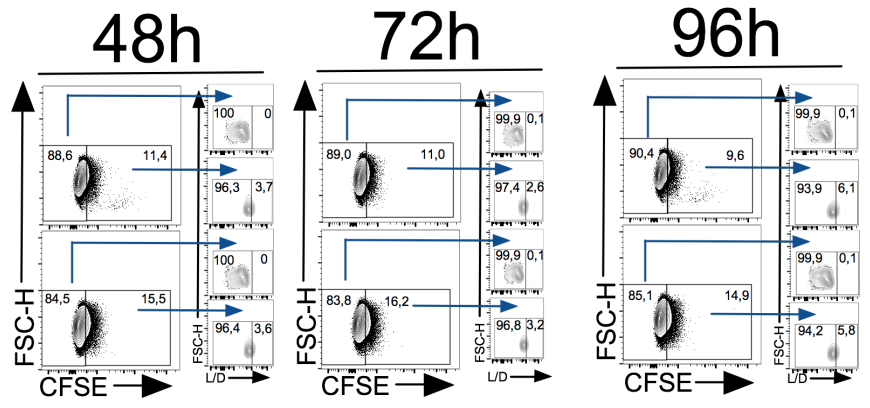

Células infectadas (dentro dos BMDMs CFSE+)

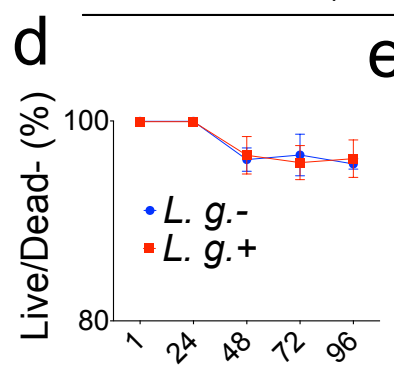

e

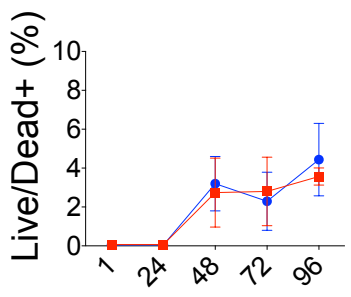

Células não-infectadas (dentro dos BMDMs CFSE-)

Horas após a infecção

Horas após a infecção

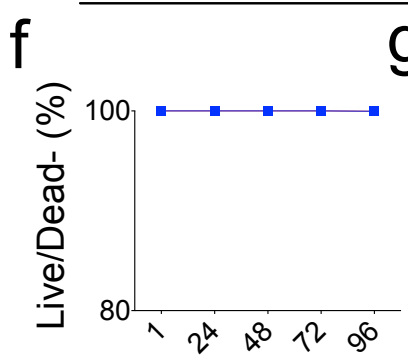

9

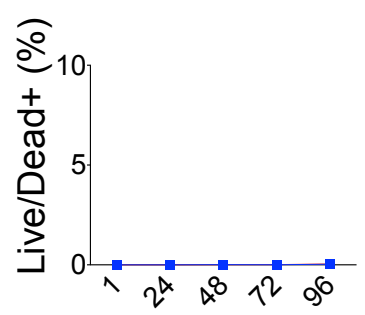

Horas após a infecção Horas após a infecção

Figura 17. LRV aumenta a virulência de L.g. in vitro. (a-g) BMDMs de animais WT foram infectados com promastigotas metacíclicos de L.g.- e L.g +, em MOI de 1. As células foram lavadas após 1 hora de infecção e mantidas em cultura durante 1, 24, 48, 72 ou 96 h. (a, b) Ensaio de killing in vitro (Panotico Giemsa), mostrando a porcentagem de células infectadas (a) e o número médio de parasitas por célula infectada (b), no final de cada tempo. (c-g) Análise por FACS de BMDMs infectados com L.g.- e L.g. + previamente incubados com a sonda CFSE, antes da infecção. Os plots representativos (c), as porcentagens de células infectadas vivas e mortas (d,e), ou não infectadas $(\mathbf{f}, \mathbf{g})$, são mostrados. Um experimento representativo de dois experimentos independentes realizados é mostrado, com replicatas técnicas. Os resultados são mostrados como média \pm DP. A análise estatística foi realizada por ANOVA de duas vias com o teste de comparação múltipla de Bonferroni. $P<0,05$ foi considerado estatisticamente significativo $\left(^{*}\right)$.

\subsection{LRV atenua a ativação do inflamassoma por L.g.}

Nossos dados indicando que pacientes infectados com parasitos LRV+ induzem uma produção mais robusta de IL-1ß e Casp1, sustentam a hipótese de 
que o vírus possa modular a ativação do inflamassoma. Assim, avaliamos a ativação do inflamassoma em resposta à infecção por L.g + e L.g.- em macrófagos. De forma interessante, observamos que a infecção por L.g.- induz maiores níveis de IL-1ß quando comparado à L.g.+ (Fig. 18a), sendo este efeito observado desde 9 horas após a infecção (Fig. 18b). A nigericina foi usada como um controle positivo para a ativação do inflamassoma. É importante ressaltar que a ativação do inflamassoma só pode ser atingida de forma robusta após um período de "priming" prévio (Fig. 19a), assim como observado em outros estudos (LIMA-JUNIOR et al., 2013a; DE CARVALHO et al., 2019b). As razões para tal fenômeno foram estudadas em detalhes em um artigo recém-publicado pelo nosso grupo de pesquisa, também referente a esta tese, e pode ser lido em mais detalhes (DE CARVALHO et al., 2019a). Diferentemente da IL-1ß, a presença do vírus não afeta a produção de citocinas independentes de inflamassoma, como o TNF-a (Fig. 18c). A produção reduzida de IL-1 em resposta a L.g.+ também foi observada quando macrófagos foram infectados com diferentes $\mathrm{MOI}$ de promastigotas metacíclicos (MC), que são as formas altamente virulentas que são injetadas pelo vetor flebotomíneo (Fig. 18df). Este efeito também foi observado usando diferentes MOls de parasitos em fase estacionária (Fig. 19b), e quando macrófagos foram "primed" com diferentes estímulos (Fig. 19c). A reduzida produção de IL-1 $\beta$ em resposta a L.g.+ também foi observada quando utilizamos macrófagos de diferentes linhagens de camundongos (Fig. 19d). Para avaliar diretamente a ativação de Casp1, macrófagos foram infectados e marcados com FAM-YVAD, uma sonda verde que se liga à Caspase-1 ativa, e quantificamos a porcentagem de células FAM-YVAD+ por FACS. Os resultados demonstram que L.g.+ induz menor ativação de Casp1 em BMDMs quando comparado a L.g.-, como demonstrado no histograma representativo (Fig. 
18g) e nos gráficos de porcentagem de células FAM-YVAD+ (Fig. 18h) e de intensidade de fluorescência média integrada (iMIF) (Fig. 18i). A clivagem de Casp1 e IL-1 $\beta$ também foi avaliada por western blot, corroborando os dados de ELISA e FACS mencionados acima (Fig. 18j).

Em seguida, avaliamos se os efeitos do LRV na ativação do inflamassoma afeta também a produção de IL-1ß induzida por um tipo diferente de microorganismo. Para testar esta hipótese, co-infectamos BMDMs com L.g.+ ou L.g.- mais Legionella pneumophila, uma bactéria gram-negativa conhecida por desencadear a ativação do inflamassoma (MASCARENHAS; ZAMBONI, 2016). Enquanto a coinfecção de L.g.- com L. pneumophila promoveu efeito aditivo sobre a secreção de IL-1ß, a coinfecção de L.g.+ com L. pneumophila diminuiu significativamente a ativação do inflamassoma, quando comparada com células infectadas apenas com L. pneumophila ( Fig. 18k), sugerindo que L.g.+, mas não L.g.-, inibe ativamente a ativação do inflamassoma. Mais além, avaliamos se variações clonais inerentes ao clone 40 (L.g.-) contribuiriam para a inibição do inflamassoma. Para isto, geramos cinco clones de M4147 LRV+ (Fig. 18I), e testamos a ativação do inflamassoma frente a todos estes. Os resultados demonstram que tanto L.g.+ (selvagem) quanto os clones derivados desta cepa induzem menor ativação do inflamassoma, quando comparados à L.g.- (Fig. 18m), sugerindo que é a presença do LRV, mais do que quaisquer variações clonais, que interfere na ativação do inflamassoma por L.g. 

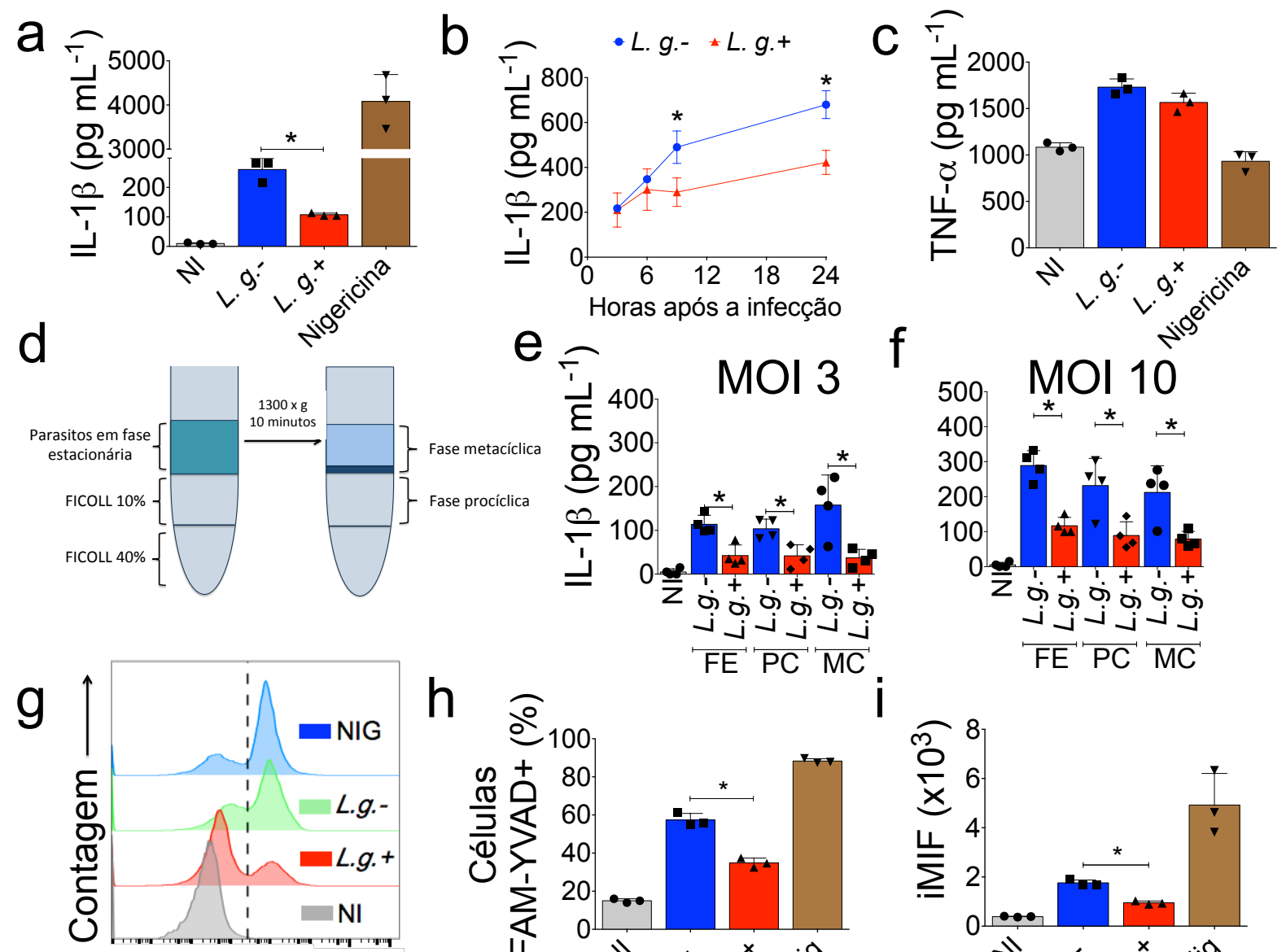

$\mathrm{h}$

FE $\mathrm{PC}$ MC

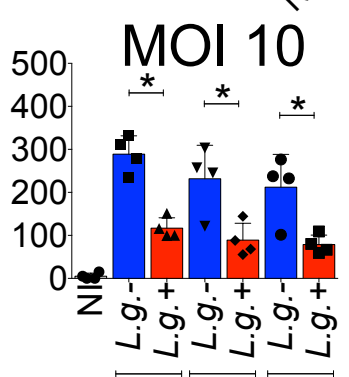

FE $\mathrm{PC} M$
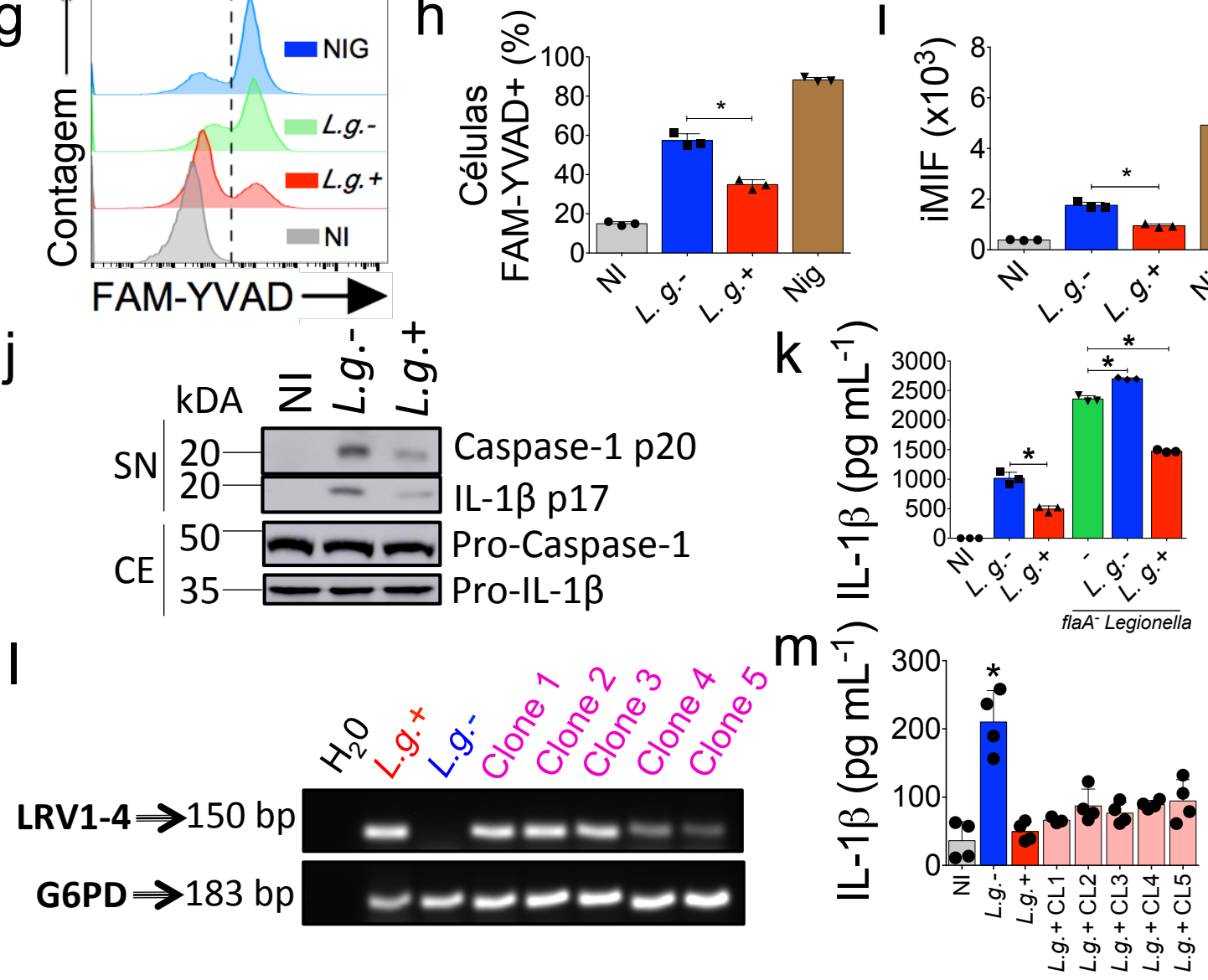

Figura 18. LRV limita a ativação do inflamassoma por L.g. em BMDMs. (a, b) C57BL/6 BMDMs foram estimulados por $4 \mathrm{~h}$ com LPS $(500 \mathrm{ng} / \mathrm{mL})$ e infectados com parasitos em fase estacionária (SP) de L.g.- ou L.g.+, em MOI 10, por 24 horas (a) ou 3, 9 e 24 horas (b). Nigericina $(20 \mu \mathrm{M})$ foi utilizada como controle positivo. Sobrenadantes livres de células foram coletados e ELISA para IL-1 $\beta$ (a,b) e TNF- $\alpha$ (c) foi realizado. (d-f) Promastigotas metacíclicos foram purificados pelo gradiente de FICOLL (d), e os níveis de IL-1 $\beta$ foram 
quantificados em BMDMs infectados por parasitos em fase estacionária (FE), procíclicos (PC) ou metacíclicos (MC), em MOI 3 (e) ou 10 (f). (g-i) Ensaio de FLICA mostrando a ativação de Casp1 após infecção com L.g.- ou L.g.+. O histograma representativo (g), a porcentagem de células positivas para Casp1 (FAM-YVAD+) (h) e MII integrado (iMFI) (i) são mostrados. Nigericina $(20 \mu \mathrm{M})$ foi usado como controle positivo. (j) BMDMs foram estimulados por LPS e infectados por 24 horas com os clones de L.g. Western blot para Casp1 ( $\mathrm{p} 20)$ e IL-1 $\beta$ ( $\mathrm{p} 17$ ) clivados foi realizado no SN livre de células, enquanto procaspase-1 e pro-IL-1 foram quantificados nos extratos celulares (CE). (k) BMDMs foram estimulados e infectados com L.g.- ou L.g.+ em um MOl de 10. Após 20 horas de infecção, as células foram infectadas com L. pneumophila (flaA-Legionella). 4 horas mais tarde, os sobrenadantes livres de células foram coletados e os níveis de IL-1 $\beta$ foram avaliados por ELISA. (I, m) BMDMs foram deixados não-infectados (NI) ou infectados com L.g.-, L.g + ou 5 clones (CL1-CL5) LRV+ diferentes, derivados de M4147. (I) O produto de amplificação do LRV e de G6PD (Leishmania) é mostrado por PCR. Água $\left(\mathrm{H}_{2} 0\right)$ foi usada como controle negativo. (m) Os níveis de IL-1 $1 \beta$ foram quantificados por ELISA. Os resultados são mostrados como média \pm DP. A análise estatística foi realizada pelo teste $t$ de Student não pareado, e $P<0,05\left(^{*}\right)$ foi considerado estatisticamente significativo. Um experimento representativo de pelo menos três experimentos independentes realizados em triplicatas ou quadruplicatas técnicas é mostrado.

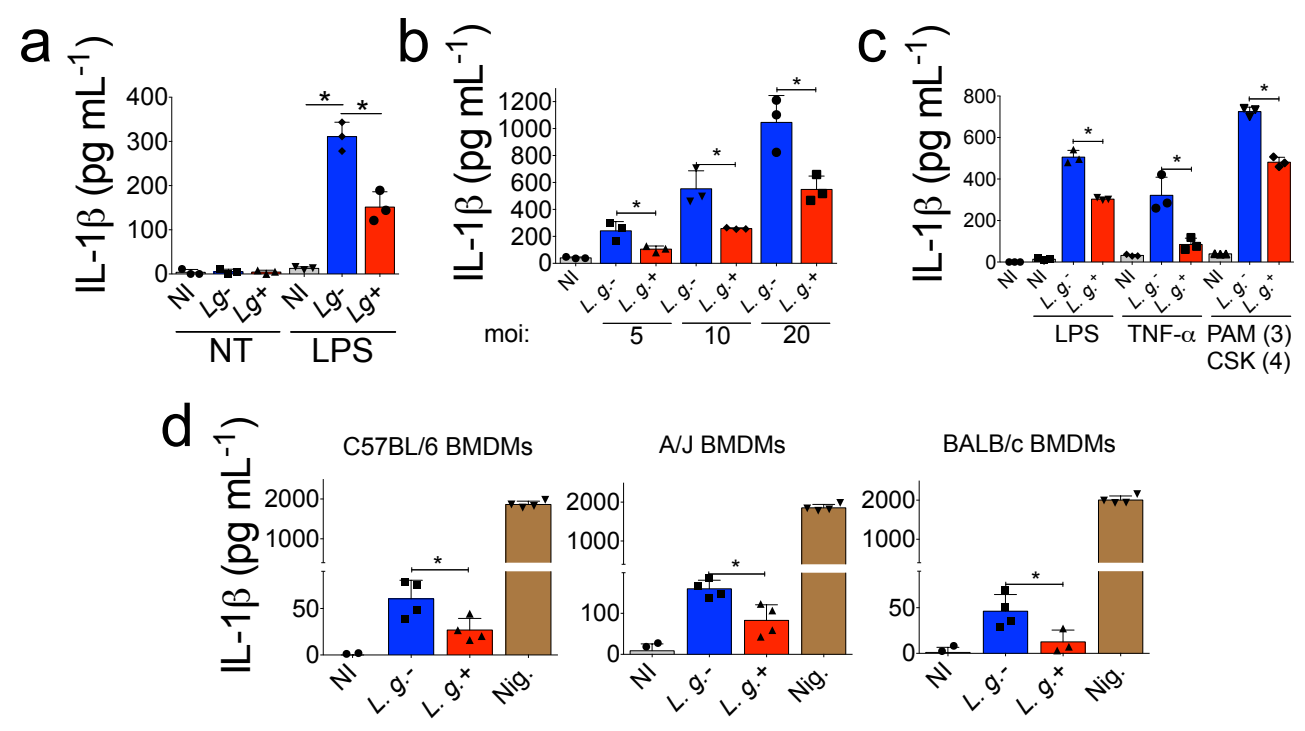

Figura 19. O LRV atenua a ativação do inflamassoma por L.g. (a) BMDMs de animais C57BL/6 foram deixados sem "priming" ou estimulados com LPS $(500 \mathrm{ng} / \mathrm{mL})$ durante 4 horas, e depois infectados com os clones de L.g. em fase estacionária, no MOl de 10. (b) BMDMs estimulados por LPS $(500 \mathrm{ng} / \mathrm{mL})$ foram infectados com três diferentes MOI de promastigotas de L.g.- ou L.g.+ em fase estacionária. (c) Macrófagos foram estimulados por 4h com LPS (500 ng/mL), PAM(3)CSK(4) (300 ng/mL) ou TNF- $\alpha$ (10 ng/mL), e então infectados por $24 \mathrm{~h}$ com L.g.- ou L.g.+. (d) BMDMs de diferentes linhagens de camundongos foram estimulados com LPS e infectados por $24 \mathrm{~h}$ com os clones de L.g., ou tratados com 20 $\mu \mathrm{M}$ de Nigericina (Nig., controle positivo). Após 24 horas, os sobrenadantes foram recolhidos e o ELISA para IL-1 $\beta$ foi realizado em sobrenadantes livres de células. Um experimento representativo de pelo menos dois ensaios independentes, realizados com replicatas técnicas, é mostrado. Os resultados são mostrados como média \pm DP. A análise estatística foi realizada pelo teste $t$ de Student não pareado, e $P<0,05\left(^{*}\right)$ foi considerado estatisticamente significativo. 


\subsection{LRV não interfere com a geração de primeiros ou segundos sinais por L.g.}

Após observar o efeito do LRV na modulação do inflamassoma, nos perguntamos se a inibição ocorreria ao nível de primeiro sinal ("priming”, afetando citocinas inflamassoma-dependentes a nível de transcrição gênica), ou a nível de segundo sinal (DAMPs) da célula hospedeira). Inicialmente, infectamos BMDMs por 6 ou $24 \mathrm{~h}$ com L.g.+ ou L.g.- e medimos a transcrição de $/ / 1 b$ por qPCR. Paradoxalmente, L.g.- não afeta a transcrição de $/ / 1 b$, enquanto L.g. + aumenta a expressão deste gene em tempos iniciais de infecção (Fig. 20a,b). Além disso, medimos a expressão de outros genes inflamatórios e encontramos que L.g.+ induz maior expressão de Tnfa (Figs. 20c,d), I/12 (Figs. 20e,f) e Ifnb (Figs. 20g,h) em comparação à L.g.-. O ligante de TLR3, Poly:IC, foi usado como controle positivo. Estes dados sugerem que a inibição do inflamassoma mediada por LRV não ocorre a nível transcricional, levantando a hipótese de que isso poderia acontecer em um nível pós-transcricional. É bem estabelecido na literatura que a produção de ROS e o efluxo de potássio são importantes segundos sinais na ativação de NLRP3 por Leishmania spp (LEFĖVRE et al., 2013; LIMA-JUNIOR et al., 2013a; SHIO et al., 2015). A fim de avaliar se o LRV interfere na geração de ROS pelos macrófagos, infectamos BMDMs com L.g.- ou L.g.+ e medimos a produção de ROS mitocondrial e ROS total. Nossos dados indicam que ambos os clones induzem produção similar de ROS total, como mostrado pelo histograma representativo e pelo iMIF (Fig. 21a,b). PMA foi usado como controle positivo. Por outro lado, nenhum dos clones induziu a produção de ROS mitocondrial (rotenona foi usada como controle positivo para este ensaio) (Fig. 21c). Em seguida, medimos o efluxo de potássio usando a sonda asante potássio verde-2, que marca especificamente $0 \mathrm{~K}+$ intracelular (RIMMELE; CHATTON, 2014). Encontramos que ambos os clones de L.g. induzem 
efluxo de $\mathrm{K}+$ de forma similar nas células infectadas, semelhante à nigericina (controle positivo) (Fig. 21d). Desta forma, nossos dados sugerem que a inibição do inflamassoma mediada por LRV não ocorre a nível de primeiro (transcricional) nem segundo sinal (efluxo de potássio e produção de ROS).

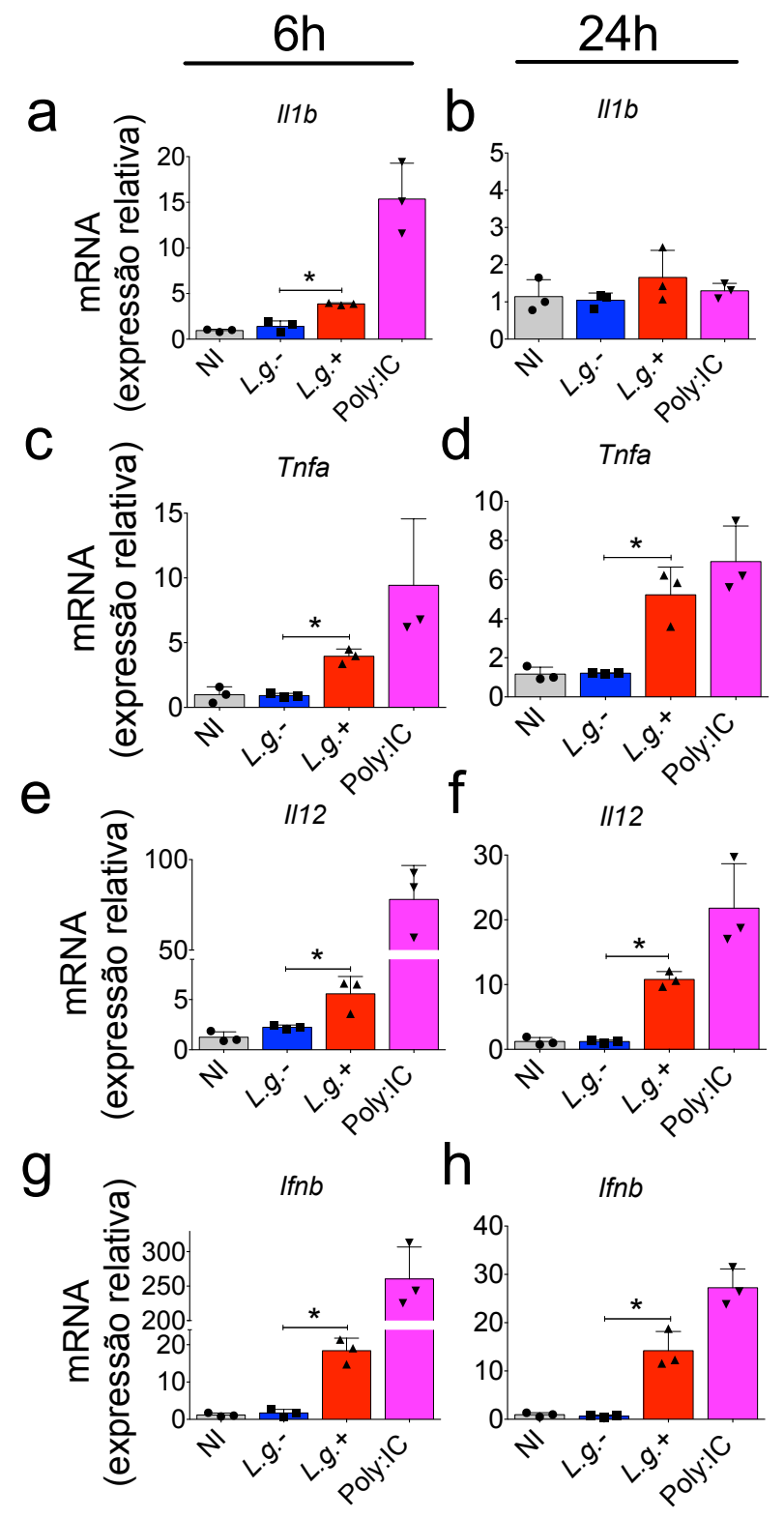

Figura 20. LRV induz a transcrição de diferentes genes inflamatórios. BMDMs de animais C57BL/6 foram infectados com L.g.- ou L.g.+ por 6 (a, c, e, g) ou 24 horas (b, d, f, h). qPCR para IIlb (a,b), Tnfa (c,d), II12 (e,f) e Ifnb (g,h). Poly:IC $(5 \mu \mathrm{g} / \mathrm{mL})$ foi usado como controle positivo. Um experimento representativo de dois experimentos independentes realizados com replicatas técnicas é mostrado. Os resultados são mostrados como média \pm DP. A análise estatística foi realizada pelo teste $t$ de Student não pareado, e $P<0,05\left(^{*}\right)$ foi considerado estatisticamente significativo. 

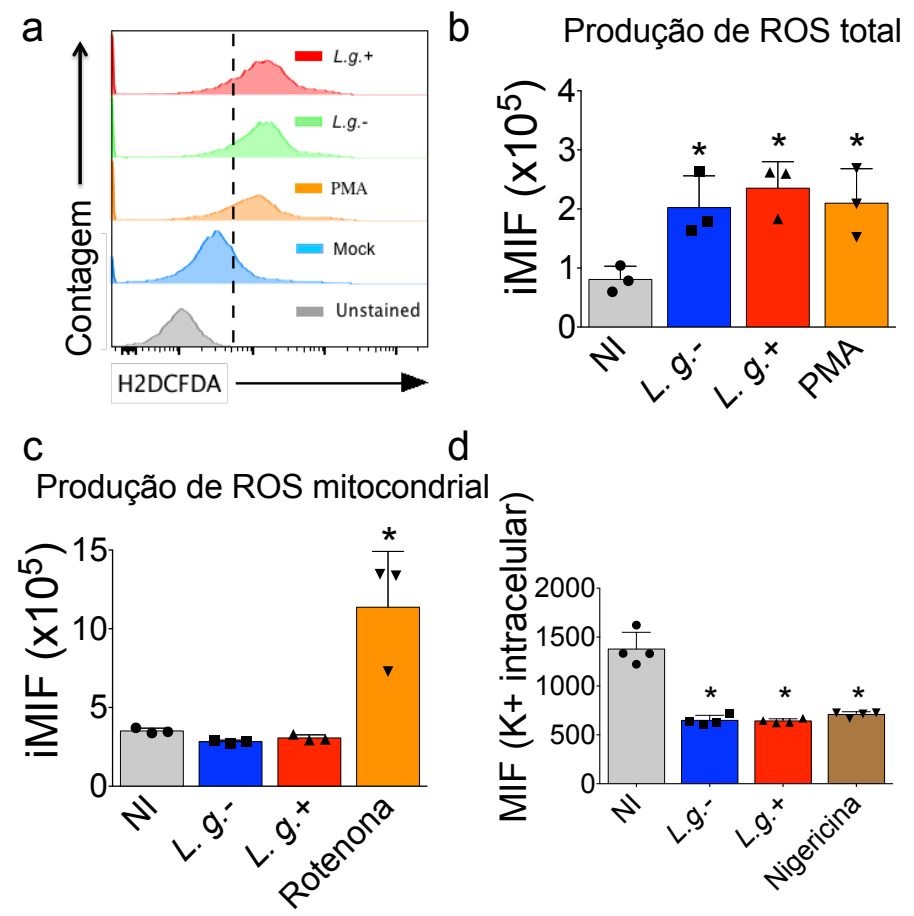

Figura 21. LRV não interfere na geração de segundos sinais por L.g. (a-c) BMDMs de animais C57BL/6 foram infectados com L.g.- ou L.g.+ por 90 minutos. Depois, foi adicionado sondas fluorescentes para marcação de ROS total $(\mathbf{a}, \mathbf{b})$ ou mitocondrial (c) durante 30 minutos adicionais. As células foram coletadas e analisadas por FACS. (d) As células foram incubadas com a sonda fluorescente para potássio APG-2 e, 12 horas após a infecção, os níveis de potássio intracelular foram determinados por um equipamento confocal "High Content". Os resultados são mostrados como média \pm DP. A análise estatística foi realizada pelo teste $t$ de Student não pareado, e $P<0,05\left(^{*}\right)$ foi considerado estatisticamente significativo. Um experimento representativo de dois experimentos independentes realizados com replicatas técnicas é mostrado.

\subsection{LRV ativa TLR3/TRIF para produzir IFN- $\beta$ e atenuar a ativação do inflamassoma de NLRP3 por L.g.}

Estudos recentes da literatura demonstraram que o LRV é detectado por TLR3 durante a infecção por L.g. (IVES et al., 2011). Logo, testamos se o TLR3 é necessário para a inibição do inflamassoma mediada por LRV. A princípio, esta hipótese se mostra improvável, uma vez que é consenso na literatura que os TLRs contribuem como primeiro sinal para ativar, e não inibir, o inflamassoma (BROZ; DIXIT, 2016). Para investigar se a ativação do TLR3 por LRV impactaria a ativação de caspase-1, BMDMs de camundongos C57BL/6, NIrp3 $3^{-/-}$e $T / r 3^{-/-}$foram infectados e 
marcados com a sonda FAM-YVAD, que se liga na caspase-1 ativa. De forma surpreendente, descobrimos que a ativação reduzida do inflamassoma em resposta a L.g.+ foi abolida na ausência de TIr3 (Fig. 22a,b). Este achado também foi evidenciado quando medimos a ativação de CASP1 por WB (Fig. 22c). Mais além, BMDMs foram infectados com parasitos em fase estacionária (FE) ou metacíclicos (Metac.), e encontramos resultados semelhantes para a liberação de IL-1ß (Fig. 22d,e). Através do ensaio de co-infecção com L. pneumophila, também demonstramos que TLR3 é necessário para a inibição do inflamassoma por L.g.+ (Fig. 22f). Para validar nossos achados em animais geneticamente modificados, adicionamos Poly:IC, um ligante sintético de TLR3, no momento da infecção por ambos os clones, e verificamos que esta complementação foi capaz de resgatar os efeitos do LRV no inflamassoma frente à infecção por L.g.- (Fig. 22g). É sabido que a ativação de TLR3 sinaliza via TRIF para induzir a produção de interferon do tipo I (SILVA-BARRIOS; STAGER, 2017). Portanto, verificamos se o IFN- $\beta$ é suficiente para complementar L.g.- na ativação do inflamassoma. Semelhante ao Poly: IC, demonstramos que o tratamento com IFN- $\beta$ é capaz de restaurar a inibição do inflamassoma em resposta a L.g.-, mas não afetou a ativação do inflamassoma induzida por L.g.+ (Fig. 22h). Em seguida, testamos se o aumento da replicação de L.g.+ em macrófagos requer a presença de NLRP3 e da via TLR3/TRIF/IFN- $\beta$. BMDMs de camundongos C57BL/6, NIrp3 $3^{-/}$, TIr3 ${ }^{-/-}$e Trif ${ }^{/-}$foram infectados por L.g.ou L.g.+ para avaliação da replicação parasitária. Se por um lado todas estas moléculas não influenciaram a internalização dos parasitos, como evidenciado $1 \mathrm{~h}$ após a infecção (Fig. 22i e 22j), detectamos uma replicação aumentada de L.g.- em macrófagos $\mathrm{NIrp3}^{-/-} 48$ horas após a infecção (Fig. 22k e 22I). Além disso, a replicação aumentada de L.g.+ em comparação à L.g.- em macrófagos C57BL/6 não 
foi observada em nenhum dos macrófagos nocautes utilizados, indicando que o LRV aumenta a replicação/sobrevivência do parasito de forma dependente de TLR3, TRIF e NLRP3 (Fig. 22k e 22I). De forma similar, adicionamos IFN- $\beta$ e Poly:IC, e medimos a replicação dos parasitos, demonstrando que ambos os tratamentos promovem a replicação intracelular de L.g.- em BMDMs de animais C57BL/6, resgatando os efeitos do vírus neste clone (Fig. 23a,b).

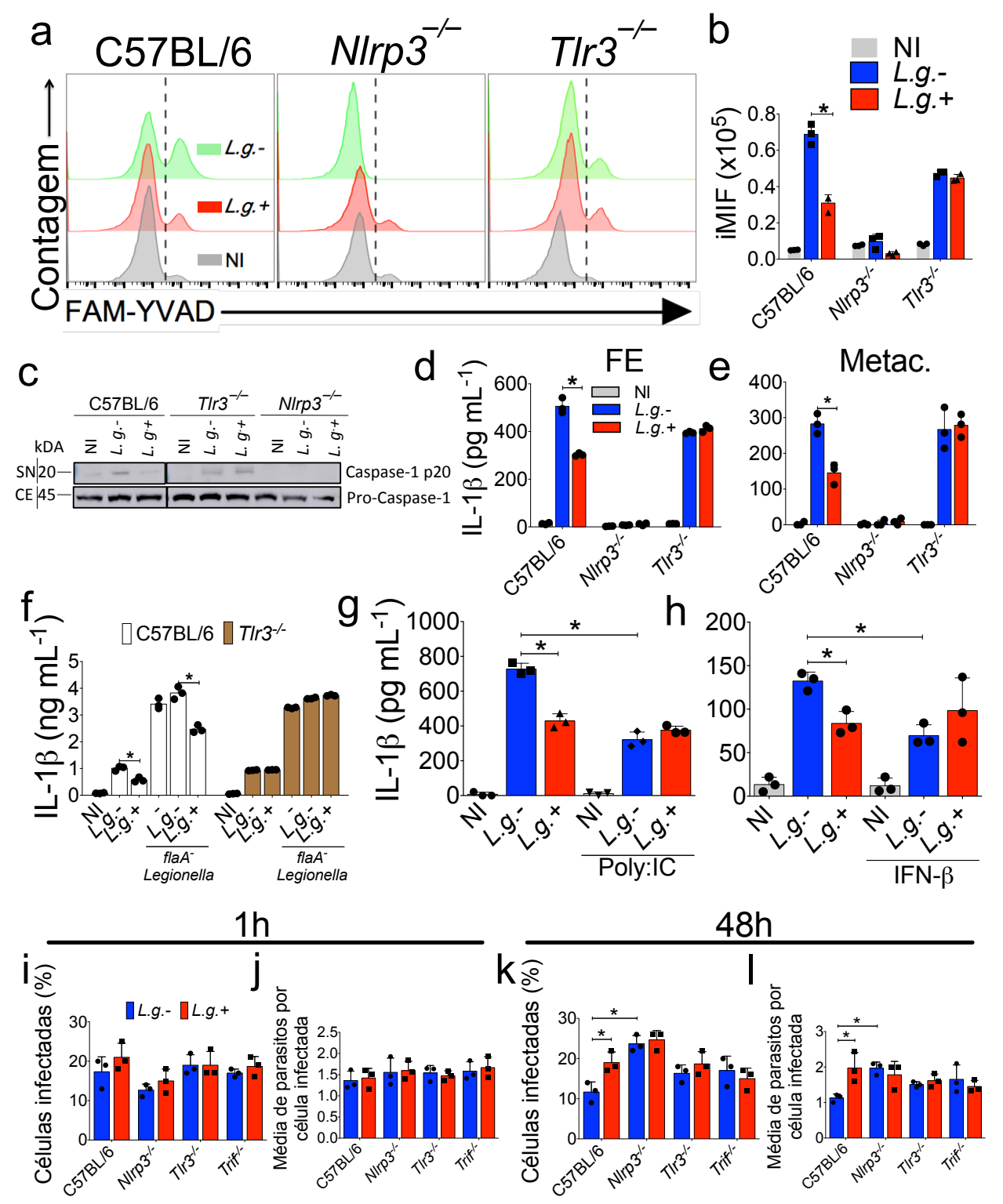

Figura 22. LRV limita a ativação do inflamassoma de NLRP3 por L.g. via TLR3, em BMDMs. (a,b) Ensaio de ativação de caspase-1 por FLICA (FAM-YVAD) em BMDMs de animais C57BL/6, NIrp3 $3^{-/-}$e TIr $3^{-/}$, infectados por L.g.- ou L.g.+ por 24 horas, em um MOI de 10. O histograma representativo (a) e a MIF integrada (iMFI) (b) são mostrados. (c) Western blotting para Casp1 clivada (p20) no sobrenadante (SN), e pró-caspase-1 nos extratos 
celulares (CE). (d,e) Ensaio de ELISA para IL-1 $\beta$ nos sobrenadantes livres de células de BMDMs previamente estimulados por LPS, e depois infectados por 24 horas com MOI 10 de promastigotas em fase estacionária (d) ou metacíclicos (e). (f) BMDMs de C57BL/6 (WT) e $T / r 3^{-/}$foram infectados com L.g.- ou L.g.+ em MOI de 10, e após $20 \mathrm{~h}$ de infecção, foram infectados com L. pneumophila (flaA- Legionella). 4 horas mais tarde, os sobrenadantes foram coletados e os níveis de IL-1 $\beta$ foram avaliados por ELISA. (g,h) C57BL/6 BMDMs foram infectados com L.g.- ou L.g.+ em MOI de 10, e tratados com Poly: IC $(5 \mu \mathrm{g} / \mathrm{mL})(\mathbf{g})$ ou IFN- $\beta$ (1000 U/mL) (h) no momento da infecção. 24 horas depois, os sobrenadantes foram coletados e o ELISA para IL-1 $\beta$ foi realizado. (i-I) BMDMs de animais C57BL/6, NIrp3 ${ }^{-/}$, TIr3 ${ }^{1-}$ e Trif $^{\prime-}$ foram infectados com MOI 1 de promastigotas metacíclicos de L.g.- ou L.g.+. Após $1 \mathrm{~h}$ de infecção, as células foram lavadas e deixado em cultura por 1 ou $48 \mathrm{~h}$. A replicação dos parasitos foi avaliada pela coloração de Panotico Giemsa. (i) Porcentagem de BMDMs infectados 1 hora após a infecção; (j) número médio de amastigotas por célula infectada $1 \mathrm{~h}$ após a infecção; (k) porcentagem de BMDMs infectados 48h após a infecção; (I) número médio de amastigotas por célula infectada $48 \mathrm{~h}$ após a infecção. Os resultados são mostrados como média $\pm \mathrm{DP}$. A análise estatística foi realizada pelo teste $t$ de Student não pareado, e $P<0,05\left(^{*}\right)$ foi considerado estatisticamente significativo. Um experimento representativo de pelo menos dois experimentos independentes, realizados em triplicatas técnicas, é mostrado.
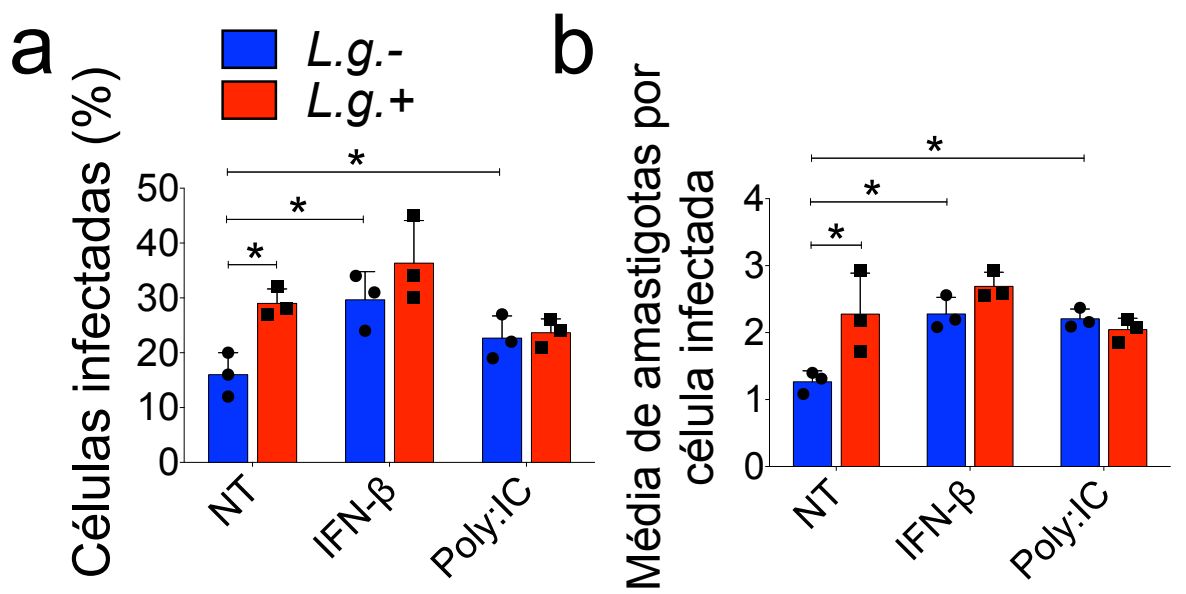

Figura 23. Poly:IC e IFN- $\beta$ aumentam a sobrevivência de parasitos L.g.-. (a,b) BMDMs de animais C57BL/6 foram infectados com parasitos metacíclicos de L.g.- ou L.g.+ em MOI de 1. Após $1 \mathrm{~h}$ de infecção, as células foram lavadas e substituídas por meio fresco contendo Poly: IC $(5 \mu \mathrm{g} / \mathrm{mL})$ ou IFN- $\beta(1000 \mathrm{U} / \mathrm{mL})$, e deixadas por 48 horas em cultura. Os resultados são mostrados como média \pm DP. A análise estatística foi realizada pelo teste $t$ de Student não pareado, e $P<0,05\left(^{*}\right)$ foi considerado estatisticamente significativo. Um experimento representativo de dois experimentos independentes realizados com replicatas técnicas é mostrado.

\subsection{LRV aumenta a indução de autofagia induzida por L.g. via TLR3/IFN- $\beta$ para}

\section{degradar NLRP3 e ASC.}

Vários trabalhos na literatura têm demonstrado que diversos vírus podem induzir autofagia (DERETIC; SAITOH; AKIRA, 2013). Além disso, o papel do IFN tipo 
I na indução da autofagia também já é conhecido (SCHMEISSER; BEKISZ; ZOON, 2014). Desta forma, nos perguntamos se o LRV promove a autofagia em macrófagos. Inicialmente, transduzimos BMDMs com lentivírus expressando o marcador autofagossomal LC3 fusionado à proteína verde fluorescente (LC3-GFP), e utilizamos esta ferramenta para avaliar a indução de punctas de LC3 em resposta à infecção, conforme descrito anteriormente (FRANCO et al., 2017). Os resultados demonstram que L.g.- e L.g.+ induzem a formação de punctas de LC3 em 3, 9 e 24 horas de infecção, sendo que nos últimos dois tempos avaliados, a indução de autofagia mostrou-se significativamente maior em células infectadas por L.g.+ (Fig. 24a,b). Curiosamente, as células não-infectadas também têm um número aumentado de punctas de LC3 24 horas após a infecção por L.g.+, o que sugere que mediadores solúveis liberados frente à infecção, como IFN do tipo I, também poderiam induzir autofagia em células não-infectadas (Fig. 24a). LC3 é expressa como uma proteína de $18 \mathrm{KDa}$ (LC3-I) no citosol e, durante o processo autofágico, é convertida em uma proteína de 16 KDa (LC3-II) (DERETIC; SAITOH; AKIRA, 2013). Baseado neste conhecimento, realizamos western blot para avaliar a indução de autofagia pelos clone de L.g., confirmando que L.g.+ é mais eficiente na indução do processo autofágico (Fig. 24c). A rapamicina foi usada como controle positivo. Em seguida, BMDMs foram tratados com Poly:IC e IFN- $\beta$, e verificamos que a estimulação dos macrófagos com ambos os agonistas é suficiente para desencadear autofagia e resgatar a capacidade de L.g.- em induzir autofagia (Fig. 24d). Corroborando estes dados, a presença do TLR3 é necessária para a indução de autofagia mediada por LRV (Fig 24e). Coletivamente, nossos dados indicam que o LRV promove a autofagia durante a infecção por L. guyanensis via TLR3 e IFN- $\beta$. 
Os autofagossomos podem direcionar diversos componentes citosólicos à degradação, como proteínas citoplasmáticas e organelas danificadas ou senescentes, sendo um processo chave na regulação da montagem e ativação do inflamassoma (SHIBUTANI et al., 2015). Tendo como base nossos achados com os clones de L.g., que indicam que o LRV aumenta a indução de autofagia enquanto diminui a ativação do NLRP3 pelo parasito, hipotetizamos que a autofagia poderia regular diretamente a expressão protéica dos componentes do inflamassoma. Através de ensaios de Western Blotting, demonstramos que a presença do LRV aumenta a degradação de NLRP3 e ASC, mas não de Casp1, de forma totalmente dependente de TLR3 (Fig. 24f). Interessantemente, o aumento da degradação dos componentes do inflamassoma por L.g. + não ocorre a nível transcricional, uma vez que não observamos diferenças na expressão de NLRP3, ASC e Casp1 frente à infecção pelos dois clones de L.g., nos diferentes tempos analisados (Fig. 25a-f). 


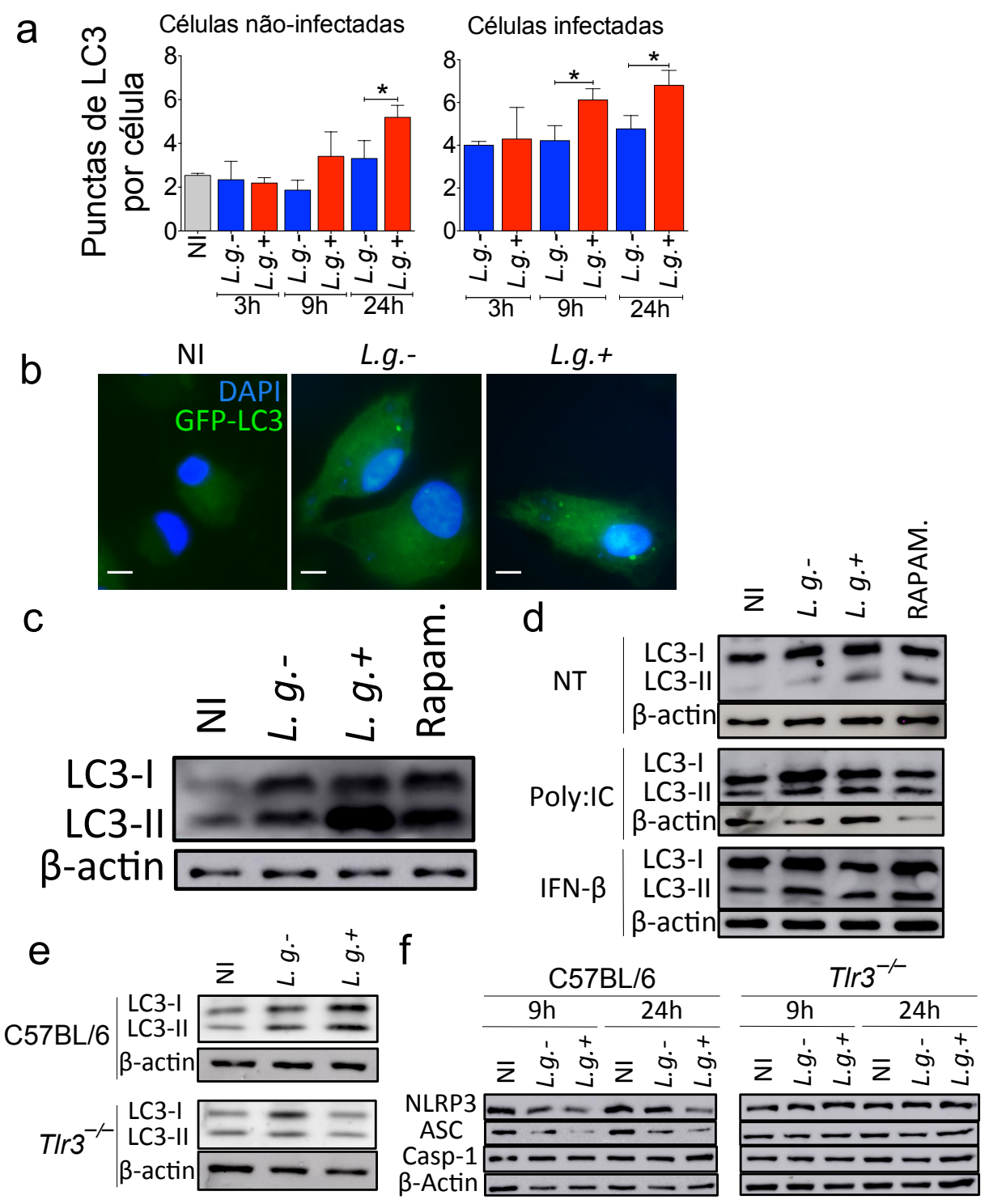

Figura 24. LRV exacerba a autofagia induzida por L.g. via TLR3, desencadeando a degradação de NLRP3 e ASC. (a) Imunofluorescência de BMDMs oriundos de animais C57BL/6 transduzidos com vetor lentiviral expressando LC3-GFP, não-infectados (NI) ou infectados com L.g.- ou L.g.+ durante 3, 9 e 24 horas. As células foram marcadas com DAPI (núcleo) e o número médio de punctas de LC3 por célula não-infectada ou infectada foi quantificado. (b) Imagens de fluorescência representativas de BMDMs não infectados (NI) ou infectados por 24 horas. Barra de escala: $5 \mu \mathrm{M}$. (c) Western Blotting (WB) para LC3-I, LC3-II e $\beta$-actina (controle) em macrófagos não infectados (NI) ou infectados por $24 \mathrm{~h}$ com L.g.- ou L.g.+. A rapamicina (Rapam., $1 \mu \mathrm{M}$ ) foi usada como controle positivo. (d) BMDMs foram infectados e tratados com Poly: IC $(5 \mu \mathrm{g} / \mathrm{mL})$ ou IFN- $\beta(1000 \mathrm{U} / \mathrm{mL})$ no momento da infecção e deixados em cultura por 24 horas. WB para LC3-I, LC3-II e $\beta$-actina (controle) foi realizado. A rapamicina $(1 \mu \mathrm{M})$ foi usada como controle positivo. (e) BMDMs de animais C57BL/6 e TIr3 ${ }^{-/}$foram infectados com L.g.- ou L.g.+. WB para LC3 foi realizado após 24 horas de infecção. (f) Após 9 ou 24 horas após a infecção, a expressão de NLRP3, ASC e Casp1 em macrófagos $\mathrm{NI}$ ou infectados pelos clones de L.g. foi avaliada. A $\beta$-actina foi usada como controle. Os resultados (a) são mostrados como média \pm DP. A análise estatística foi realizada pelo teste $t$ de Student não pareado, e $P<0,05\left(^{*}\right)$ foi considerado estatisticamente significativo. Um experimento representativo de pelo menos dois ensaios 
independentes é demonstrado. Os dados mostrados em (a) são a média de triplicatas técnicas.

\section{$6 \mathrm{~h}$}
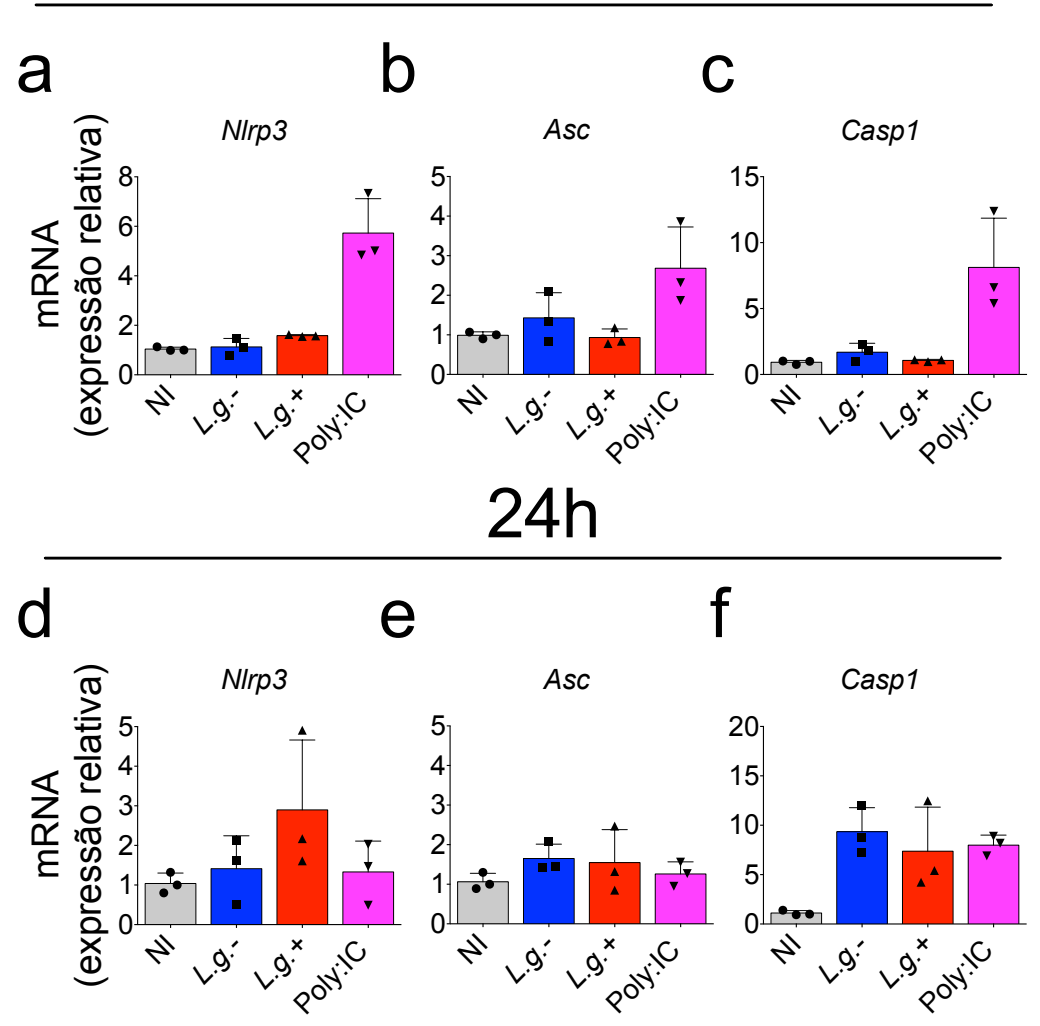

Figura 25. LRV não altera a transcrição dos componentes do inflamassoma. BMDMs de animais C57BL/6 foram infectados por L.g.- ou L.g.+. Após 6 (a-c) ou 24 horas de infecção (d-f), o RNA total foi extraído. Os níveis de transcrição gênica de NIrp3 (a,d), Asc $(\mathbf{b}, \mathbf{e})$ e casp1 (c,f) foram determinados por qPCR. Poly:IC $(5 \mu \mathrm{g} / \mathrm{mL})$ foi usado como controle positivo. Os resultados são mostrados como média \pm DP. Um experimento representativo de um total de dois experimentos independentes realizados com replicatas técnicas é mostrado.

\subsection{LRV ativa TLR3 para induzir autofagia e limitar a ativação de NLRP3 por} L.g.

Nossos achados indicam que a estimulação de TLR3 pelo LRV induz autofagia e diminui os níveis intracelulares das proteínas NLRP3 e ASC, sugerindo que a autofagia possa modular diretamente a ativação do inflamassoma. Para testar esta hipótese, silenciamos ATG5 em BMDMs primários e avaliamos a ativação do 
inflamassoma em resposta à infecção por L.g.+ e L.g.-. Nesta abordagem, utilizamos vetor lentiviral que codifica uma sequência shAtg5 que silencia eficientemente a expressão protéica de ATG5 (Fig. 26a). Nossos dados demonstram que o silenciamento de ATG5 aumenta a produção de IL-1ß em resposta à ambos os clones de L.g. (Fig. 26b), confirmando nossa hipótese de que a autofagia seria um regulador negativo do inflamassoma em resposta à infecção por Leishmania. Interessantemente, a ativação reduzida do inflamassoma observada em células infectadas por L.g.+, quando comparada à L.g.-, foi abolida em BMDMs silenciados para ATG5 (Fig. 26b). Em seguida, utilizamos BMDMs de camundongos deficientes geneticamente para Atg5, nos quais sequências loxP foram inseridas nos alelos de Atg5, fazendo com que este gene fosse especificamente deletado em células mielóides, após o cruzamento com camundongos $L y s M^{C r e /+}$. Estes animais são, portanto, denominados $L y s M^{C r e /+} / A \operatorname{tg} 5^{F L / F L}$, e seus controles possuem apenas um alelo com sequências loxP, sendo denominados $L y s M^{C r e /+} / A t g 5^{F L /+}$. Estes camundongos serão chamados apenas de $A \operatorname{tg} 5^{F L / F L}$ e $A \operatorname{tg} 5^{F L /+}$, respectivamente, a partir de agora. Através do ensaio de FLICA, confirmamos a maior ativação de Casp1 por L.g.- em BMDMs Atg5 $5^{F L /+}$, mas essa diferença foi abolida nas células $\operatorname{Atg} 5^{F L / F L}$ (Fig. 26c,d). Resultados semelhantes foram obtidos quando medimos a produção de IL-1ß (Fig. 26e). De forma similar, a estimulação de IFN- $\beta$ restaurou a inibição do inflamassoma por L.g.- em BMDMs $A t g 5^{F L /+}$, mas não na ausência de autofagia $\left(A \operatorname{tg} 5^{F L / F L}\right)$ (Fig. 26e). Dado que a degradação das mitocôndrias senescentes e a produção de ROS via mitofagia têm se mostrado como importantes mecanismos de limitação do inflamassoma (NAKAHIRA et al., 2011), avaliamos um possível efeito mediado pelo LRV na indução de mitofagia. Utilizando BMDMs sem Parkin, uma E3-ubiquitina ligase crítica para o processo mitofágico $\left(\right.$ Prkn $\left.^{-/}\right)$(SLITER 
et al., 2018), descobrimos que a inibição do inflamassoma por LRV independe da mitofagia (Fig. 26f). Em seguida, utilizamos células $A \operatorname{tg} 5^{F L / F L}$ para investigar o efeito da autofagia na degradação de NLRP3 e ASC induzida pelo vírus. Confirmando dados anteriores indicando que LRV promove a degradação de NLRP3 e ASC via TLR3, demonstramos que este processo requer também a presença de ATG5 (Fig. 26g). Por fim, avaliamos a replicação intracelular de L.g.+ e L.g.- em BMDMs $A \operatorname{tg} 5^{F L /+}$ e $\operatorname{Atg} 5^{F L / F L}$, demonstrando que o LRV confere maior resistência e capacidade replicativa à L.g., de forma dependente de ATG5 (Fig. 26h,i). Em conjunto, estes dados indicam que o LRV utiliza a autofagia para limitar a ativação do inflamassoma e promover melhor sobrevivência ao parasito dentro dos macrófagos. 


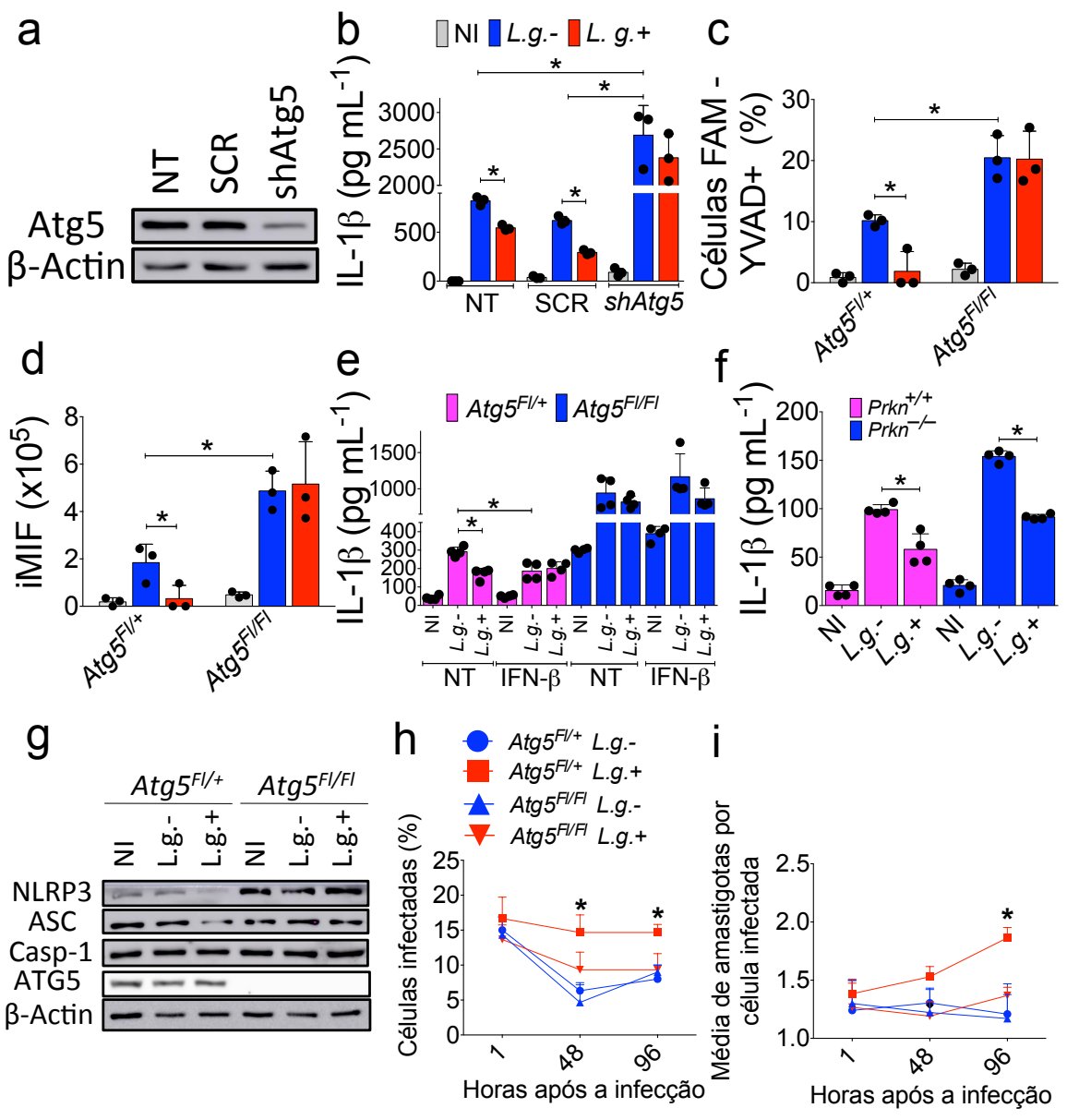

Figura 26. LRV limita a ativação do inflamassoma por L.g. via autofagia. (a,b) BMDMs foram silenciados com uma sequência scramble (SCR) ou shRNA específico para Atg5, e então infectados por L.g.- ou L.g.+. A eficiência do processo (a) foi confirmada por WB. $\beta$ actina foi utilizada como controle do WB. (b) Após 24 horas de infecção, os níveis de IL-1 $\beta$ foram determinados por ELISA em sobrenadantes livres de células. NT: BMDMs não transduzidos. (c,d) BMDMs de camundongos LysM $\mathrm{Cre}^{\mathrm{C} /+} / \mathrm{Atg} 5^{\mathrm{Fl/+}}$ (controle de ninhada) ou LysM $^{\text {Cre/+ }} /$ Atg $^{\text {Fl/FI }}$ foram infectados com L.g.- ou L.g.+ por 24 horas, e a ativação de Casp1 foi avaliada por FLICA (FACS). A porcentagem de células Casp1 + (FAM-YVAD) (c) e o iMIF (d) são mostrados. (e) Durante a infecção, BMDMs foram não-tratados ou tratados com IFN$\beta(1000 \mathrm{U} / \mathrm{mL})$ no momento da infecção. Níveis de IL-1 em SNs livres de células foram quantificados por ELISA, após 24 horas de infecção. (f) ELISA para IL-1 $1 \beta$ em BMDMs deficientes em Parkin $\left(\right.$ Prkn $\left.^{-/}\right)$e seu respectivo controle de ninhada $\left(\right.$Prkn $\left.^{+/+}\right)$após 24 horas de infecção. (g) WB para componentes do inflamassoma de NLRP3 e ATG5 em BMDMs de Lys $M^{\text {Cre/+ }} / A t g 5^{F / /+}$ e LysM ${ }^{C r e /+} / A t g 5^{F / F I}$ após 24 horas de infecção com L.g.- ou L.g.+. $\beta$-actina foi usada como controle do WB. (h,i) BMDMs foram infectados com promastigotas metacíclicos de L.g.- ou L.g.+, em MOI 1. $1 \mathrm{~h}$ após a infecção, as células foram lavadas e deixadas em cultura durante 1, 48 ou $96 \mathrm{~h}$. A porcentagem de células infectadas (h) e o número médio de amastigotas por célula infectada (i) foram avaliadas por Panotico Giemsa. Os resultados são mostrados como média \pm DP. A análise estatística foi realizada pelo teste $t$ de Student não pareado. $P<0,05\left(^{*}\right)$ foi considerado estatisticamente significativo. Um experimento representativo de pelo menos dois experimentos independentes realizados em replicatas técnicas é mostrado. 


\subsection{O material genético do LRV encontra-se em EVs do parasito, é} transmissível e modula a resposta imune em macrófagos.

Em artigo recentemente publicado, foi demonstrado que o LRV encontra-se compartimentalizado em vesículas extracelulares (EVs) derivadas de L. guyanensis (ATAYDE et al., 2019), nos levando a investigar se a liberação de EVs LRV+ por L.g.+ poderia ser um dos mecanismos de ativação de TLR3 e de toda a cascata de sinalização que culmina em menor ativação do inflamassoma. Inicialmente, purificamos EVs (ATAYDE et al., 2015) de ambos os clones (L.g.- e L.g.+) e confirmamos a presença de RNA do LRV dentro das vesículas de L.g.+ (Fig. 27a). Interessantemente, o perfil de EVs secretados por cada clone é muito semelhante, com o tamanho médio da maioria das vesículas variando de 50 a 200 nm, sugestivo de exossomos (COLOMBO; RAPOSO; THÉRY, 2014) (Fig. 27b). Em seguida, tratamos diferentes BMDMs com EVs derivadas de ambos os clones, no momento da infecção. Enquanto EVs derivadas de L.g.- não afetaram a produção de IL-1ß frente à infecção por ambos os clones, EVs oriundas de L.g.+ resgataram a capacidade de L.g.- em bloquear a ativação do inflamassoma, de forma dependente de TLR3 (Fig. 27c). Os mesmos efeitos foram observados para células LysM $M^{C r e /+} / A t g 5^{F L /+}$, mas não para BMDMs $L y s M^{C r e /+} / A \operatorname{tg} 5^{F L /+}$ (Fig. 27d). Em seguida, avaliamos a transmissibilidade do LRV via EVs, tratando promastigotas de fase estacionária de L.g.- com EVs derivadas de L.g.+, como previamente descrito (ATAYDE et al., 2019). Observamos que o material genético do LRV foi eficientemente transferido via EVs para L.g.- (Fig. 27e), resgatando os efeitos do LRV na produção de IL-1ß (Fig. 27f) e na capacidade de L.g. em resistir ao killing exercido pelos macrófagos (Fig. 27g-j). Em conjunto, estes resultados sugerem que 
o LRV pode ser transmitido via EVs para modular a ativação do inflamassoma e a sobrevivência do parasito em BMDMs.

a
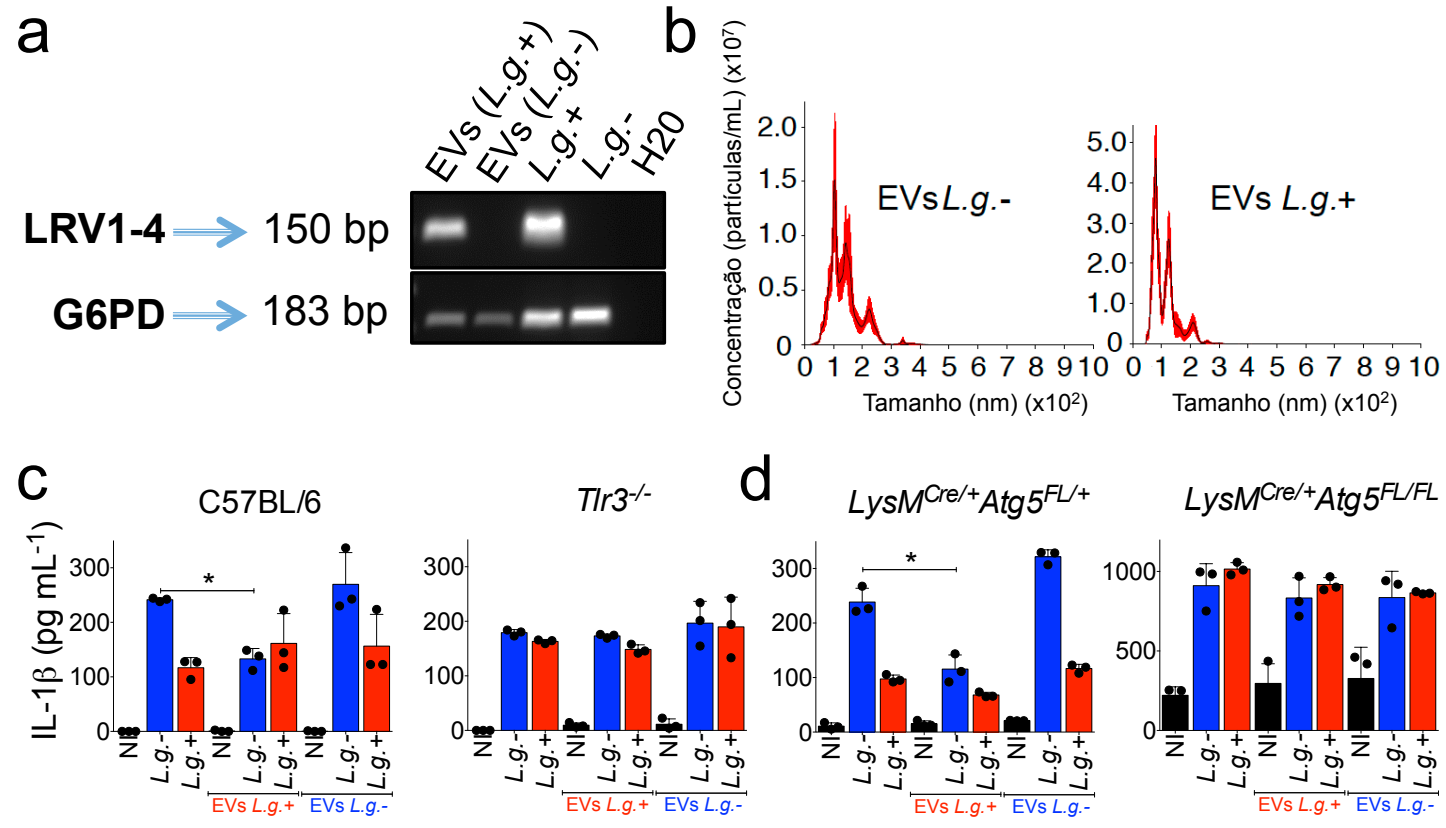

e
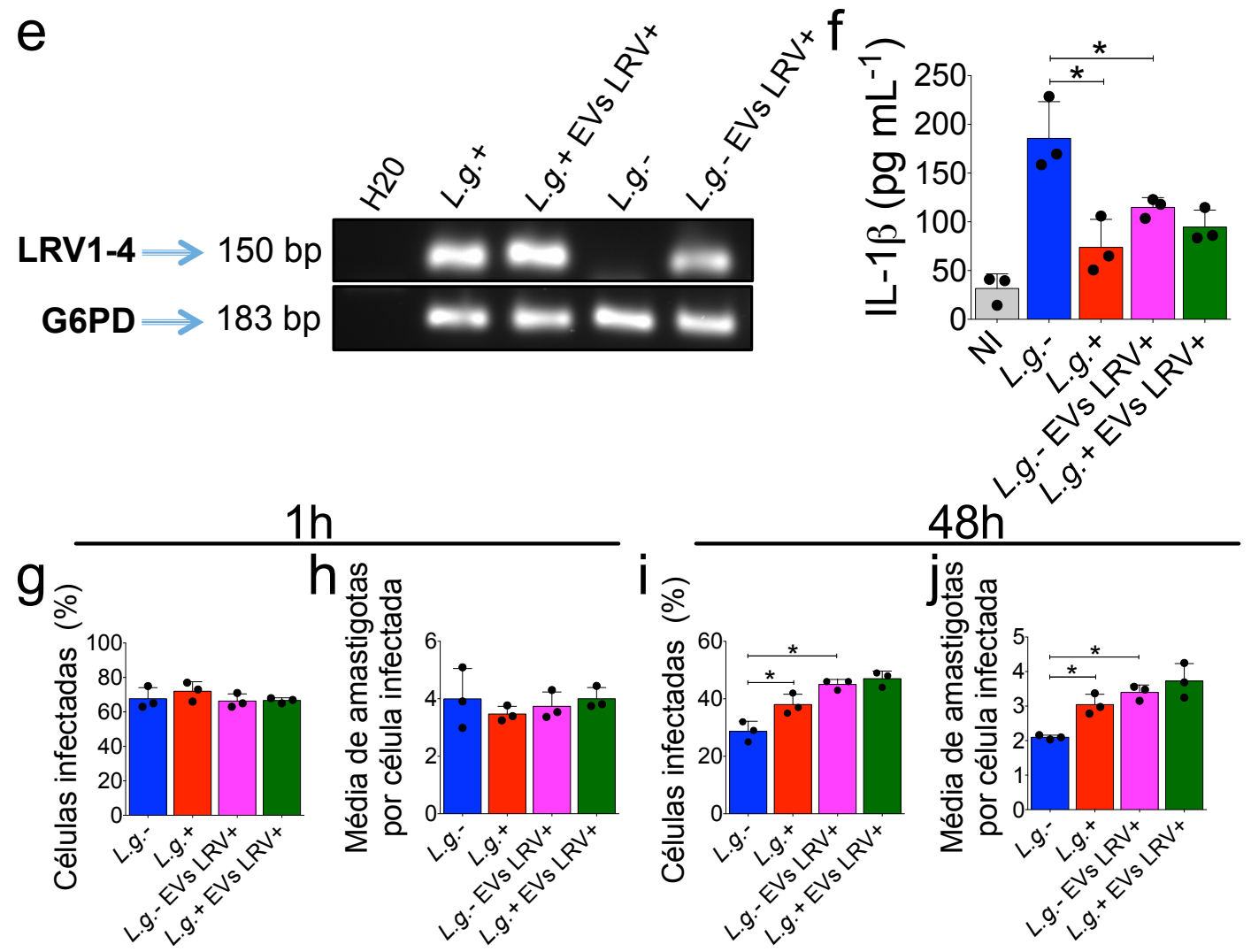

Figura 27. O RNA viral dentro das vesículas extracelulares (EVs) é transmissível e regula a ativação do inflamassoma por L.g. (a) PCR de EVs purificadas de ambos os clones de L.g., para G6PD e LRV. $\mathrm{H}_{2} \mathrm{O}$ foi utilizado como controle de amplificação, enquanto 
os extratos de parasitos de ambos os clones foram utilizados como controles de amplificação para LRV. (b) Análise de rastreamento de nanopartículas nas EVs produzidas

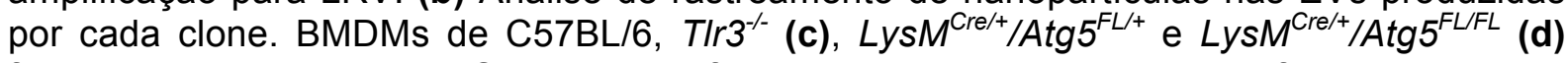
foram estimulados com LPS e depois infectados com promastigotas em fase estacionária em MOI 10. No momento da infecção, as células foram tratadas com EVs purificadas de L.g.- ou L.g.+. 24 horas depois, os níveis de IL-1 $\beta$ foram determinados por ELISA em sobrenadantes livres de células. NI: não infectado. (e, f) Promastigotas de fase estacionária de L.g.- ou L.g.+ (Controle) foram incubados com EVs derivadas de L.g.+ por 2 horas, em meio Schneider (L.g + EVs LRV+ e L.g.- EVs LRV+). Em seguida, os parasitos foram isolados para extração de RNA e PCR (e) ou utilizados para infecção em BMDMs, em MOI

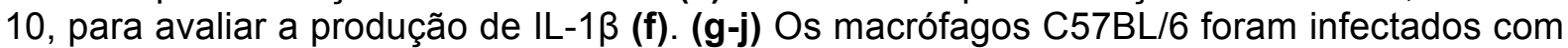
estes quatro tipos de parasitos em MOI 5 por $1(\mathbf{g}, \mathbf{h})$ ou 48 horas $(\mathbf{i}, \mathbf{j})$. O ensaio de killing foi realizado através da quantificação da porcentagem de células infectadas e do número médio de parasitos por célula infectada. Os resultados são apresentados como média \pm DP e a análise estatística foi realizada pelo teste $t$ de Student não pareado. $P<0,05\left({ }^{*}\right)$ foi considerado estatisticamente significativo. Um experimento representativo de pelo menos dois experimentos independentes realizados com replicatas técnicas é mostrado.

\subsection{LRV agrava a infecção por L.g. in vivo via TLR3, ATG5, NLRP3, ASC e}

\section{CASP1.}

Nossos dados revelam um mecanismo induzido por LRV durante a infecção por L.g., no qual o vírus ativa TLR3 para induzir a autofagia, que inibe a ativação do inflamassoma e aumenta a sobrevivência do parasito em BMDMs. A fim de investigar se estes achados in vitro são fisiologicamente relevantes durante a infecção in vivo, infectamos camundongos C57BL/6 e NIrp3 $3^{-/}$com L.g.- ou L.g.+. Apesar da infecção por L.g.+ induzir o aumento da espessura da orelha quando comparada à L.g.-, em animais C57BL/6 (Fig. 28a e Fig. 29a), este efeito não foi observado em camundongos NIrp3 $3^{-/}$(Fig. 28b), Asc ${ }^{-/}$(Fig. 29b), Casp $1^{-/}$(Fig. 29c) ou $\mathrm{TIr}^{-/}$(Fig. 29d). Adicionalmente, a carga parasitária de animais selvagens infectados por L.g.+ mostrou-se aumentada frente a parasitos L.g.- na orelha e linfonodo drenante, mas não em camundongos deficientes em NLRP3 (Fig. 28c,d), ASC, CASP1 ou TLR3 (Fig. 29e,f). Por fim, infectamos animais $A \operatorname{tg} 5^{\mathrm{FL} /+}$ e $\operatorname{Atg} 5^{F L / F I}$ com ambos os clones de L.g. Embora as espessuras das orelhas não tenham apresentado diferenças entre ambos os animais (Fig. 28e,f), camundongos $\operatorname{Atg} 5^{F L /+}$ 
exibiram quantidades de parasitos aumentadas na orelha (Fig. 28g) e linfonodo (Fig.

28h), fenômeno não observado nos $\operatorname{Atg} 5^{F L / F I}$.
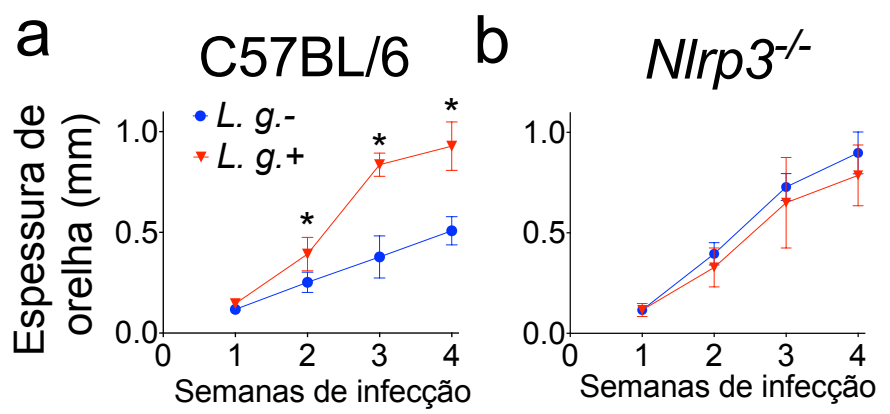

C

d

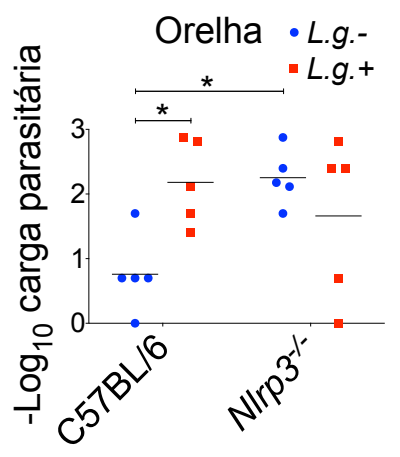

LN
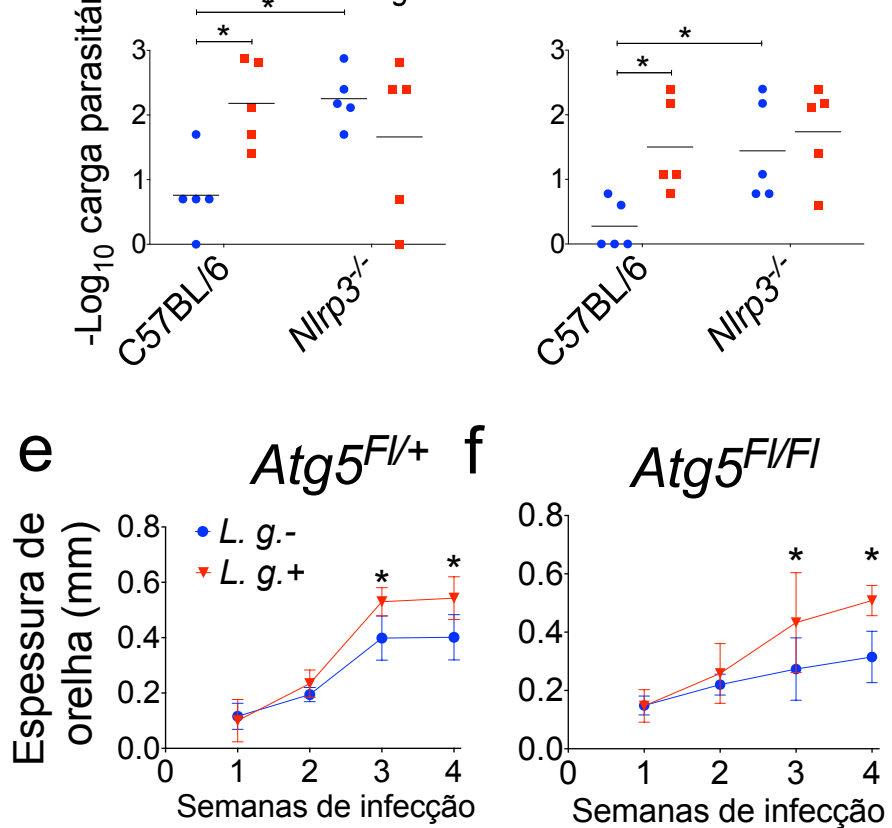

9

$\mathrm{h}$
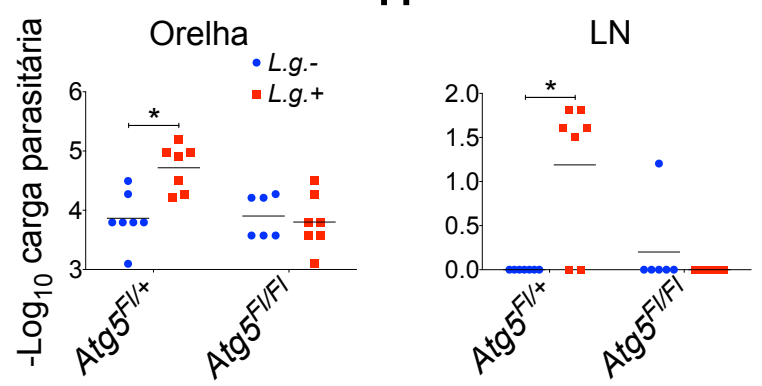

Figura 28. LRV exacerba a infecção por L.g. via NLRP3 e autofagia in vivo. (a) camundongos C57BL/6 e (b) N/rp3 $3^{-/}$foram infectados com $10^{5}$ promastigotas Metacíclicos de L.g.- ou L.g.+ ( $n=5$ camundongos por grupo), e as medidas de espessura da orelha foram acompanhadas semanalmente. 4 semanas após a infecção, a carga parasitária foi 
determinada na orelha (c) e no linfonodo drenante da garganta (d). Animais

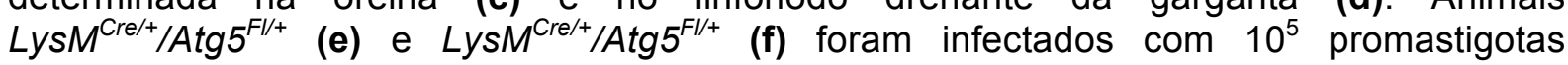
Metacíclicos de L.g.- ou L.g.+ e as espessuras das orelhas foram seguidas semanalmente. 4 semanas após a infecção, a carga de parasitos foi determinada na orelha (g) e no linfonodo drenante (h). Os resultados são apresentados como média $(\mathbf{c}, \mathbf{d}, \mathbf{g}, \mathbf{h})$ ou média $\pm \mathrm{dp}(\mathbf{a}, \mathbf{b}$, e, f) a partir de dados agrupados de dois experimentos independentes ( $n=6$ a 7 camundongos por grupo). A análise estatística foi realizada por ANOVA de duas vias com o teste de comparação múltipla de Bonferroni. $P<0,05\left({ }^{*}\right)$ foi considerado estatisticamente significante. Um experimento representativo de pelo menos dois experimentos independentes com replicatas biológicas é mostrado.

a

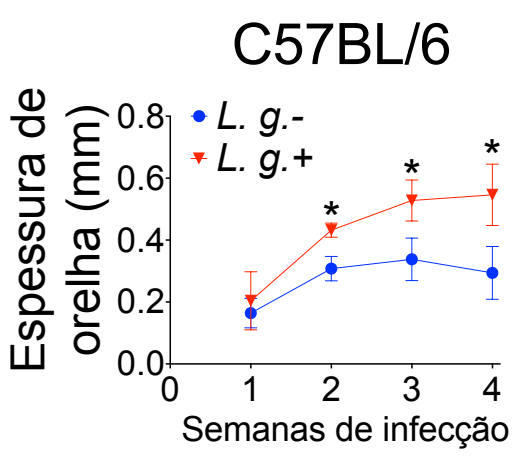

b $\quad \mathrm{Asc}^{-/}$

C
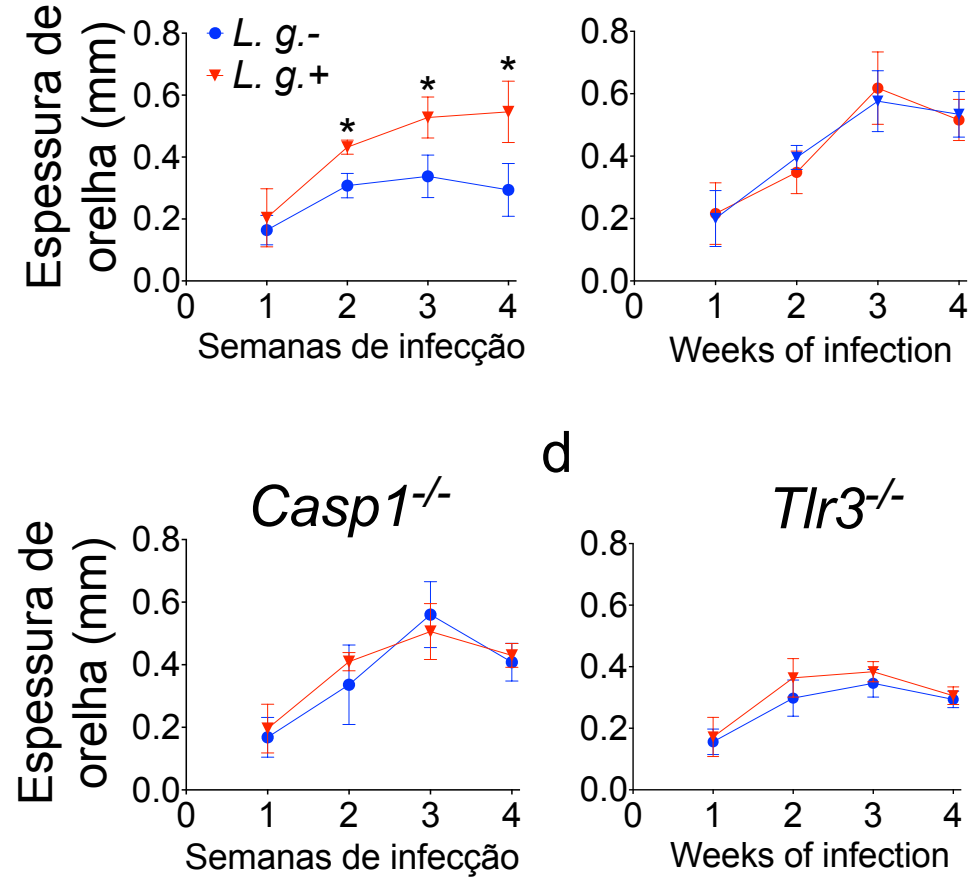

d
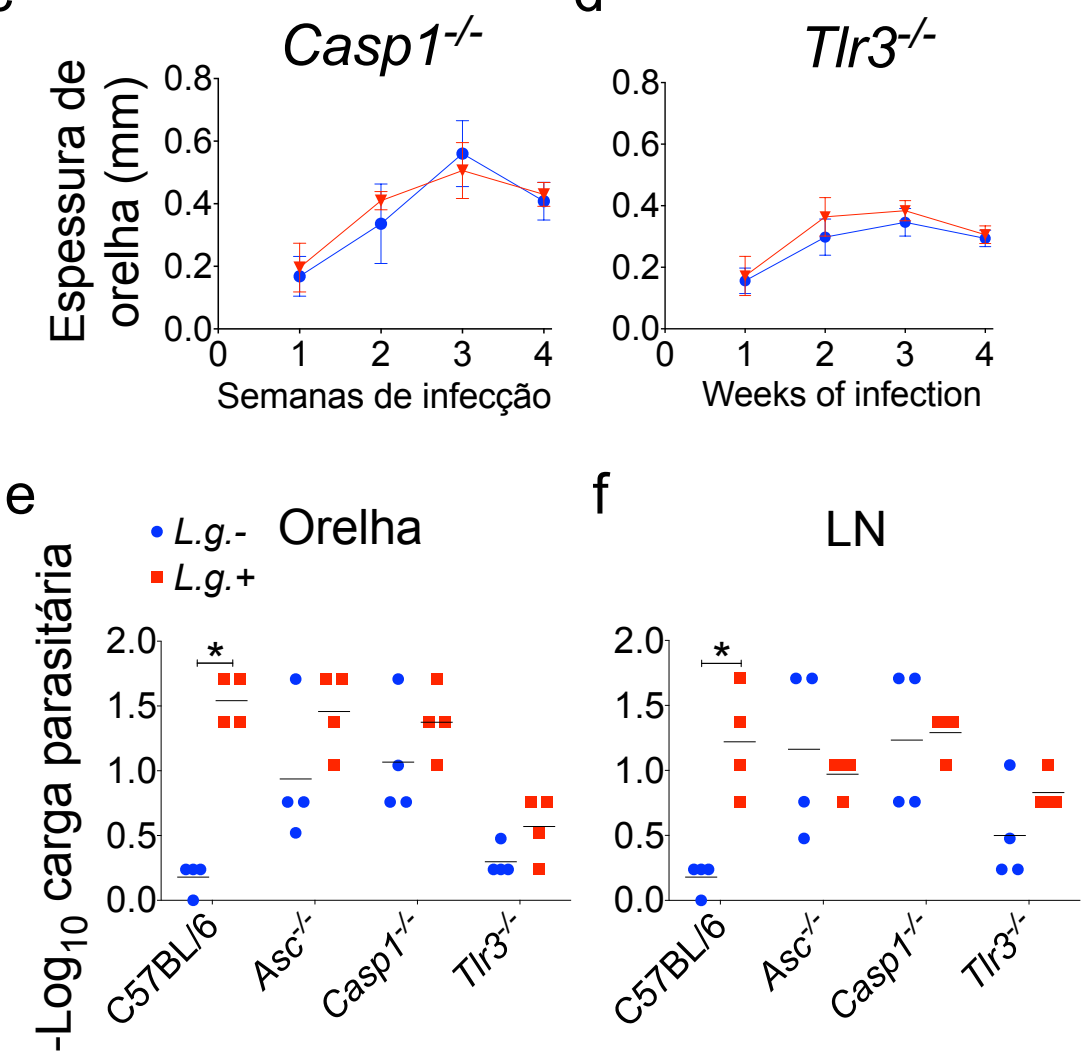

Figura 29. O LRV exacerba a infecção por L.g. via ASC, CASP1 e TLR3 in vivo. (a-d) Camundongos C57BL/6 (a), Asc ${ }^{-/}$(b), $\operatorname{Casp}^{-/-}$(c) e $T / 3^{-/}$(d) foram infectados com $10^{6}$ promastigotas em fase estacionária de L.g.- ou L.g.+ $(n=4$ animais por grupo), e as espessuras das orelhas foram seguidas semanalmente (a-d). 4 semanas após a infecção, a 
carga parasitária foi determinada na orelha (e) e no linfonodo drenante (f). Os resultados são apresentados como média (e, f) ou média \pm dp (a, b, c, d) de dados obtidos de dois experimentos independentes realizados com replicatas biológicas. A análise estatística foi realizada por ANOVA de duas vias com o teste de comparação múltipla de Bonferroni. $P<0,05\left(^{*}\right)$ foi considerado estatisticamente significativo.

\subsection{LRV limita a ativação de NLRP3 por L.g. via TLR3 em macrófagos humanos.}

A descoberta de uma via de sinalização desencadeada pelo LRV que modula a resposta imune inata em modelo murino de infecção in vitro, nos fez perguntar se os mesmos mecanismos ocorreriam em macrófagos humanos. Para responder esta pergunta, diferenciamos monócitos CD14+ purificados de diferentes doadores saudáveis em macrófagos, cultivando estas células na presença de GMCSF durante 7 dias. Após este período, infectamos as células com os clones de L.g. e medimos a ativação do inflamassoma, demonstrando que ambos induzem a clivagem de IL-1ß (Fig. 30a) e Casp1 (Fig. 30b) em macrófagos humanos. Assim como observado em células de camundongos, L.g.+ induz menor ativação do inflamassoma em macrófagos humanos quando comparado à L.g.- (Fig. 30a,b). Optamos por estimular macrófagos humanos com o agonista de TLR2, PAM(3)CSK(4), ao invés do LPS, uma vez que o LPS é conhecido por induzir a ativação do inflamassoma dependente de TLR4 em monócitos humanos (GAIDT et al., 2016). Depois, testamos se o LRV afeta a indução de autofagia por L.g. em células humanas. Semelhante aos nossos dados utilizando BMDMs, a infecção com L.g.+ induz autofagia de forma mais eficiente que L.g.- (Fig. 30c, d). Para investigar os mecanismos de inibição promovidos pelo LRV no inflamassoma nestas células, quantificamos a produção de IL-1ß e Casp1 p20 em resposta à infecção por L.g.- e L.g.+ em células tratadas com $\mathrm{KCl}$ (que prejudica o efluxo de potássio e, consequentemente, a ativação de NLRP3) ou Poly: IC (agonista de TLR3). NaCl foi 
usado como controle do tratamento com KCl. Nossos dados indicam que o LRV limita a ativação de NLRP3 e Poly: IC resgata o efeito inibitório do LRV em células infectadas por L.g.- (Fig. 30e,f). Como esperado, o tratamento com $\mathrm{KCl}$, mas não com $\mathrm{NaCl}$, inibiu completamente a produção de IL-1ß e Casp1 p20 em resposta à infecção, confirmando a participação do inflamassoma de NLRP3 em células humanas (Fig. 30e,f). Embora o tratamento com KCl e Poly: IC não tenha interferido na internalização dos parasitos (Fig. $\mathbf{3 0 g}, \mathbf{h}$ ), ambos os tratamentos resgataram o fenótipo de L.g.- na replicação intracelular, como observado para L.g.+. Estes dados são mostrados tanto pela porcentagem de células infectadas (Fig. 30i) quanto pelo número médio de parasitos por célula infectada (Fig. 30j). Em conjunto, estes resultados expandem para as células humanas nossos achados mecanísticos mostrados em BMDMs sobre os efeitos biológicos do LRV durante a infecção por Leishmania. 


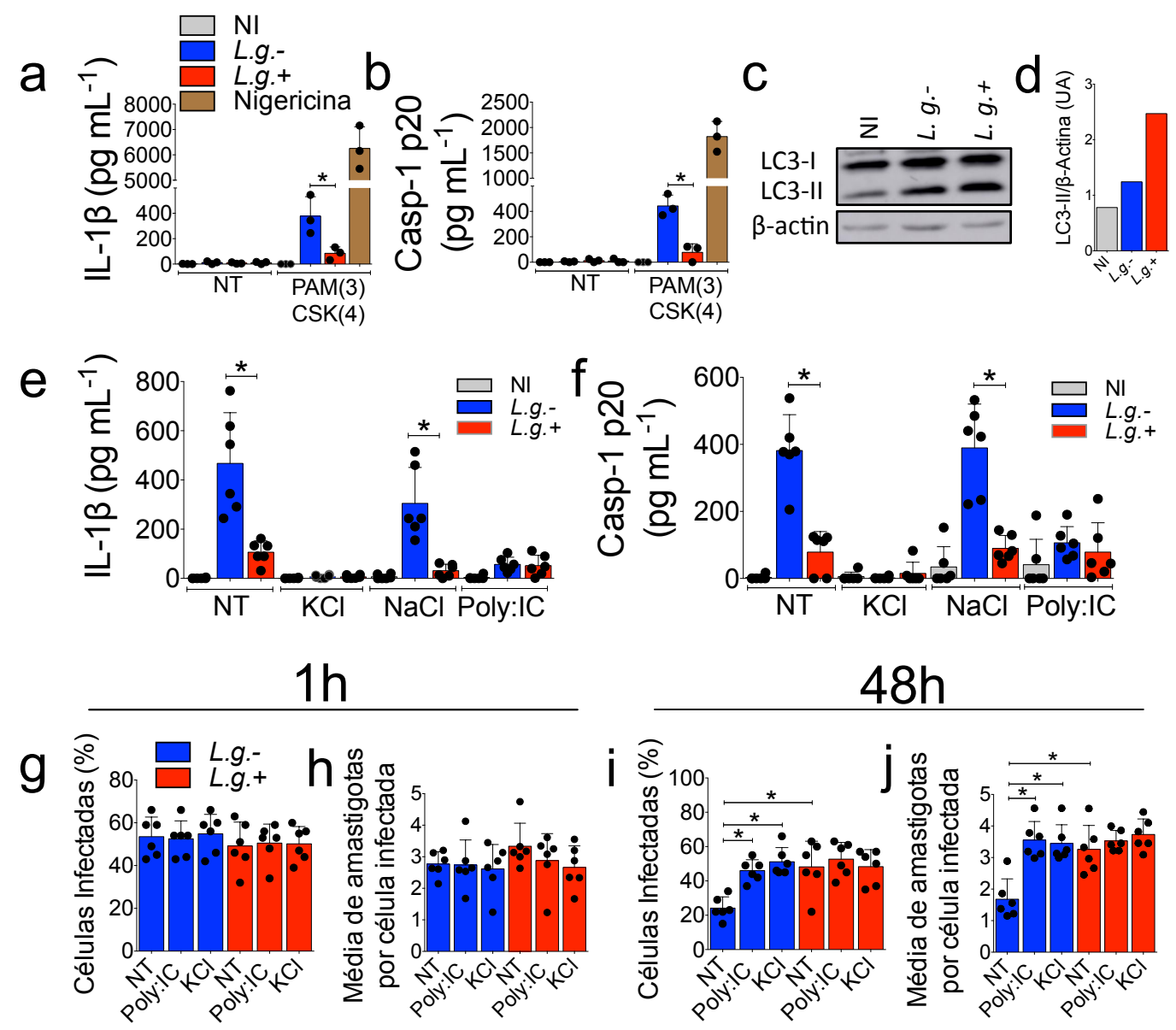

Figura 30. O LRV modula a ativação do inflamassoma de NLRP3 em macrófagos humanos via TLR3. Macrófagos derivados de monócitos humanos foram estimulados com $\operatorname{PAM}(3)$ CSK(4) $(300 \mathrm{ng} / \mathrm{mL})$ durante 4 horas, e depois infectados com L.g.- ou L.g.+. Os níveis de IL-1 $\beta$ (a) e Casp1 p20 (b) foram determinados em sobrenadantes livres de células por ELISA. (c) Os macrófagos humanos de 3 doadores diferentes foram juntados, plaqueados e deixados não-infectados (NI) ou infectados com L.g.- ou L.g.+. A expressão de LC3-I e LC3-II foi medida por Western Blotting. (d) A quantificação de LC3-II foi realizada dividindo os valores de densitometria LC3-II fornecidos por ImageJ por $\beta$-actina (unidades arbitrárias, UA). (e, f) Macrófagos humanos tratados com PAM(3)CSK(4) foram deixados sem tratamento (NT) ou tratados com Poly: IC $(5 \mu \mathrm{g} / \mathrm{mL}), \mathrm{NaCl}(100 \mathrm{mM})$ ou $\mathrm{KCl}(100 \mathrm{mM})$ no momento da infecção. Os níveis de IL-1ß (e) e Casp1 p20 (f) foram avaliados em sobrenadantes livres de células por ELISA. (g-j) Macrófagos humanos foram tratados como descrito acima para avaliar killing intracelular por Panótico Giemsa. A porcentagem de

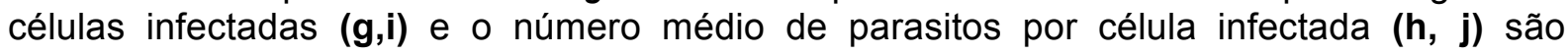
mostrados em 1 e 48 horas após a infecção. Os resultados são mostrados como média \pm DP. A análise estatística foi realizada pelo teste $t$ de Student não pareado, e $P<0,05\left(^{*}\right)$ foi considerado estatisticamente significativo. Um experimento representativo de pelo menos dois ensaios independentes realizados, é mostrado. Cada ponto nos gráficos representa macrófagos de um doador individual. Os resultados são demonstrados como a média de replicatas biológicas. 


\subsection{Leishmania spp. ativa caspase-11 e a via não-canônica de NLRP3.}

Conforme mencionado na introdução, a ativação de NLRP3 pode ocorrer de forma canônica, pela geração direta de DAMPs, que ativam e oligomerizam o sensor e induzem a montagem do inflamassoma, ou através da via não-canônica, mediada por caspase-11 (CASP11) (LAMKANFI; DIXIT, 2014b; BROZ; DIXIT, 2016). Neste caso, apenas um PAMP (LPS bacteriano) (KAYAGAKI et al., 2011; HAGAR et al., 2013) e um DAMP (lipídeos oxidados) (ZANONI et al., 2016) são reportados na literatura como ativadores desta outra caspase inflamatória. Portanto, decidimos investigar se CASP11 seria ativada também no contexto de infecções parasitárias, como por exemplo, Leishmania. Para isto, ao invés de L. guyanensis, inicialmente utilizamos a cepa $\mathrm{PH} 8$ de $L$. amazonensis, a primeira espécie que ativa $\mathrm{O}$ inflamassoma de NLRP3 a ser reportada (LIMA-JUNIOR et al., 2013a). Inicialmente, avaliamos se CASP11 contribui para a ativação não-canônica de NLRP3, infectando BMDMs WT, NIrp3 $3^{--}$e Casp $11^{-/}$com L. amazonensis, e quantificando a produção de

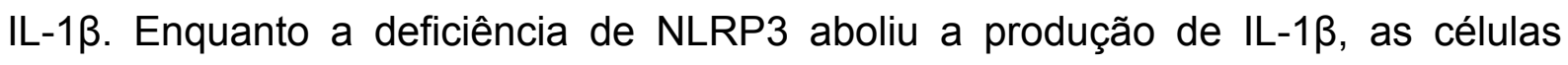
Casp $11^{/-}$apresentaram secreção de IL-1 $\beta$ significativamente diminuída (Fig. 31a), mas não de TNF-a (Fig. 31b). Utilizando estimulação prévia com TNF- $\alpha$ ao invés de LPS, demonstramos que em condições livres de endotoxina, CASP11 também é necessária para a ativação eficiente do inflamassoma de NLRP3 frente à infecção por Leishmania (Fig. 31c). Mais além, investigamos se CASP11 estaria envolvida diretamente na ativação de CASP1. BMDMs foram infectados e marcados com FLICA (FAM-YVAD). Os resultados demonstram que NLRP3 e CASP11 são necessários para a ativação eficiente de CASP1 em resposta à infecção por $L$. amazonensis (Fig. 31c-f). Para melhor avaliar o efeito de CASP11 na ativação de CASP1, quantificamos a ativação e a secreção de CASP1 em resposta à infecção, 
por ELISA. Corroborando os dados obtidos por FACS, CASP11 mostrou-se necessária para a ativação eficiente de CASP1 em resposta a L.a. (Fig. 31g). Assim, demonstramos inequivocamente que CASP11 é responsável pela ativação de CASP1 e pela secreção de IL-1ß; no entanto, encontramos consistentemente uma via independente de CASP11 para a ativação do inflamassoma em resposta à infecção. Em seguida, avaliamos diretamente a ativação de CASP11 pela técnica de pull-down de CASP11 ativa, conforme descrito anteriormente (CUNHA et al., 2015). Interessantemente, os resultados demonstram que CASP11 é ativada em resposta a várias espécies de Leishmania, como mostrado no blot (Fig. 31h). Legionella pneumophila (L.p. flaA-) foi usada como controle positivo neste experimento.

Mais adiante, demonstramos o papel de CASP11 no controle da infecção tanto in vitro, quanto in vivo. Além disso, demonstramos que a molécula LPG é a responsável pela ativação de CASP11. Porém, diferentemente do LPS, LPG não interage fisicamente com CASP11, o que sugere que moléculas adicionais estejam envolvidas nesta ativação. Estes resultados também pertencem à presente tese, e podem ser lidos em detalhes no artigo publicado em Janeiro deste ano pelo nosso grupo de pesquisa (DE CARVALHO et al., 2019b). 

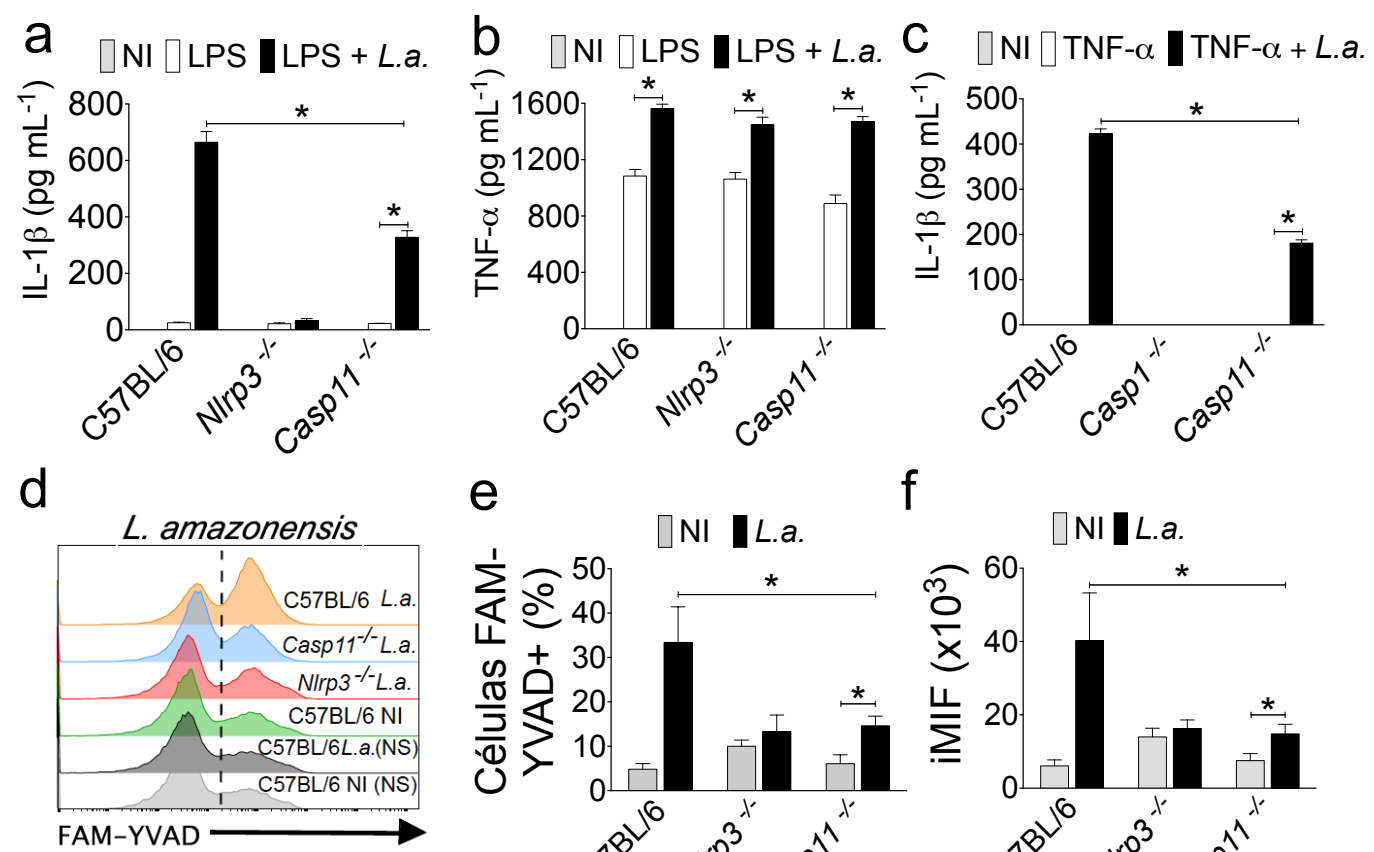

f
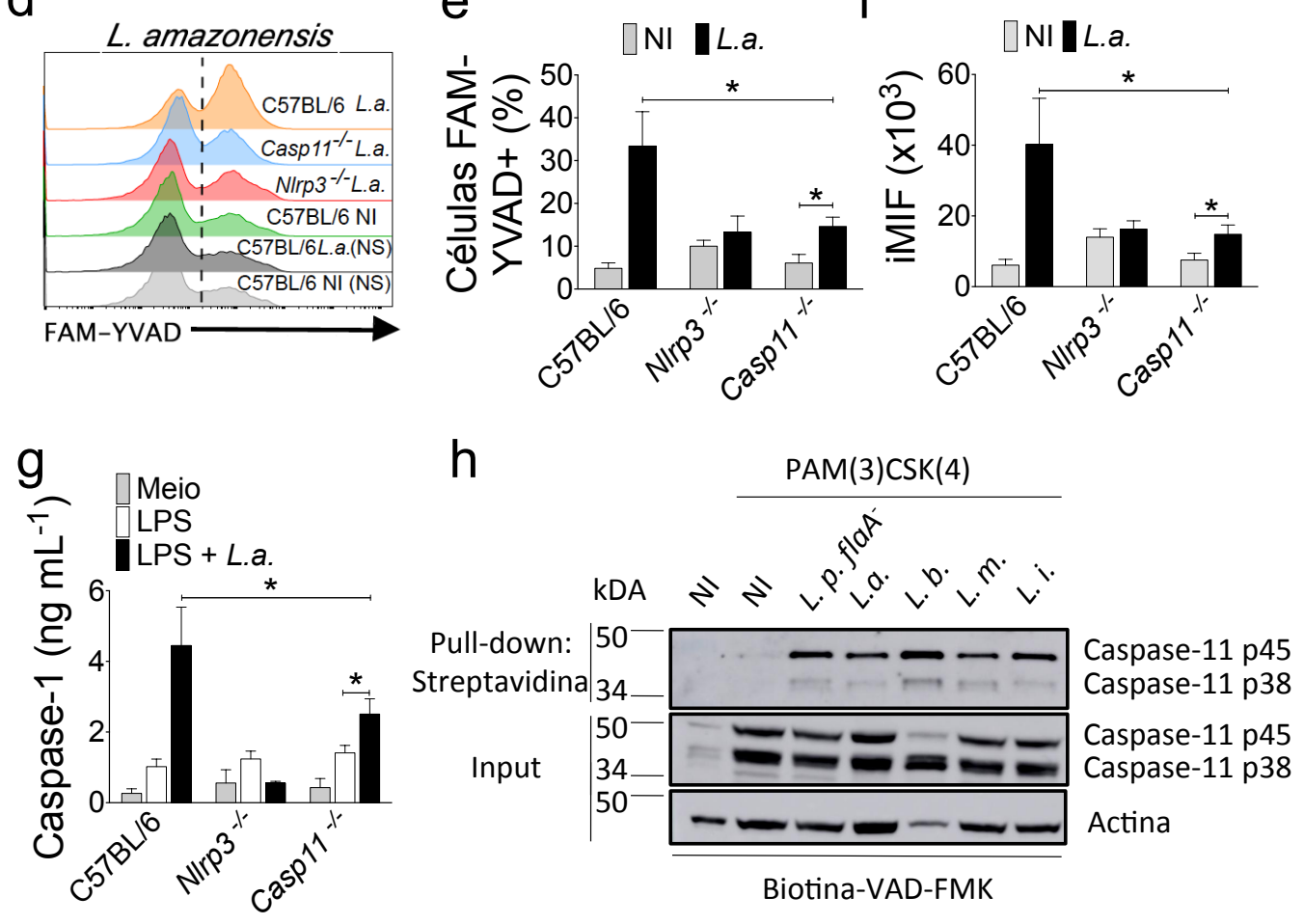

Figura 31. Leishmania desencadeia a ativação do inflamassoma não-canônico, mediado por caspase-11, em macrófagos. (a-c) BMDMs foram previamente estimulados com LPS (a,b) ou TNF- $\alpha$ (c) e depois infectados com promastigotas em fase estacionária de L.a. em MOI de 10. Os níveis de IL-1 $\beta$ (a,c) ou TNF- $\alpha$ (b) foram medidos por ELISA. (d-g) BMDMs de animais C57BL/6, NIrp3 $3^{-/-}$e Casp $11^{-/-}$foram marcados com FAM-YVAD após infecção por $L$. amazonensis em $\mathrm{MOI}$ de 10 , e as porcentagens de células positivas para CASP1 (e) e a média integrada de intensidade de fluorescência (iMIF) (f) foram avaliadas. Um histograma representativo é mostrado (d). As células foram infectadas com $L$. amazonensis (L.a) (g) e os níveis de CASP1 foram medidos nos sobrenadantes por ELISA. (h) BMDMs foram tratados com PAM(3)CSK(4) $(300 \mathrm{ng} / \mathrm{mL})$ e posteriormente incubados com biotina-VAD-FMK e infectados com diferentes espécies de Leishmania (MOI 10) ou L. pneumophila flaA- (controle positivo). Western blotting mostra a presença de CASP11 p45 e p38 no lisado celular (input). A $\beta$-actina foi usada como controle. A fração incubada com streptavidina mostra as frações de caspase-11 ativa (pull-down). Os dados são representados como as médias \pm DP de amostras em triplicatas técnicas (a-g) e são representativos dos dados obtidos de três (a-c) ou dois (d-h) experimentos independentes, que produziram resultados semelhantes. A análise estatística foi realizada pelo teste $t$ de Student. Os asteriscos indicam diferenças estatisticamente significativas. ${ }^{*} P<0,05$. 


\subsection{LRV inibe a ativação de caspase-11 por L.g.}

A descoberta de que parasitos do gênero Leishmania induzem a ativação de caspase-11 e da via não-canônica do NLRP3, nos levou a questionar se o LRV poderia regular a ativação do inflamassoma via caspase-11. Inicialmente, realizamos ensaio de ELISA para detecção de IL-1ß em macrófagos derivados de camundongos C57L/6, NIrp3 ${ }^{-/-}$e Casp11 $1^{-/}$. Os resultados demonstram que, assim como observado para outras espécies de Leishmania (DE CARVALHO et al., 2019b), L.g. ativa o inflamassoma de forma parcialmente dependente de caspase-11 (Fig. 32a). Interessantemente, o LRV parece limitar a ativação da via não-canônica, dado que seu efeito desaparece em BMDMs deficientes em caspase-11 (Fig. 32a). Para avaliar a ativação de caspase-11 diretamente, realizamos o ensaio de pull-down das formas ativas desta enzima, e observamos que o LRV bloqueia a ativação de CASP11 por L.g. (Fig. 32b). Estes dados in vitro sugerem fortemente que esta enzima possa ter também importante papel na patogênese da infecção por L.g., o que nos levou a realizar experimentos in vivo para verificar esta hipótese. De fato, LRV aumenta a espessura de orelha e a carga parasitária na orelha e linfonodo drenante de forma dependente de NLRP3, e também de caspase-11 (Fig. 32c,d). Portanto, estes resultados em conjunto sugerem fortemente que o LRV interfere na ativação de caspase-11 pelo parasito para agravar a infecção. 
a

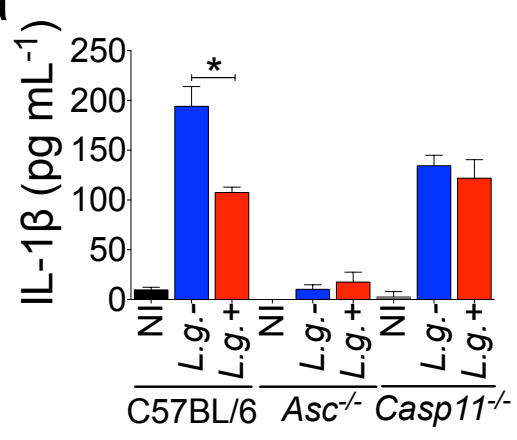

b

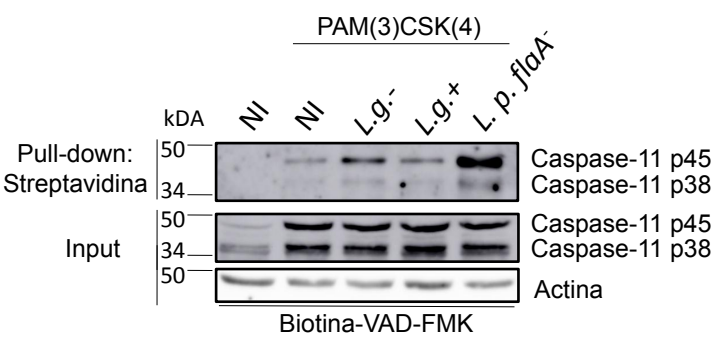

C

C57BL/6

NIrp3-/-

Casp $11^{-/}$
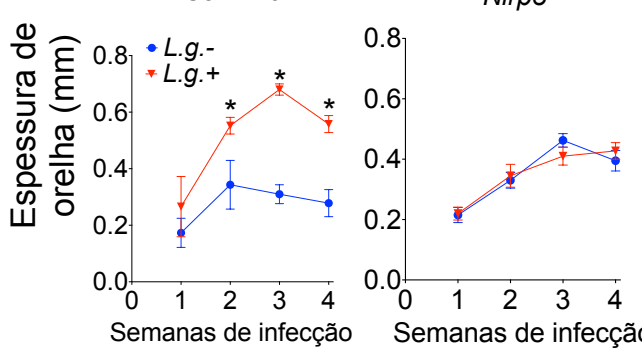

Semanas de infecção Semanas de infecção

d
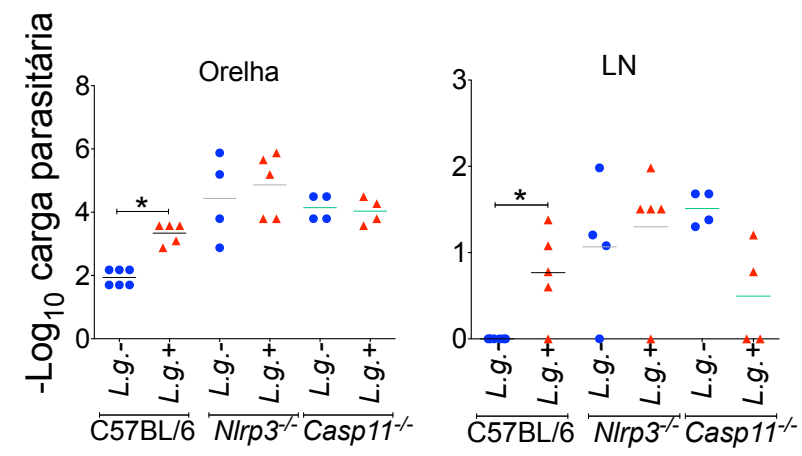

Figura 32. LRV limita a ativação de caspase-11 por L.g. (a,b) BMDMs foram previamente estimulados com LPS e depois infectados com promastigotas em fase estacionária de ambos os clones de L.g. em MOI de 10. Os níveis de IL-1 $\beta$ (a) foram medidos por ELISA. (b) BMDMs foram tratados com PAM(3)CSK(4) (300 ng mL-1) e posteriormente incubados com biotina-VAD-FMK e infectados com ambos os clones de L.g. (MOI 10) ou L. pneumophila flaA- (controle positivo). Western blotting mostra a presença de CASP11 p45 e p38 total no lisado celular (input). A $\beta$-actina foi usada como controle. A fração incubada com streptavidina mostra as frações de caspase-11 ativa (pull-down). (c,d) Camundongos C57BL/6, NIrp3 $3^{-/}$e Casp $11^{-/-}$foram infectados com $10^{6}$ promastigotas em fase estacionária de L.g.- ou L.g.+ ( $n=4-6$ animais por grupo), e as espessuras das orelhas foram seguidas semanalmente (c). 4 semanas após a infecção, a carga parasitária foi determinada na orelha e no linfonodo drenante (d). Os resultados são apresentados como média (c,d) ou média $\pm \mathrm{dp}$ (a) de dados obtidos de ao menos dois experimentos independentes realizados com replicatas técnicas (a) ou biológicas (c,d). A análise estatística foi realizada pelo teste $t$ de Student (a) ou ANOVA de via dupla com pós-teste de Bonferrroni (c,d). Os asteriscos indicam diferenças estatisticamente significativas. ${ }^{*} P<0,05$. 


\subsection{Isolados clínicos LRV+ de Leishmania spp. induzem menor ativação do inflamassoma quando comparados a parasitos LRV-.}

Nossos estudos mecanísticos realizados até agora empregaram a cepa M4147 (L.g.+) e o clone 40 (L.g.-), que perdeu espontaneamente o LRV. Para expandir o número de parasitos testados, obtivemos 3 cepas adicionais de $L$. guyanensis da coleção de Leishmania da Fundação Oswaldo Cruz (FIOCRUZ) (o isolado IOCL3539 é LRV+, enquanto IOCL3460 e IOCL3538 são LRV-), e avaliamos a ativação do inflamassoma em BMDMs frente a estes isolados. O mapa com os detalhes dos isolados clínicos utilizados na Figura 34 são mostrados (Fig. 33). Nossos dados demonstram que o isolado clínico LRV+ induziu níveis semelhantes de IL-1ß à L. guyanensis M4147 (L.g.+), e significativamente menor que o clone 40 (L.g.-) (Fig. 34a). Por outro lado, as cepas LRV- (IOCL3460 e IOCL3538) induziram a ativação do inflamassoma de forma semelhante ao clone 40 , e, portanto, em maiores níveis quando comparados à L.g.+ e IOCL3539 (Fig. 34a). Além da espécie L. guyanensis, outras espécies do Novo Mundo do subgênero Viannia, incluindo L. braziliensis, também podem ser LRV+. A partir disso, obtivemos 20 isolados clínicos de L. braziliensis da coleção da FIOCRUZ e avaliamos a secreção de IL-1ß individualmente para cada isolado, frente à infecção em BMDMs. Todos os parasitos foram sincronizados em conjunto, sendo as infecções realizadas todas dentro de um mesmo experimento. Os resultados demonstram que a ativação do inflamassoma é significativamente reduzida em resposta à infecção com os 12 isolados clínicos que são LRV+, quando comparados aos 8 isolados LRV- (Fig. 34b). Como conclusão de todo este trabalho, nossos dados indicam que, independentemente das espécies e variações individuais, a presença de LRV em espécies de Leishmania do Novo 
Mundo limita a ativação do inflamassoma via TLR3/TRIF/IFN- $\beta / A T G 5$, sendo este um importante mecanismo para o agravamento da infecção (Fig 34c).

\begin{tabular}{|c|c|c|c|c|}
\hline Número & Nome na coleção & Código Internacional & Espécie do parasito & LRV STATUS \\
\hline 1 & IOCL 3569 (299) & MHOM/BR/2014/299 & L. braziliensis & POSITIVO \\
\hline 2 & IOCL 3570 (303) & MHOM/BR/2014/303 & L. braziliensis & POSITIVO \\
\hline 3 & IOCL 3571 (304) & MHOM/BR/2014/304 & L. braziliensis & POSITIVO \\
\hline 4 & IOCL $3622(476)$ & MHOM/BR/2015/RO476 & L. braziliensis & POSITIVO \\
\hline 5 & IOCL 3625 (313) & MHOM/BR/2014/RO313 & L. braziliensis & POSITIVO \\
\hline 6 & IOCL 3639 (390) & MHOM/BR/2015/RO390 & L. braziliensis & POSITIVO \\
\hline 7 & IOCL 3626 (314) & MHOM/BR/2014/RO314 & L. braziliensis & NEGATIVO \\
\hline 8 & IOCL 3642 (412) & MHOM/BR/2015/RO412 & L. braziliensis & NEGATIVO \\
\hline 9 & IOCL 3710 (666) & MHOM/BR/2017/RO666 & L. braziliensis & POSITIVO \\
\hline 10 & IOCL 3708 (667) & MHOM/BR/2017/RO667 & L. braziliensis & NEGATIVO \\
\hline 11 & IOCL 3714 (760) & MHOM/BR/2017/RO760 & L. braziliensis & NEGATIVO \\
\hline 12 & IOCL 3713 (767) & MHOM/BR/2017/RO767 & L. braziliensis & NEGATIVO \\
\hline 13 & IOCL 3711 (818) & MHOM/BR/2017/RO818 & L. braziliensis & POSITIVO \\
\hline 14 & IOCL $3712(820)$ & MHOM/BR/2017/RO820 & L. braziliensis & NEGATIVO \\
\hline 15 & IOCL 3637 (384) & MHOM/BR/2015/RO384 & L. braziliensis & POSITIVO \\
\hline 16 & IOCL $3540(268)$ & MHOM/BR/2014/268 & L. braziliensis & POSITIVO \\
\hline 17 & IOCL 3546 (276) & MHOM/BR/2014/276 & L. braziliensis & NEGATIVO \\
\hline 18 & IOCL 3549 (283) & MHOM/BR/2014/283 & L. braziliensis & NEGATIVO \\
\hline 19 & IOCL 3567 (291) & MHOM/BR/2014/291 & L. braziliensis & POSITIVO \\
\hline 20 & IOCL 3545 (275) & MHOM/BR/2014/275 & L. braziliensis & POSITIVO \\
\hline
\end{tabular}

Figura 33. Isolados clínicos obtidos de pacientes com Leishmaniose em diferentes quadros clínicos da doença. O diagrama mostra a distribuição dos parasitos testados na figura $X$, de acordo com a espécie do parasito infectante, seu código internacional, rótulo de coleta da FIOCRUZ e status do LRV. 

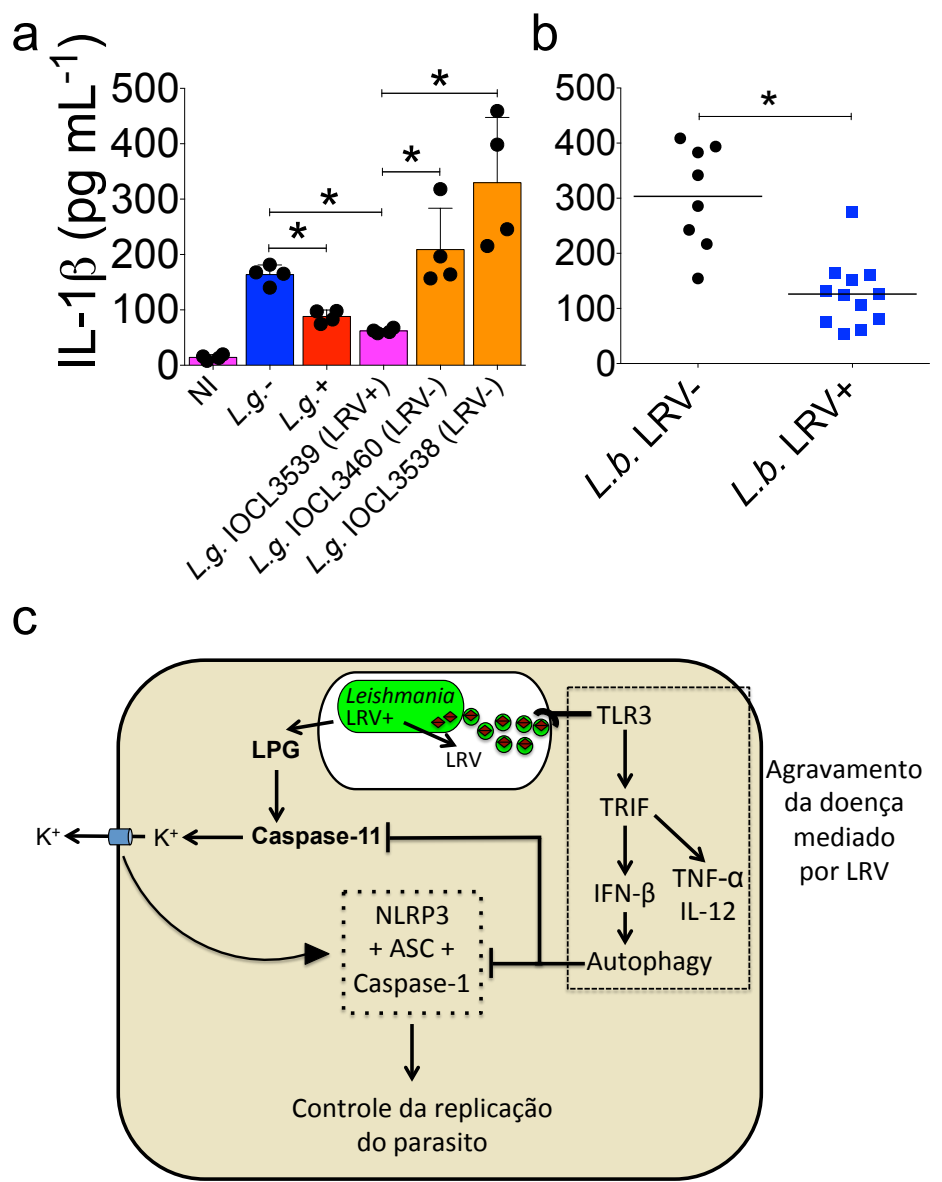

Figura 34. Os isolados clínicos LRV + induzem menor ativação do inflamassoma (a) Macrófagos derivados da medula óssea estimulados com LPS (BMDMs) foram infectados (MOI 10) com L.g.-, L.g.+, ou diferentes isolados clínicos de L. guyanensis. Enquanto dois destes são LRV- (barras laranja), o outro é LRV+ (barra rosa). (b) BMDMs estimulados com LPS foram infectados com 20 isolados clínicos diferentes de L. braziliensis (MOI 10) obtidos de diferentes pacientes. Os isolados LRV- são mostrados como círculos (círculos pretos) e os isolados LRV+, são mostrados como quadrados (quadrados azuis). A informação de cada isolado está contida na Figura 33. Após 24 horas de infecção, os sobrenadantes livres de células foram coletados e os níveis de IL-1 $\beta$ foram avaliados por ELISA. O valor médio para cada isolado clínico foi plotado em conjunto, de acordo com a presença/ausência do LRV. Os resultados são mostrados como média \pm DP. A análise estatística foi realizada pelo teste $t$ de Student não pareado, com $P<0,05\left(^{*}\right)$ considerado estatisticamente significativo. Um experimento representativo de um total de três experimentos independentes realizados com replicatas técnicas, é mostrado. (c) O inflamassoma é importante para o controle de Leishmania in vitro e in vivo. Demonstramos que o NLRP3 pode ser ativado pela via nãocanônica, dependente de caspase-11, via o PAMP LPG, do parasito. Espécies do Novo Mundo podem ser portadoras de um vírus endossimbionte de dupla fita de RNA (LRV), que conferem maior virulência ao parasito e maior risco de desenvolvimento da Leishmaniose mucocutânea. Mecanisticamente, o LRV (em marrom) transita dentro de vesículas extracelulares (círculos verdes) no vacúolo, culminando na sinalização da via de TLR3/TRIF para induzir várias citocinas inflamatórias, como pró-IL-1 $\beta$, TNF- $\alpha$ e IL-12. Se por um lado esta via de sinalização aumenta a inflamação, também há a produção de IFN- $\beta$, que ativa a maquinaria autofágica para degradar NLRP3 e ASC e inibir a ativação de caspase-11, limitando a ativação de NLRP3 e favorecendo a replicação de Leishmania. 
Discussão 


\section{DISCUSSÃO}

Apesar da importância da Leishmaniose, uma doença que afeta milhões de pessoas em todo o mundo, os mecanismos celulares e moleculares envolvidos na patogênese da infecção não são totalmente caracterizados e muitos aspectos da doença permanecem desconhecidos (SCOTT; NOVAIS, 2016). Neste estudo, demonstramos um mecanismo de evasão desencadeado por espécies de Leishmania do Novo Mundo (complexo Viannia) que abrigam o vírus endossimbionte de dupla fita de RNA (dsRNA), que vêm sendo reportado como um importante fator de risco para o desenvolvimento de doença mucocutânea (HARTLEY et al., 2012). Embora o LRV contribua para a gravidade da doença, outros fatores de risco, como coinfecções (HIV), a resposta imune individual de cada hospedeiro e variações individuais intrínsecas das cepas do parasito também podem ser críticos para determinar o quadro clínico da Leishmaniose em pacientes (HARTLEY et al., 2014). No presente estudo, identificamos que o LRV promove a indução da autofagia via TLR3, através da indução do IFN tipo I. Este processo resulta em menor ativação do inflamassoma não-canônico de NLRP3, mediado por caspase-11, visto que a indução de autofagossomos resulta na degradação de componentes específicos do inflamassoma, como NLRP3 e ASC. Nossa hipótese é que a inibição do inflamassoma mediada pelo LRV nos estágios iniciais da infecção resulta na eliminação ineficaz dos parasitos nos tecidos. Como conseqüência, a ativação robusta de células $\mathrm{T}$ poderia promover a resposta imune exacerbada e não-regulada observada nas formas mucocutâneas graves da doença (RUIZ; BECKER, 2007; FARIA et al., 2009). Paradoxalmente, ao inibir a ativação do inflamassoma através de autofagia, nossos dados indicam que a ativação de TLR3 mediada por LRV também favorece a indução de citocinas inflamatórias, tais como TNF- $\alpha$ e IL-12. 
Estes achados estão de acordo com dados da literatura, que indicam que TLR3 reconhece o LRV e piora a doença por indução de citocinas inflamatórias (IVES et al., 2011). No caso da doença mucocutânea, hipotetizamos que o inflamassoma de NLRP3 atue mais como uma plataforma microbicida, gerando NO, importante mediador que ajuda na eliminação intracelular de Leishmania, do que como uma plataforma inflamatória que gere imunopatologia. Neste caso, as citocinas encarregadas de exercer um papel deletério ao hospedeiro, seriam justamente as citocinas inflamassoma-independentes produzidas via TLR3.

Alguns estudos relataram os efeitos deletérios do LRV no hospedeiro durante a infecção. Um estudo em particular avaliou o impacto do LRV no curso da infecção por Leishmania, comparando dois isolados clínicos independentes, um que promove a metástase (L.g.M+), e o outro não metastático (L.g.M-) (IVES et al., 2011). Outros estudos compararam a cepa M4147 (LRV+) e um clone derivado desta, obtido através da inserção de um plasmídeo de resistência à Higromicina B (EREN et al., 2016; HARTLEY et al., 2016, 2018). Um aspecto importante do nosso estudo é o fato de que obtivemos, com sucesso, um clone isogênico de M4147 sem o vírus (L.g.-), independentemente de manipulação genética da cepa parental. Isso nos proporcionou uma ferramenta poderosa para abordar os efeitos do vírus na patogênese da infecção e na indução de respostas imunes inatas. É importante ressaltar que um estudo anterior de Hartley e colegas não detectou nenhuma ativação do inflamassoma ao comparar Leishmania guyanensis com e sem o vírus (HARTLEY et al., 2018). Embora a ativação do inflamassoma em macrófagos infectados por Leishmania tenha sido previamente relatada por muitos grupos independentes (LIMA-JUNIOR et al., 2013a; SHIO et al., 2015; SANTOS et al., 2018; DE CARVALHO et al., 2019b), é consenso no campo de estudo de inflamassoma, 
que a magnitude da ativação dos NLRs em resposta à Leishmania é baixa quando comparada a outros microrganismos, incluindo outros parasitos protozoários (ZAMBONI; LIMA-JUNIOR, 2015). De acordo com estas observações, alguns outros estudos têm sugerido que diferentes espécies de Leishmania inibem ativamente a ativação do inflamassoma (SHIO et al., 2015; GUPTA et al., 2017; PITALE et al., 2019), uma característica que é consistente com o importante papel do inflamassoma na restrição da replicação do parasito (LEFÈVRE et al., 2013; LIMAJUNIOR et al., 2013b; ZAMBONI; SACKS, 2019). Neste cenário, hipotetizamos que condições específicas de infecção por macrófagos usadas por Hartley e colegas não permitiram a detecção de qualquer ativação do inflamassoma e, consequentemente, os autores daquele estudo não reportaram o efeito dos parasitos LRV+ na inibição do inflamassoma quando comparado com a linhagem LRV- de L. guyanensis.

Embora a ativação de NLRP3 por Leishmania tenha sido bastante investigada em modelos murinos de infecção (GURUNG et al., 2015; CHARMOY et al., 2016; LIMA-JUNIOR et al., 2017; DE CARVALHO et al., 2019a, 2019b), este é o primeiro estudo a comparar a magnitude de ativação do inflamassoma em pacientes com diferentes formas da doença. Enquanto alguns grupos relataram um efeito deletério da sinalização de NLRP3 e IL-1R no hospedeiro (GURUNG et al., 2015; CHARMOY et al., 2016; NOVAIS et al., 2017; SANTOS et al., 2018), outros mostraram um papel protetor do inflamassoma durante a infecção (LEFĖVRE et al., 2013; LIMA-JUNIOR et al., 2013a, 2017; CHAVES et al., 2019; DE CARVALHO et al., 2019a, 2019b). No presente estudo, demonstramos uma correlação inversa entre a gravidade da leishmaniose e a ativação do inflamassoma, suportando um papel protetor ao inflamassoma durante a leishmaniose. No entanto, é possível que o inflamassoma favoreça a imunopatologia e/ou controle parasitário dependendo do momento da 
infecção, da cepa parasitária e de fatores genéticos associados ao hospedeiro. Ressaltamos que nossos dados com macrófagos humanos e amostras clínicas de pacientes LRV+ e LRV-, juntamente com L.g.+ e diferentes isolados clínicos de Leishmania obtidos de humanos, demonstram que o LRV limita a ativação da NLRP3 para favorecer a infecção e a patogênese. Apesar de vários grupos relatarem os mecanismos que favorecem a ativação de NLRP3 por Leishmania, os mecanismos que regulam sua inibição ainda são pouco conhecidos (ZAMBONI; SACKS, 2019). Embora seja consenso na literatura que os TLRs forneçam o primeiro sinal necessário para ativar inflamassomas, nossos resultados obtidos com células deficientes em TLR3 e com Poly: IC mostram que o TLR3 é ativado pelo LRV para inibir a ativação de NLRP3 por L.g. Diferentemente de todos os outros TLRs, TLR3 sinaliza exclusivamente via TRIF, desencadeando potente produção de IFN tipo I (O'NEILL; GOLENBOCK; BOWIE, 2013; ZHANG et al., 2013), um processo que foi anteriormente relatado como inibindo a ativação do inflamassoma (GUARDA et al., 2011). Da mesma forma, o papel do IFN tipo I na indução de autofagia já foi demonstrado (SCHMEISSER; BEKISZ; ZOON, 2014). Esta citocina já foi associada em estudos prévios com o crescimento parasitário e agravamento da infecção por Leishmania, embora os mecanismos responsáveis por estes fenômenos ainda não serem completamente conhecidos (KHOURI et al., 2009; ROSSI et al., 2017; SILVABARRIOS; STAGER, 2017). No presente estudo, conectamos TLR3 e IFN- $\beta$ com a autofagia, que por sua vez inibe a ativação do inflamassoma não-canônico de NLRP3, fornecendo uma possível explicação para os efeitos deletérios atribuídos ao IFN tipo I no contexto da leishmaniose.

Embora a ativação do inflamassoma não-canônico de NLRP3 tenha sido bem descrita no contexto de infecções por bactérias gram-negativas, nosso trabalho é 
pioneiro ao demonstrar que caspase-11 pode ser ativada por Leishmania spp. Mais além, um dos estudos gerados pela presente tese (DE CARVALHO et al., 2019b) é o primeiro a demonstrar um PAMP não bacteriano envolvido com a ativação da via não-canônica. Interessantemente, LRV parece modular justamente a ativação de caspase-11 por L.g., mas os mecanismos exatos pelos quais esta inibição acontece serão objetivos de estudos futuros.

Diversos estudos relataram que a infecção por Leishmania induz autofagia na célula hospedeira, mas as consequências deste processo no resultado da infecção podem variar dependendo da espécie do parasito, da linhagem de camundongo utilizada e de outros fatores (PINHEIRO et al., 2009b; CYRINO et al., 2012; FRANCO et al., 2017; THOMAS et al., 2018; PITALE et al., 2019). Neste estudo, relatamos que a autofagia é desencadeada por L.g.- e regula a atividade do inflamassoma, mas não desempenha um papel significativo na replicação do parasito. No entanto, a sinalização via TLR3 pelo LRV aumenta a indução de autofagia para degradar NLRP3 e ASC, promovendo a sobrevivência do microrganismo. Paralelamente, o LRV estimula a produção de citocinas inflamatórias, como o TNF-a e a IL-12. É possível que a aquisição do LRV durante a evolução tenha promovido uma vantagem seletiva em hospedeiros mamíferos ao inibir o controle da replicação do parasito mediada pelo inflamassoma. No entanto, o vírus também promove a produção de citocinas inflamatórias independentes de inflamassoma mediadas por TLR3, o que pode contribuir para o desenvolvimento de lesões mucocutâneas em pacientes. Tomados de maneira conjunta, nossos resultados combinados de amostras clínicas e camundongos demonstram um mecanismo de evasão desencadeado pelo LRV para promover a patogênese de Leishmania. Este trabalho também demonstra uma nova concepção sobre as 
interações de vias do sistema imune inato, uma vez que demonstra um efeito negativo do TLR3 sobre a ativação do NLRP3, também destacando a autofagia como um importante regulador da ativação do inflamassoma durante a infecção por Leishmania. Este trabalho contribui para o nosso entendimento global de fatores de risco específicos relacionados ao desenvolvimento da Leishmaniose mucocutânea em humanos. Além disso, fornece diversos alvos específicos para o desenvolvimento de novas estratégias terapêuticas. O desenvolvimento futuro de drogas que interfiram em vias específicas desencadeadas por este vírus pode ser extremamente útil na prática clínica, melhorando o tratamento e/ou prevenção em pacientes que sofrem da forma altamente debilitante da leishmaniose mucocutânea. 
Sumário 


\section{SUMÁRIO}

- Pacientes com leishmaniose cutânea ou mucocutânea exibem diferentes magnitudes de ativação do inflamassoma.

- Pela primeira vez, um clone LRV- (L.g.-) é gerado espontaneamente, a partir de uma cepa padrão de L. guyanensis (M4147 - L.g.+).

- A presença do LRV agrava a infecção por L.g. em macrófagos e in vivo.

- A ativação do inflamassoma de NLRP3 é atenuada pela presença do LRV.

- LRV induz IFN- $\beta$ via TLR3 para limitar a ativação do inflamassoma por L.g.

- A ativação do TLR3 pelo vírus induz a degradação de ASC e NLRP3 dentro da célula.

- LRV potencializa a indução de autofagia por L.g

- LRV induz autofagia para bloquear o inflamassoma e favorecer o crescimento de L.g.

- LRV encontra-se dentro de vesículas extracelulares (EVs) de Leishmania e pode ser transmitido via EVs.

- Leishmania ativa caspase-11 e o inflamassoma não-canônico de NLRP3.

- LRV bloqueia a ativação de caspase-11 por L.g.

- Isolados clínicos LRV- ativam o inflamassoma de forma mais exacerbada do que parasitos LRV+.

- A ativação de TLR3 pelo LRV induz IFN- $\beta$, que por sua vez induz autofagia, a qual impede a ativação do inflamassoma de maneira mais robusta. Este mecanismo ocorre em macrófagos murinos e humanos e agrava a infecção por L.g. em modelo murino experimental (in vivo). Estes achados avançam no entendimento dos mecanismos moleculares pelos quais LRV agrava a patogênese da Leishmaniose. 
Conclusão 


\section{CONCLUSÃO}

A presença do vírus de RNA de Leishmania (LRV) em espécies do Novo Mundo agrava a infecção por um mecanismo dependente de TLR3/TRIF/IFNß/Autofagia, que culmina na inibição do inflamassoma de NLRP3, uma importante plataforma microbicida do hospedeiro. Paralelamente, a ativação deste eixo iniciado pelo TLR3 induz a uma resposta hiperinflamatória, com enorme produção de citocinas, como TNF- $\alpha$ e IL-12. De forma conjunta, nossos achados elucidam um mecanismo de evasão induzido por parasitos LRV+, apontando diversos alvos moleculares com potencial para futuras intervenções terapêuticas. Sugerimos que a confirmação da presença do LRV em pacientes recém-diagnosticados com Leishmaniose pode indicar a necessidade de tratamentos farmacológicos com inibidores das vias de TLR3/IFN- $\beta$ /Autofagia, ou ativadores da via do inflamassoma, que contribuiriam não apenas para a melhora do quadro clínico da leishmaniose cutânea, como também evitaria os efeitos devastadores frente à metastização dos parasitos, evitando o surgimento da doença mucocutânea. 


\section{Referências Bibliográficas}




\section{REFERÊNCIAS BIBLIOGRÁFICAS}

ACESTOR, N. et al. Resistance to Oxidative Stress Is Associated with Metastasis in Mucocutaneous Leishmaniasis. The Journal of Infectious Diseases, 2006.

AFONSO, L. C.; SCOTT, P. Immune responses associated with susceptibility of C57BL/10 mice to Leishmania amazonensis. Infection and immunity, 1993.

AGA, E. et al. Inhibition of the Spontaneous Apoptosis of Neutrophil Granulocytes by the Intracellular Parasite Leishmania major . The Journal of Immunology, 2002.

AKIRA, S.; TAKEDA, K. Toll-like receptor signalling. Nature Reviews Immunology, 2004.

ALIAGA, L. et al. Localized mucosal Leishmaniasis due to Leishmania (Leishmania) infantum clinical and microbiologic findings in 31 patients. Medicine, 2003.

ALVAR, J. et al. Leishmaniasis worldwide and global estimates of its incidence. PLoS ONE, 2012.

ARMSTRONG, T. C. et al. Successful transient introduction of Leishmania RNA virus into a virally infected and an uninfected strain of Leishmania. Proceedings of the National Academy of Sciences of the United States of America, 1993.

ASHFORD, R. W. The leishmaniases as emerging and reemerging zoonoses. International Journal for Parasitology, 2000.

ATAYDE, V. D. et al. Exosome Secretion by the Parasitic Protozoan Leishmania within the Sand Fly Midgut. Cell Reports, 2015.

ATAYDE, V. D. et al. Exploitation of the Leishmania exosomal pathway by Leishmania RNA virus 1. Nature Microbiology 2019, 2019.

ATHMAN, R.; PHILPOTT, D. Innate immunity via Toll-like receptors and Nod proteins. Current Opinion in Microbiology, 2004.

BAILEY, M.S., LOCKWOOD, D. N. Cutaneous leishmaniasis. Clinics in Dermatology, 2007.

BARRAL, A. et al. Leishmaniasis in Bahia, Brazi: Evidence that Leishmania amazonensis produces a wide spectrum of clinical disease. American Journal of Tropical Medicine and Hygiene, 1991.

BECKER, I. et al. Leishmania lipophosphoglycan (LPG) activates NK cells through toll-like receptor-2. Molecular and Biochemical Parasitology, 2003.

BITTENCOURT, A. L.; BARRAL, A. Evaluation of the histopathological classifications of American cutaneous and mucocutaneous leishmaniasis. Memórias do Instituto Oswaldo Cruz, 1991.

BOUVIER, J.; ETGES, R. J.; BORDIER, C. Identification and purification of membrane and soluble forms of the major surface protein of Leishmania promastigotes. Journal of Biological Chemistry, 1985.

BROZ, P.; DIXIT, V. M. Inflammasomes: mechanism of assembly, regulation and signalling. Nature Reviews Immunology, 2016. 
CARVALHO, E. M. et al. Clinical and immunopathological aspects of disseminated cutaneous leishmaniasis. Acta Tropica, 1994.

CHAPPUIS, F. et al. Visceral leishmaniasis: What are the needs for diagnosis, treatment and control? Nature Reviews Microbiology, 2007.

CHARMOY, M. et al. The NIrp3 inflammasome, IL-1b, and neutrophil recruitment are required for susceptibility to a nonhealing strain of Leishmania major in C57BL/6 mice. European Journal of Immunology, 2016.

CHAVES, M. M. et al. Non-canonical NLRP3 inflammasome activation and IL-1 $\beta$ signaling are necessary to L. amazonensis control mediated by P2X7 receptor and leukotriene B4. PLOS Pathogens, 2019.

CHEN, G. et al. NOD-Like Receptors: Role in Innate Immunity and Inflammatory Disease. Annual Review of Pathology: Mechanisms of Disease, 2009.

COLOMBO, M.; RAPOSO, G.; THÉRY, C. Biogenesis, Secretion, and Intercellular Interactions of Exosomes and Other Extracellular Vesicles. Annual Review of Cell and Developmental Biology, 2014.

COSTA, J. M. L. et al. Disseminated cutaneous leishmaniasis in a field clinic in Bahia, Brazil: A report of eight cases. Journal of Tropical Medicine and Hygiene, 1986.

CUENTAS, E. A. L. et al. POSSIBLE RISK FACTORS IN DEVELOPMENT OF MUCOSAL LESIONS IN LEISHMANIASIS. The Lancet, 1984.

CUNHA, L. D. et al. Inhibition of inflammasome activation by Coxiella burnetii type IV secretion system effector IcaA. Nature Communications, 2015.

CYRINO, L. T. et al. In vivo and in vitro Leishmania amazonensis infection induces autophagy in macrophages. Tissue and Cell, 2012.

DE CARVALHO, R. V. H. et al. Macrophage priming is dispensable for NLRP3 inflammasome activation and restriction of Leishmania amazonensis replication. Journal of Leukocyte Biology, 2019a.

DE CARVALHO, R. V. H. et al. Leishmania Lipophosphoglycan Triggers Caspase-11 and the Non-canonical Activation of the NLRP3 Inflammasome. Cell Reports, 2019b.

DE VEER, M. J. et al. MyD88 is essential for clearance of Leishmania major: Possible role for lipophosphoglycan and Toll-like receptor 2 signaling. European Journal of Immunology, 2003.

DELGADO, M. A. et al. Toll-like receptors control autophagy. The EMBO journal, 2008.

DERETIC, V.; SAITOH, T.; AKIRA, S. Autophagy in infection, inflammation and immunity. Nature Reviews Immunology, 2013.

DESJEUX, P. Leishmaniasis: Public health aspects and control. Clinics in Dermatology, 1996.

DEY, R. et al. Gut Microbes Egested during Bites of Infected Sand Flies Augment Severity of Leishmaniasis via Inflammasome-Derived IL-1ß. Cell Host \& Microbe, 2018.

DIAS, B. R. S. et al. Autophagic induction Greatly Enhances Leishmania major intracellular survival compared to Leishmania amazonensis in CBA/j-infected macrophages. Frontiers in Microbiology, 2018. 
EREN, R. O. et al. Mammalian Innate Immune Response to a Leishmania-Resident RNA Virus Increases Macrophage Survival to Promote Parasite Persistence. Cell Host and Microbe, 2016.

EVANS, T. G. et al. Effect of in Vivo Inhibition of Nitric Oxide Production in Murine Leishmaniasis. Journal of Immunology, 1993.

FARIA, D. et al. Interleukin 17 Production among Patients with American Cutaneous Leishmaniasis. Journal of Infectious Diseases, 2009.

FERNÁNDEZ-FIGUEROA, E. A. et al. Disease severity in patients infected with Leishmania mexicana relates to IL-1 $\beta$. PLoS Neglected Tropical Diseases, 2012.

FRANCO, L. H. et al. Autophagy downstream of endosomal Toll-like Receptors Signaling in Macrophages is a Key Mechanism for Resistance to Leishmania major Infection. The Journal of biological chemistry, 2017.

GAIDT, M. M. et al. Human Monocytes Engage an Alternative Inflammasome Pathway. Immunity, 2016.

GANTT, K. R. et al. Oxidative Responses of Human and Murine Macrophages During Phagocytosis of Leishmania chagasi . The Journal of Immunology, 2001.

GRIMALDI, G.; DAVID, J. R.; MCMAHON-PRATT, D. Identification and distribution of new world Leishmania species characterized by serodeme analysis using monoclonal antibodies. American Journal of Tropical Medicine and Hygiene, 1987.

GRIMALDI, G.; TESH, R. B. Leishmaniases of the New World: Current concepts and implications for future research. Clinical Microbiology Reviews, 1993.

GUARDA, G. et al. Type I Interferon Inhibits Interleukin-1 Production and Inflammasome Activation. Immunity, 2011.

GUO, H.; CALLAWAY, J. B.; TING, J. P.-Y. Inflammasomes: mechanism of action, role in disease, and therapeutics. Nature medicine, 2015.

GUPTA, A. K. et al. Leishmania donovani inhibits inflammasome-dependent macrophage activation by exploiting the negative regulatory proteins A20 and UCP2. FASEB Journal, 2017.

GURUNG, P. et al. An NLRP3 inflammasome - triggered Th2-biased adaptive immune response promotes leishmaniasis. The Journal of Clinical Investigation, 2015.

HAGAR, J. A. et al. Cytoplasmic LPS activates caspase-11: Implications in TLR4independent endotoxic shock. Science, 2013.

HANEKLAUS, M.; O'NEILL, L. A. J. NLRP3 at the interface of metabolism and inflammation. Immunological Reviews, 2015.

HARTLEY, M.-A. et al. Leishmania RNA virus: when the host pays the toll. Frontiers in cellular and infection microbiology, 2012.

HARTLEY, M. et al. Leishmania guyanensis parasites block the activation of the inflammasome by inhibiting maturation of IL - 1ß. Microbial Cell, 2018.

HARTLEY, M. A. et al. The immunological, environmental, and phylogenetic perpetrators of metastatic leishmaniasis. Trends in Parasitology, 2014. 
HARTLEY, M. A. et al. Leishmaniavirus-Dependent Metastatic Leishmaniasis Is Prevented by Blocking IL-17A. PLoS Pathogens, 2016.

HEINZEL, F. P. et al. Endogenous IL-12 is required for control of Th2 cytokine responses capable of exacerbating leishmaniasis in normally resistant mice. Journal of immunology (Baltimore, Md. : 1950), 1995.

HERWALDT, B. L.; ARANA, B. A.; NAVIN, T. R. The Natural History of Cutaneous Leishmaniasis in Guatemala. Journal of Infectious Diseases, 1992.

HIBINO, T. et al. The immune gene repertoire encoded in the purple sea urchin genome. Developmental Biology, 2006.

ILG, T. Proteophosphoglycans of Leishmania. Parasitology Today, 2000.

ILGOUTZ, S. C.; MCCONVILLE, M. J. Function and assembly of the Leishmania surface coat. International Journal for Parasitology, 2001.

INOHARA, N. et al. NOD-LRR PROTEINS: Role in Host-Microbial Interactions and Inflammatory Disease. Annual Review of Biochemistry, 2005.

INOHARA, N.; NUÑEZ, G. NODS: Intracellular proteins involved in inflammation and apoptosis. Nature Reviews Immunology, 2003.

IVES, A. et al. Leishmania RNA virus controls the severity of mucocutaneous leishmaniasis. Science (New York, N.Y.), 2011.

IVES, A. et al. MyD88 and TLR9 dependent immune responses mediate resistance to Leishmania guyanensis infections, irrespective of Leishmania RNA virus burden. PLoS ONE, 2014.

KARIN, M.; LAWRENCE, T.; NIZET, V. Innate immunity gone awry: Linking microbial infections to chronic inflammation and cancer. Cell, 2006.

KAYAGAKI, N. et al. Non-canonical inflammasome activation targets caspase-11. Nature, 2011.

KAYE, P.; SCOTT, P. Leishmaniasis: complexity at the host-pathogen interface. Nature Reviews. Microbiology, 2011.

KEMP, M. Regulator and effector functions of T-cell subsets in human Leishmanaia infections. APMIS, 1997.

KHARFI, M. et al. Mucosal localization of leishmaniasis in Tunisia: 5 Cases. Annales de Dermatologie et de Venereologie, 2003.

KHOURI, R. et al. IFN-beta impairs superoxide-dependent parasite killing in human macrophages: evidence for a deleterious role of SOD1 in cutaneous leishmaniasis. Journal of immunology (Baltimore, Md. : 1950), 2009.

KLIONSKY, D. et al. Guidelines for the use and interpretation of assays for monitoring autophagy. Autophagy, 2016.

KONECNY, P. et al. Murine dendritic cells internalize Leishmania major promastigotes, produce IL-12 p40 and stimulate primary T cell proliferation in vitro. European Journal of Immunology, 1999.

KROPF, P. et al. Infection of C57BL/10ScCr and C57BL/10ScNCr mice with Leishmania 
major reveals a role for Toll-like receptor 4 in the control of parasite replication. Journal of Leukocyte Biology, 2004a.

KROPF, P. et al. Toll-Like Receptor 4 Contributes to Efficient Control of Infection with the Protozoan Parasite Leishmania major. Infection and Immunity, 2004b.

LAMKANFI, M.; DIXIT, V. M. Mechanisms and functions of inflammasomes. Cell, 2014a.

LASKAY, T.; VAN ZANDBERGEN, G.; SOLBACH, W. Neutrophil granulocytes - Trojan horses for Leishmania major and other intracellular microbes? Trends in Microbiology, 2003.

LAUFS, H. et al. Intracellular survival of Leishmania major in neutrophil granulocytes after uptake in the absence of heat-labile serum factors. Infection and Immunity, 2002.

LEFÈVRE, L. et al. The C-type Lectin Receptors Dectin-1, MR, and SIGNR3 Contribute Both Positively and Negatively to the Macrophage Response to Leishmania infantum. Immunity, 2013.

LESSA, M. M. et al. Mucosal leishmaniasis: Epidemiological and clinical aspects. Brazilian Journal of Otorhinolaryngology, 2007.

LIESE, J.; SCHLEICHER, U.; BOGDAN, C. TLR9 signaling is essential for the innate NK cell response in murine cutaneous leishmaniasis. European Journal of Immunology, 2007.

LIMA-JUNIOR, D. S. et al. Inflammasome-derived IL-1 $\beta$ production induces nitric oxidemediated resistance to Leishmania. Nature Medicine, 2013.

LIMA-JUNIOR, D. S. et al. Dectin-1 Activation during Leishmania amazonensis Phagocytosis Prompts Syk-Dependent Reactive Oxygen Species Production To Trigger Inflammasome Assembly and Restriction of Parasite Replication. The Journal of Immunology, 2017.

LIMA, G. M. A. C. et al. The role of polymorphonuclear leukocytes in the resistance to cutaneous Leishmaniasis. Immunology Letters, 1998.

MAN, S. M.; KANNEGANTI, T. D. Gasdermin D: The long-awaited executioner of pyroptosis. Cell Research, 2015.

MARIATHASAN, $\mathrm{S}$. et al. Cryopyrin activates the inflammasome in response to toxins and ATP. Nature, 2006.

MARIM, F. M. et al. A Method for Generation of Bone Marrow-Derived Macrophages from Cryopreserved Mouse Bone Marrow Cells. PLoS ONE, 2010.

MARSDEN, P. D. Mucosal leishmaniasis ("espundia" escomel, 1911). Transactions of the Royal Society of Tropical Medicine and Hygiene, 1986.

MARTÍN-FONTECHA, A. et al. Induced recruitment of NK cells to lymph nodes provides IFNY for TH1 priming. Nature Immunology, 2004.

MARTINON, F.; BURNS, K.; TSCHOPP, J. The Inflammasome: A molecular platform triggering activation of inflammatory caspases and processing of prolL- $\beta$. Molecular Cell, 2002.

MARTINON, F.; MAYOR, A.; TSCHOPP, J. The Inflammasomes: Guardians of the Body. Annual Review of Immunology, 2009.

MASCARENHAS, D. P. A.; ZAMBONI, D. S. Inflammasome biology taught by Legionella 
pneumophila. Journal of Leukocyte Biology, 2016.

MEAGHER, L. C. et al. Phagocytosis of apoptotic neutrophils does not induce macrophage release of thromboxane B2. Journal of Leukocyte Biology, 1992.

MEDZHITOV, R.; JANEWAY, C. Innate immune recognition: Mechanisms and pathways. Immunological Reviews, 2000.

MOLL, H. The Role of Dendritic Cells at the Early Stages of Leishmania Infection. In: Adv. Exp. Med., 2000.

MOLYNEUX, D. H. Virus-like particles in Leishmania parasites. Nature, 1974.

MORAVEJ, A. et al. IL-1 $\beta$ (-511T/C) gene polymorphism not IL-1 $\beta(+3953 T / C)$ and LT- $\alpha$ $(+252 A / G)$ gene variants confers susceptibility to visceral leishmaniasis. Molecular Biology Reports, 2012.

MORSY, T. A. et al. Mucosal leishmaniasis caused by Leishmania tropica in Saudi Arabia. Journal of the Egyptian Society of Parasitology, 1995.

MOTTA, A. C. F. et al. Disseminated mucocutaneous leishmaniasis resulting from chronic use of corticosteroid. International Journal of Dermatology, 2003.

MUKBEL, R. M. et al. Macrophage killing of Leishmania amazonensis amastigotes requires both nitric oxide and superoxide. American Journal of Tropical Medicine and Hygiene, 2007.

MURRAY, H. W.; NATHAN, C. F. Macrophage Microbicidal Mechanisms In Vivo: Reactive Nitrogen versus Oxygen Intermediates in the Killing of Intracellular Visceral Leishmania donovani. The Journal of Experimental Medicine, 1999.

NAKAHIRA, K. et al. Autophagy proteins regulate innate immune responses by inhibiting the release of mitochondrial DNA mediated by the NALP3 inflammasome. Nature Immunology, 2011.

NOVAIS, F. O. et al. CD8+T cell cytotoxicity mediates pathology in the skin by inflammasome activation and IL-1b production. PLoS Pathogens, 2017.

O'NEILL, L. A. J.; GOLENBOCK, D.; BOWIE, A. G. The history of Toll-like receptors redefining innate immunity. Nature Reviews Immunology, 2013.

OLIVIER, M.; MINGUEZ-MENENDEZ, A.; FERNANDEZ-PRADA, C. Leishmania Viannia guyanensis. Trends in Parasitology, 2019.

PETERS, C.; STIERHOF, Y. D.; ILG, T. Proteophosphoglycan secreted by Leishmania mexicana amastigotes causes vacuole formation in macrophages. Infection and Immunity, 1997.

PIGOTT, D. M. et al. Global distribution maps of the leishmaniases. eLife, 2014.

PINHEIRO, R. O. et al. Induction of autophagy correlates with increased parasite load of Leishmania amazonensis in BALB/c but not C57BL/6 macrophages. Microbes and Infection, 2009a.

PITALE, D. M. et al. Leishmania donovani Induces Autophagy in Human Blood-Derived Neutrophils. The Journal of Immunology, 2019.

PRINA, E., ABDI, S.Z., lebastARD, M., PERRET, E., Winter, N., ANTOINE, J. C. 
Dendritic cells as host cells for the promastigote and amastigote stages of Leishmania amazonensis: the role of opsonins in parasite uptake and dendritic cell maturation. Journal of Cell Science, 2004.

REITHINGER, R. et al. Anthroponotic cutaneous leishmaniasis, Kabul, Afghanistan. Emerging Infectious Diseases, 2003.

REITHINGER, R. et al. Cutaneous leishmaniasis. The Lancet, 2007.

RIMMELE, T. S.; CHATTON, J. Y. A novel optical intracellular imaging approach for potassium dynamics in astrocytes. PLoS ONE, 2014.

RO, Y. T.; SCHEFFTER, S. M.; PATTERSON, J. L. Hygromycin B resistance mediates elimination of Leishmania virus from persistently infected parasites. Journal of virology, 1997.

ROSSI, M. et al. Type I interferons induced by endogenous or exogenous viral infections promote metastasis and relapse of leishmaniasis. Proceedings of the National Academy of Sciences, 2017.

RUIZ, J. H.; BECKER, I. CD8 cytotoxic T cells in cutaneous leishmaniasis. Parasite Immunology, 2007.

RYAN, L.; LAINSON, R.; SHAW, J. J. Leishmaniasis in Brazil. XXIV. Natural flagellate infections of sandflies (Diptera: Psychodidae) in Pará State, with particular reference to the rôle of Psychodopygus wellcomei as the vector of Leishmania braziliensis braziliensis in the Serra dos Carajás. Transactions of the Royal Society of Tropical Medicine and Hygiene, 1987.

SACKS, D.; KAMHAWI, S. Molecular Aspects of Parasite-Vector and Vector-Host Interactions in Leishmaniasis. Annual Review of Microbiology, 2002.

SACKS, D. L. et al. An analysis of T cell responsiveness in Indian kala-azar. Journal of immunology, 1987.

SACKS, D. L.; BRODIN, T. N.; TURCO, S. J. Developmental modification of the lipophosphoglycan from Leishmania major promastigotes during metacyclogenesis. Molecular and Biochemical Parasitology, 1990.

SANTOS, D. et al. IL-1 $\beta$ Production by Intermediate Monocytes Is Associated with Immunopathology in Cutaneous Leishmaniasis. Journal of Investigative Dermatology, 2018.

SANTRICH, C. et al. Mucosal disease caused by Leishmania braziliensis guyanensis. American Journal of Tropical Medicine and Hygiene, 1990.

SARAVIA, N. G. et al. Mucocutaneous leishmaniasis in Colombia: Leishmania braziliensis subspecies diversity. American Journal of Tropical Medicine and Hygiene, 1985.

SARAVIA, N. G. et al. The Relationship of Leishmania braziliensis Subspecies and Immune Response to Disease Expression in New World Leishmaniasis. Journal of Infectious Diseases, 1989.

SAVILL, J. S. et al. Macrophage phagocytosis of aging neutrophils in inflammation. Programmed cell death in the neutrophil leads to its recognition by macrophages. Journal of Clinical Investigation, 1989.

SCHAMBER-REIS, B. L. F. et al. UNC93B1 and nucleic acid-sensing toll-like receptors 
mediate host resistance to infection with leishmania major. Journal of Biological Chemistry, 2013.

SCHARTON-KERSTEN, T.; SCOTT, P. The role of the innate immune response in Th1 cell development following Leishmania major infection. Journal of Leukocyte Biology, 1995.

SCHEFFTER, S. M. et al. The Complete Sequence of Leishmania RNA Virus LRV2-1, a Virus of an Old World Parasite Strain. Virology, 1995.

SCHMEISSER, H.; BEKISZ, J.; ZOON, K. C. New Function of Type I IFN: Induction of Autophagy. Journal of Interferon \& Cytokine Research, 2014.

SCORZA, B. M.; CARVALHO, E. M.; WILSON, M. E. Cutaneous manifestations of human and murine leishmaniasis. International Journal of Molecular Sciences, 2017.

SCOTT, P.; NOVAIS, F. O. Cutaneous leishmaniasis: immune responses in protection and pathogenesis. Nature Reviews Immunology, 2016.

SHI, C. S. et al. Activation of autophagy by inflammatory signals limits IL-1beta production by targeting ubiquitinated inflammasomes for destruction. Nature Immunology, 2012.

$\mathrm{SHI}$, J. et al. Cleavage of GSDMD by inflammatory caspases determines pyroptotic cell death. Nature, 2015.

SHI, Y.; EVANS, J. E.; ROCK, K. L. Molecular identification of a danger signal that alerts the immune system to dying cells. Nature, 2003.

SHIBUTANI, S. T. et al. Autophagy and autophagy-related proteins in the immune system. Nature Immunology, 2015.

SHIO, M. T. et al. PKC/ROS-mediated NLRP3 inflammasome activation is attenuated by leishmania zinc- metalloprotease during infection. PLoS Neglected Tropical Diseases, 2015.

SILVA-BARRIOS, S.; STAGER, S. Protozoan parasites and Type I IFNs. Frontiers in Immunology, 2017.

SINGH, A. K. et al. MicroRNA expression profiling of Leishmania donovani-infected host cells uncovers the regulatory role of MIR30A-3p in host autophagy. Autophagy, 2016.

SLITER, D. A. et al. Parkin and PINK1 mitigate STING-induced inflammation. Nature, 2018.

SPÄTH, G. F.; BEVERLEY, S. M. A Lipophosphoglycan-Independent Method for Isolation of Infective Leishmania Metacyclic Promastigotes by Density Gradient Centrifugation. Experimental Parasitology, 2001.

STUART, K. D. et al. Molecular organization of Leishmania RNA virus 1. Proceedings of the National Academy of Sciences of the United States of America, 1992.

SUTTERWALA, F. S.; MOSSER, D. M. The taming of IL-12: Suppressing the production of proinflammatory cytokines. Journal of Leukocyte Biology, 1999.

SWANSON, K. V.; DENG, M.; TING, J. P. Y. The NLRP3 inflammasome: molecular activation and regulation to therapeutics. Nature Reviews Immunology, 2019.

TARR, P. I. et al. LR1: a candidate RNA virus of Leishmania. Proceedings of the National Academy of Sciences, 1988. 
THOMAS, S. A. et al. Countervailing, time-dependent effects on host autophagy promote intracellular survival of Leishmania. Journal of Biological Chemistry, 2018.

TING, J. P. Y. et al. The NLR Gene Family: A Standard Nomenclature. Immunity, 2008.

TING, J. P. Y.; KASTNER, D. L.; HOFFMAN, H. M. CATERPILLERs, pyrin and hereditary immunological disorders. Nature Reviews Immunology, 2006.

VAN ZANDBERGEN, G. et al. Cutting Edge: Neutrophil Granulocyte Serves as a Vector for Leishmania Entry into Macrophages. The Journal of Immunology, 2004.

VENDRAME, C. M. V. et al. Insulin-like growth factor-I induced and constitutive arginase activity differs among isolates of Leishmania derived from patients with diverse clinical forms of Leishmania braziliensis infection. Transactions of the Royal Society of Tropical Medicine and Hygiene, 2010.

VINCE, J. E.; SILKE, J. The intersection of cell death and inflammasome activation. Cellular and Molecular Life Sciences, 2016.

WANG, A. Viruses Of The Protozoa. Annual Review of Microbiology, 1991.

WARBURG, A.; SCHLEIN, Y. The effect of post-bloodmeal nutrition of Phlebotomus papatasi on the transmission of Leishmania major. American Journal of Tropical Medicine and Hygiene, 1986.

WARREN, M. K.; VOGEL, S. N. Bone marrow-derived macrophages: development and regulation of differentiation markers by colony-stimulating factor and interferons. Journal of immunology, 1985.

WEEKS, R. et al. LRV1 viral particles in Leishmania guyanensis contain double-stranded or single-stranded RNA. Journal of virology, 1992.

WEINKOPFF, T. et al. Role of toll-like receptor 9 signaling in experimental leishmania braziliensis infection. Infection and Immunity, 2013.

WHO. Report of a meeting of the WHO Expert Committee on Leishmaniases. Pan American Health, 2010.

WOLDAY, D. et al. Leishmania-HIV interaction: Immunopathogenic mechanisms. Parasitology Today, 1999.

WORLD HEALTH ORGANIZATION. Control of the leishmaniases. World Health Organization technical report series, 2010.

ZAMBONI, D. S.; LIMA-JUNIOR, D. S. Inflammasomes in host response to protozoan parasites. Immunological Reviews, 2015.

ZAMBONI, D. S.; SACKS, D. L. Inflammasomes and Leishmania: in good times or bad, in sickness or in health. Current Opinion in Microbiology, 2019.

ZANONI, I. et al. An endogenous caspase-11 ligand elicits interleukin-1 release from living dendritic cells. Science, 2016.

ZHANG, S.-Y. et al. TLR3 immunity to infection in mice and humans. Current opinion in immunology, 2013.

ZINK, S. D.et al.The Dot/lcm type IV secretion system of Legionella pneumophila is essential for the induction of apoptosis in human macrophages. Infection and Immunity, 2002. 
Anexos 


\section{ANEXOS}

\subsection{Anexo 1: Prêmios recebidos durante o Doutorado}

2019 Prêmio de Didática em Imunologia "Profa. Vânia Luíza Deperon Bonato", pela melhor aula (Biologia dos linfócitos B) ministrada durante o XII Curso de Inverno em Imunologia da FMRP/USP.

2019 Global Health Travel Award - "Why so many ways to die? Apoptosis, Necroptosis, Pyroptosis and Beyond", Keystone Meeting., Bill and Melinda Gates Foundation.

2019 Global Health Travel Award - "Positive-strand RNA viruses", Keystone Meeting., Bill and Melinda Gates Foundation.

2018 Menção Honrosa pela aula ministrada "Animais Trangênicos" - Prêmio de Didática em Imunologia "Vânia Bonato" - XI Curso de Inverno em Imunologia da FMRP-USP, FMRP-USP.

2018 Society of Leukocyte Biology Award - prêmio concedido durante o "IMMUNO 2018" - XLIII Congress of the Brazilian Society of Immunology, IMMUNO 2018 - XLIII Congress of the Brazilian Society of Immunology.

2018 Segunda melhor apresentação oral de Doutorado, durante o XIII Workshop of Immunology (FMRP-USP), FMRP-USP.

2018 Travel Award para o Congresso "TOLL 2018 - Editing Innate Immunity", no Porto, Portugal., TOLL 2018. 
2017 Ziegman Brenner Award - Best PhD work - SBPz 2017, Sociedade Brasileira de Protozoologia.

2017 Melhor apresentação oral de Doutorado no I SIBA (Simpósio de Imunologia Básica e Aplicada), FMRP - USP.

2017 Thereza Kipnis Award - maior Prêmio concedido à jovens imunologistas pela Sociedade Brasileira de Imunologia (SBI), durante o MUCOSAL IMMUNO 2017 em Salvador, BA.

$20163^{\circ}$ Lugar - Prêmio Didática em Imunologia "Profa Vania Luiza Deperon Bonato", IX Curso de Inverno em Imunologia - FMRP-USP., FMRP-USP.

2016 Premiação melhores apresentações (pôster) no XII Workshop of Immunology FMRP-USP, FMRP-USP.

2016 Walter Colli Award - Best oral presentation - SBPz 2016., Sociedade Brasileira de Protozoologia. 


\title{
9.2. Anexo 2: Trabalhos de primeira autoria
}

9.2.1 Artigo publicado (de Carvalho et al, Cell Reports, 2019): "Leishmania Lipophosphoglycan Triggers Caspase-11 and the Non-canonical Activation of the NLRP3 Inflammasome". Publicado em Janeiro de 2019.

\begin{abstract}
Activation of the NLRP3 inflammasome by Leishmania parasites is critical for the outcome of leishmaniasis, a disease that affects millions of people worldwide. We investigate the mechanisms involved in NLRP3 activation and demonstrate that caspase-11 (CASP11) is activated in response to infection by Leishmania species and triggers the non-canonical activation of NLRP3. This process accounts for host resistance to infection in macrophages and in vivo. We identify the parasite membrane glycoconjugate lipophosphoglycan (LPG) as the molecule involved in CASP11 activation. Cytosolic delivery of LPG in macrophages triggers CASP11 activation, and infections performed with $L p g 1^{-/-}$parasites reduce CASP11/NLRP3 activation. Unlike bacterial LPS, purified LPG does not activate mouse CASP11 (or human Casp4) in vitro, suggesting the participation of additional molecules for LPG-mediated CASP11 activation. Our data identify a parasite molecule involved in CASP11 activation, thereby establishing the mechanisms underlying inflammasome activation in response to Leishmania species.
\end{abstract}




\subsubsection{Artigo publicado (L. Castro-Jorge*, R.V.H. de Carvalho* et al, Plos}

Pathogens, 2019): "The NLRP3 inflammasome is involved with the pathogenesis of Mayaro virus". Publicado em Agosto de 2019. *co-primeiros autores.

\section{ABSTRACT}

Mayaro virus (MAYV) is an arbovirus that circulates in Latin America and is emerging as a potential threat to public health. Infected individuals develop Mayaro fever, a severe inflammatory disease characterized by high fever, rash, arthralgia, myalgia and headache. The disease is often associated with a prolonged arthralgia mediated by a chronic inflammation that can last months. Although the immune response against other arboviruses, such as chikungunya virus (CHIKV), dengue virus (DENV) and Zika virus (ZIKV), has been extensively studied, little is known about the pathogenesis of MAYV infection because there is no animal model for pathogenesis investigation. In this study, we established models of MAYV infection in macrophages and in mice and found that MAYV can replicate in bone marrow-derived macrophages and robustly induce expression and activation of inflammasome proteins such as NLRP3, ASC, AIM2, and Caspase-1 (CASP1). Infection performed in macrophages derived from $\mathrm{NIrp3}^{-/}, \mathrm{Aim2}^{-/}, \mathrm{AsC}^{-/}$and Casp $1 / 11^{-/}$mice indicate that the NLRP3, but not AIM2 inflammasome is essential for production of inflammatory cytokines, such as IL $1 \beta$. We also determined that MAYV triggers NLRP3 inflammasome activation by inducing reactive oxygen species (ROS) and potassium efflux. In vivo infections performed in C57BL/6 and inflammasome-deficient mice indicate that NLRP3 and IL-1R signaling negatively regulates footpad swelling, inflammation and pain, establishing an important role of the NLRP3 inflammasome in the regulation of MAYV pathogenesis. Accordingly, we detected higher levels of caspase1-p20, IL-1 $\beta$ and IL-18 in the serum of MAYVinfected patients as compared to healthy individuals. This study reveals molecular mechanisms underlying this disease and establishes an in vivo model for further investigation of MAYV pathogenesis. 


\title{
9.2.3 Artigo publicado (de Carvalho et al, Journal of Leukocyte Biology,
}

2019): "Macrophage priming is dispensable for NLRP3 inflammasome activation and restriction of Leishmania amazonensis replication". Publicado em Maio de 2019.

\begin{abstract}
The NLRP3 inflammasome is activated in response to multiple stimuli and triggers activation of caspase-1 (CASP1), IL-1 $\beta$ production, and inflammation. NLRP3 activation requires two signals. The first leads to transcriptional regulation of specific genes related to inflammation, and the second is triggered when pathogens, toxins, or specific compounds damage cellular membranes and/or trigger the production of reactive oxygen species (ROS). Here, we assess the requirement of the first signal (priming) for the activation of the NLRP3 inflammasome in bone marrow-derived macrophages (BMDMs) infected with Leishmania amazonensis. We found that BMDMs express the inflammasome components NLRP3, ASC, and CASP1 at sufficient levels to enable the assembly and activation of NLRP3 inflammasome in response to infection. Therefore, priming was not required for the formation of ASC specks, CASP1 activation (measured by fluorescent dye FAM-YVAD), and restriction of $L$. amazonensis replication via the NLRP3 inflammasome. By contrast, BMDM priming was required for CASP1 cleavage (p20) and IL-1 $\beta$ secretion, because priming triggers robust up-regulation of pro-IL-1 $\beta$ and CASP11 that are important for efficient processing of CASP1 and IL-1 13 . Taken together, our data shed light into the cellular and molecular processes involved in activation of the NLRP3 in macrophages by Leishmania, a process that is important for the outcome of Leishmaniasis.
\end{abstract}




\title{
9.2.4 Artigo publicado (de Carvalho et al, Cytokine, 2015): "Plasmodium
} berghei ANKA infection results in exacerbated immune responses from C57BL/6 mice displaying hypothalamic obesity". Publicado em Julho de 2015.

\begin{abstract}
The relationship between obesity and cerebral malaria has only been described once, in a study involving animals lacking the ability to produce leptin $(o b / o b)$, an important mediator against infections. Since obesity is currently considered a worldwide epidemic and cerebral malaria is a disease of great concern, establishing a relationship between these two pathologies would be relevant for understanding how hypothalamic lesions and their effects could modulate the immune system of C57BL/6 mice. In this study, we used the MSG model of obesity, which results in severe hyperleptinemia, to evaluate the immune responses of obese mice against $P$. berghei ANKA. We show that the outcome of this pathology significantly differs between obese and lean animals. Despite having a lower parasitemia compared to the control group, an altered profile of cytokine production in the MSG mice might have accelerated the immune-mediated damage in the brain, resulting in an earlier death.
\end{abstract}


9.2.5 Artigo em revisão (de Carvalho et al): "Leishmania RNA virus worsens infection by limiting NLRP3 inflammasome activation through a TLR3/type I IFN/autophagy pathway". Em revisão.

\begin{abstract}
Leishmania RNA virus (LRV) was described as an important virulence factor associated with the severity of mucocutaneous Leishmaniasis, a severe form of cutaneous disease caused by some species, including L. guyanensis and L. braziliensis. Activation of TLR3 by the virus was reported to be key for LRVmediated disease exacerbation, but downstream mechanisms remain largely unexplored. Here, we combine human and mouse data to demonstrate that LRV triggers TLR3 and TRIF to induce type I IFN production, which induces autophagy. This process results in autophagy-mediated degradation of NLRP3 and ASC, thereby limiting NLRP3 inflammasome activation in macrophages. NLRP3 is important to control Leishmania replication in macrophages and in vivo and the signaling pathway triggered by LRV results in increased parasite survival and disease progression. In support to this data, we found that lesions in patients infected with LRV+ Leishmania are associated with reduced inflammasome activation and the development of the severe mucocutaneous form of the disease. Our findings mechanistically reveal an evasion mechanism triggered by LRV to worsen Leishmaniasis, identifying autophagy as an important regulator of inflammasome activation by Leishmania. This work also unravels a previously unappreciated role for TLR3 in negatively regulating inflammasome assembly and activation, advancing our knowledge in TLR3-driven regulatory mechanisms and host-pathogen interactions influencing the outcome of the disease. These findings may also account for the definition of better treatments for the severe and debilitating mucocutaneous form of Leishmaniasis.
\end{abstract}




\title{
9.3. Anexo 3: Trabalhos de co-autoria
}

\subsubsection{Artigo publicado (de Soares-Schanoski et al, Plos Pathogens,} 2019): "Systems analysis of subjects acutely infected with the Chikungunya virus". Publicado em Junho de 2019.

\begin{abstract}
The largest ever recorded epidemic of the Chikungunya virus (CHIKV) broke out in 2004 and affected four continents. Acute symptomatic infections are typically associated with the onset of fever and often debilitating polyarthralgia/polyarthritis. In this study, a systems biology approach was adopted to analyze the blood transcriptomes of adults acutely infected with the CHIKV. Gene signatures that were associated with viral RNA levels and the onset of symptoms were identified. Among these genes, the putative role of the Eukaryotic Initiation Factor (eIF) family genes and apolipoprotein $B$ mRNA editing catalytic polypeptide-like (APOBEC3A) in the CHIKV replication process were displayed. We further compared these signatures with signatures induced by the Dengue virus infection and rheumatoid arthritis. Finally, we demonstrated that the CHIKV in vitro infection of murine bone marrow-derived macrophages induced IL-1 beta production in a mechanism that is significantly dependent on the inflammasome NLRP3 activation. The observations provided valuable insights into virus-host interactions during the acute phase and can be instrumental in the investigation of new and effective therapeutic interventions.
\end{abstract}




\subsubsection{Artigo publicado (Franco et al, Journal of Biological Chemistry,}

2017): "Autophagy downstream of endosomal Toll-like receptor signaling in macrophages is a key mechanism for resistance to Leishmania major infection". Publicado em Junho de 2017.

\section{ABSTRACT}

Leishmaniasis is caused by protozoan parasites of the genus Leishmania. In mammalians, these parasites survive and replicate in macrophages and parasite elimination by macrophages is critical for host resistance. Endosomal Toll-like receptors (TLRs) have been shown to be crucial for resistance to Leishmania major in vivo. For example, mice in the resistant C57BL/6 genetic background that are triple-deficient for TLR3, -7 , and-9 $\left(\mathrm{T} / \mathrm{r} 3 / 7 / \mathrm{9}^{-/}\right)$are highly susceptible to $L$. major infection. TIr $3 / 7 / 9^{-/-}$mice are as susceptible as mice deficient in MyD88 or UNC93B1, a chaperone required for appropriate localization of endosomal TLRs, but the mechanisms are unknown. Here we found that macrophages infected with $L$. major undergo autophagy, which effectively accounted for restriction of parasite replication. Signaling via endosomal TLRs was required for autophagy because macrophages deficient for TLR3, -7, and 9, UNC93B1, or MyD88 failed to undergo L. major-induced

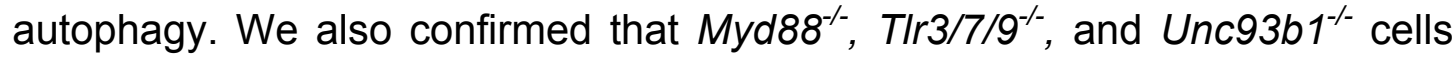
were highly permissive to $L$. major replication. Accordingly, shRNA-mediated suppression of Atg5, an E3 ubiquitin ligase essential for autophagosome elongation, in macrophages impaired the restriction of $L$. major replication in

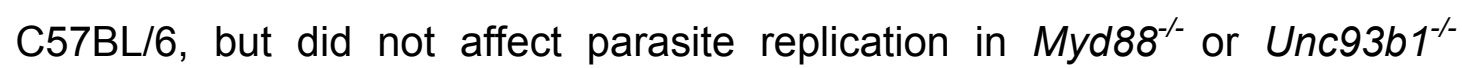
macrophages. Rapamycin treatment reduced inflammatory lesions formed in the ears of Leishmania-infected C57BL/6 and TIr3/7/9/- mice, indicating that autophagy operates downstream of TLR signaling and is relevant for disease development in vivo. Collectively, our results indicate that autophagy contributes to macrophage resistance to $L$. major replication, and mechanistically explain the previously described endosomal TLR-mediated resistance to $L$. major infection. 


\subsection{Anexo 4: Repercussão deste trabalho no cenário nacional e internacional}

Como mostrado no anexo 1 , os trabalhos resultantes dessa tese foram publicados nos maiores periódicos de prestígio internacional. Um dos artigos gerados pela presente tese (de Carvalho et al, Cell Reports, 2019) foi o primeiro a demonstrar uma molécula não bacteriana capaz de ativar a enzima caspase-11, sendo portanto altamente inflamatória. Já no trabalho principal oriundo desta tese, demonstramos um mecanismo intracelular desencadeado pelo LRV que agrava a infecção por espécies de Leishmania do Novo Mundo, finalmente explicando a patogênese da doença mucocutânea, até então pobremente caracterizada.

Além do impacto científico mundial, devemos destacar a importância desse trabalho para a ciência nacional, uma vez que o artigo principal resultante desta tese foi totalmente realizado em território nacional e por pesquisadores brasileiros. Este trabalho tem papel importante no encorajamento à comunidade científica brasileira em buscar a publicação de artigos com grande solidez científica, e que avancem significativamente em seus campos de conhecimento. Trabalhos desta magnitude destacam nossa comunidade científica frente ao cenário internacional, e também frente ao público leigo brasileiro.

O reconhecimento aos trabalhos resultantes desta tese levaram o aluno Renan V. H. de Carvalho a ser convidado para palestrar em diversas eventos científicos, como Congressos e Simpósios, o fazendo ganhar um total de 13 prêmios até agora. Além disso, recebeu convites para mostrar seus resultados em diversas Instituições de renome Mundiais, como a 
Universidade Rockefeller (Nova Iorque, EUA), o Instituto Pasteur (Paris, França) e a Universidade de Bonn (Bonn, Alemanha).

Por fim, gostaria de destacar que as perspectivas futuras resultantes desta tese são amplas. Os resultados obtidos nesse estudo auxiliaram significativamente na compreensão da patogênese e da resposta imune na Leishmaniose. Acreditamos que esses dados poderão contribuir diretamente para o futuro desenvolvimento de terapias efetivas e/ou vacinas contra a doença, prevenindo e tratando, principalmente, a forma altamente desfigurante da doença, a Leishmaniose mucocutânea. 